NATIONAL LABORATORY

MANAGED BY UT-BATTELLE

FOR THE DEPARTMENT OF ENERGY

\title{
HTGR Measurements and Instrumentation Systems
}

\author{
May 2012
}

\author{
Prepared by \\ S. J. Ball \\ D. E. Holcomb \\ S. M. Cetiner
}

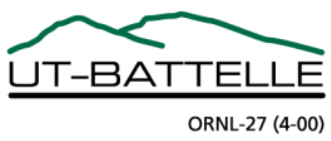




\section{DOCUMENT AVAILABILITY}

Reports produced after January 1, 1996, are generally available free via the U.S. Department of Energy (DOE) Information Bridge.

Web site http://www.osti.gov/bridge

Reports produced before January 1, 1996, may be purchased by members of the public from the following source.

National Technical Information Service

5285 Port Royal Road

Springfield, VA 22161

Telephone 703-605-6000 (1-800-553-6847)

TDD 703-487-4639

Fax 703-605-6900

E-mail info@ntis.gov

Web site http://www.ntis.gov/support/ordernowabout.htm

Reports are available to DOE employees, DOE contractors, Energy Technology Data Exchange (ETDE) representatives, and International Nuclear Information System (INIS) representatives from the following source.

Office of Scientific and Technical Information

P.O. Box 62

Oak Ridge, TN 37831

Telephone 865-576-8401

Fax 865-576-5728

E-mail reports@osti.gov

Web site http://www.osti.gov/contact.html

This report was prepared as an account of work sponsored by an agency of the United States Government. Neither the United States Government nor any agency thereof, nor any of their employees, makes any warranty, express or implied, or assumes any legal liability or responsibility for the accuracy, completeness, or usefulness of any information, apparatus, product, or process disclosed, or represents that its use would not infringe privately owned rights. Reference herein to any specific commercial product, process, or service by trade name, trademark, manufacturer, or otherwise, does not necessarily constitute or imply its endorsement, recommendation, or favoring by the United States Government or any agency thereof. The views and opinions of authors expressed herein do not necessarily state or reflect those of the United States Government or any agency thereof. 
Reactor and Nuclear Systems Division

\section{HTGR MEASUREMENTS AND INSTRUMENTATION SYSTEMS}

S. J. Ball, D. E. Holcomb, and S. M. Cetiner

Oak Ridge National Laboratory

May 2012

Prepared by

OAK RIDGE NATIONAL LABORATORY

Oak Ridge, Tennessee 37831-6165

managed by

UT-BATTELLE, LLC

for the

U.S. DEPARTMENT OF ENERGY

under contract DE-AC05-00OR22725 



\section{CONTENTS}

Page

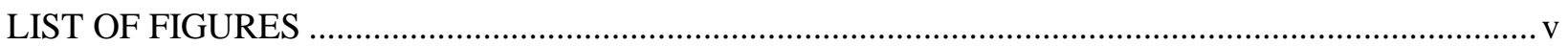

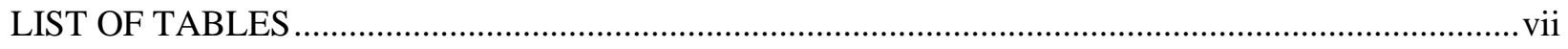

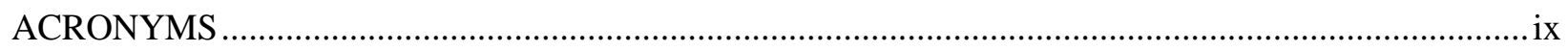

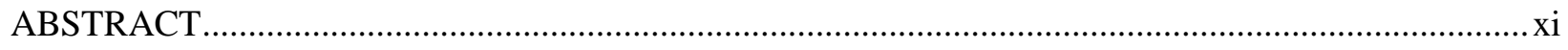

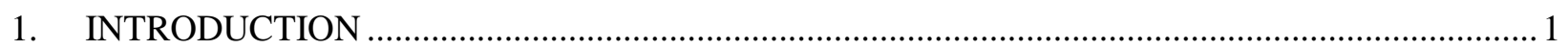

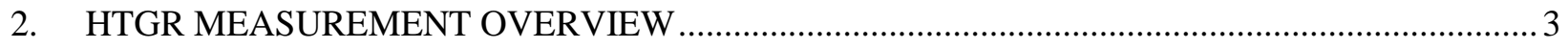

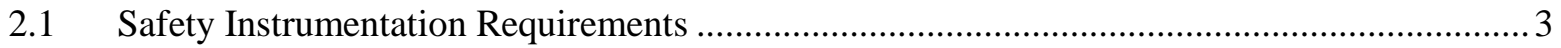

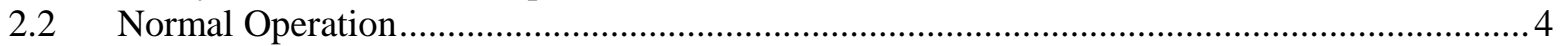

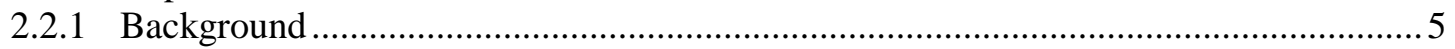

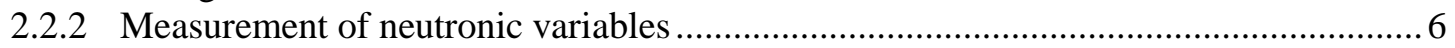

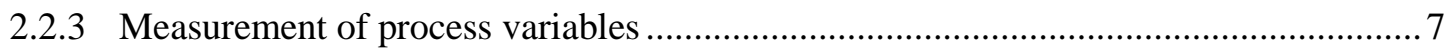

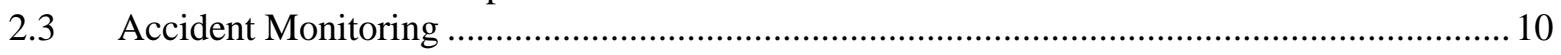

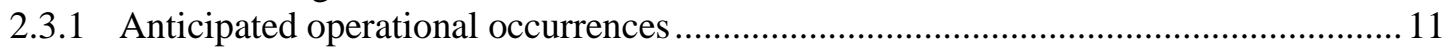

2.3.2 Heat removal accidents - pressurized loss-of-forced circulation (P-LOFC) ............... 12

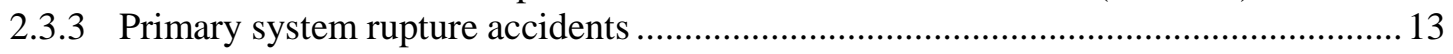

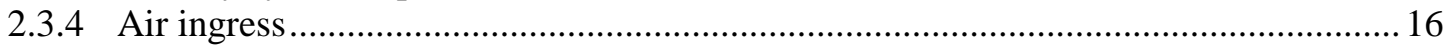

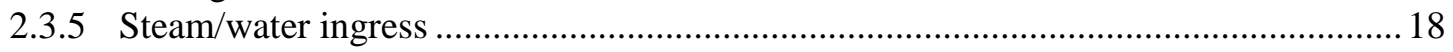

2.3.6 Reactivity events and anticipated transients without scram (ATWS) ......................... 22

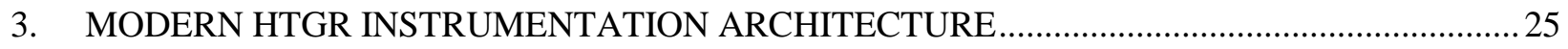

3.1 Conceptual Digital Network Topology Overview …….....................................................26

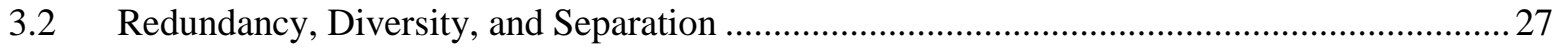

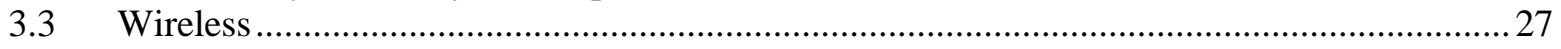

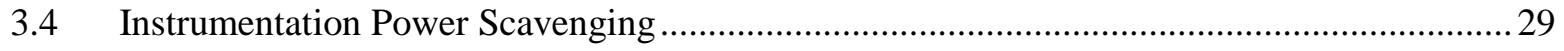

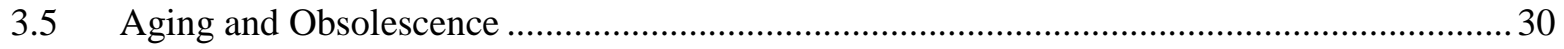

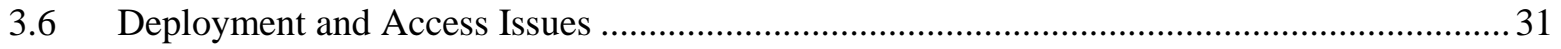

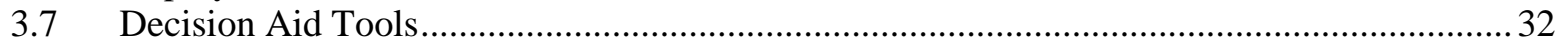

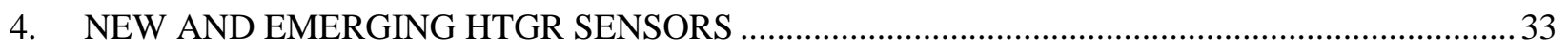

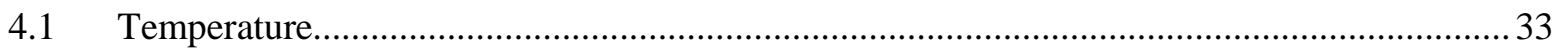

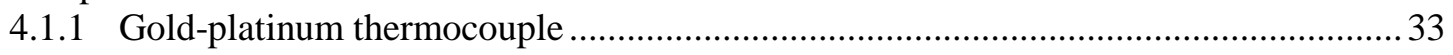

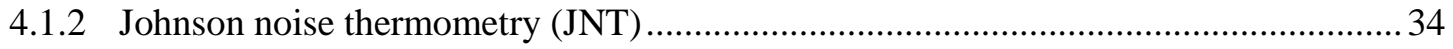

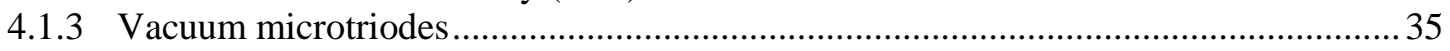

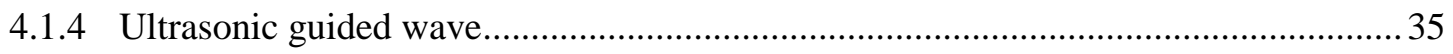

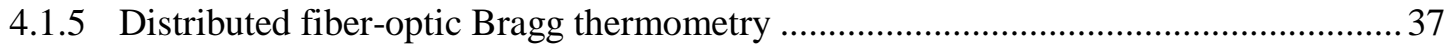

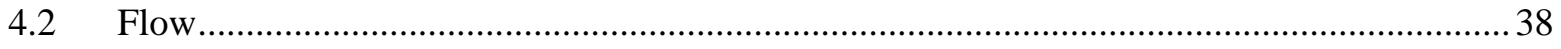

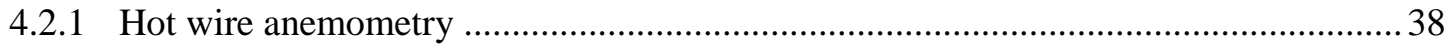

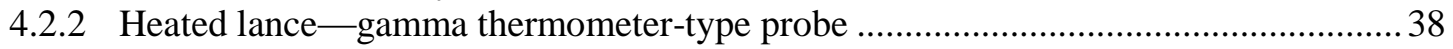

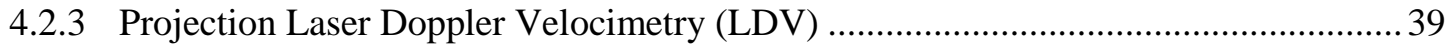

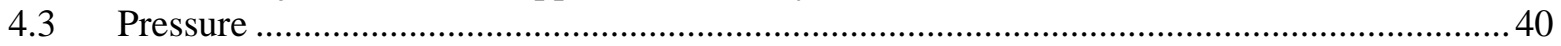

4.3.1 SiCN internally self-referenced composite ceramic ….............................................. 40

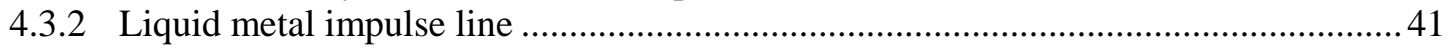

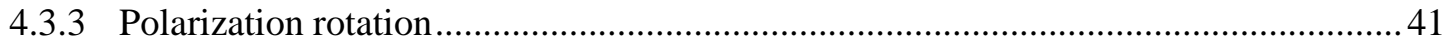

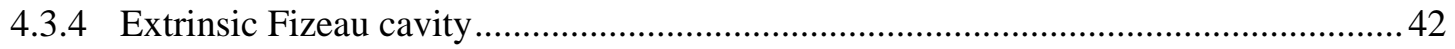




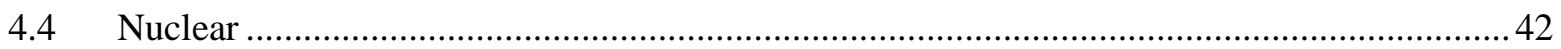

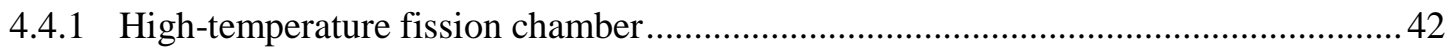

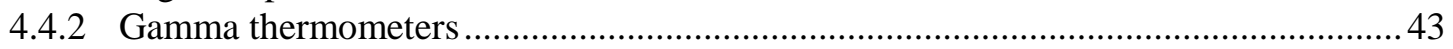

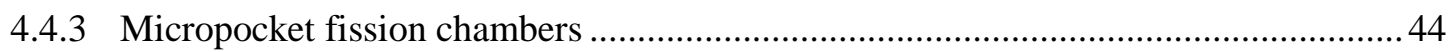

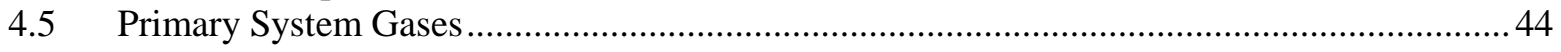

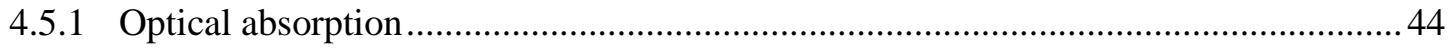

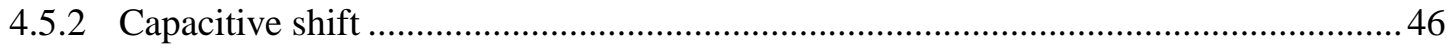

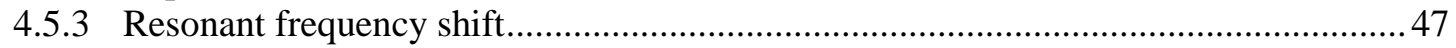

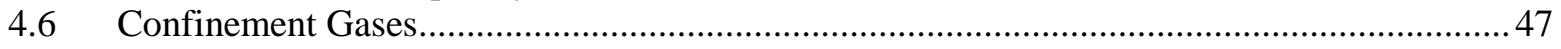

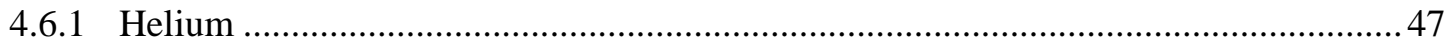

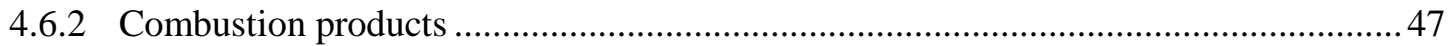

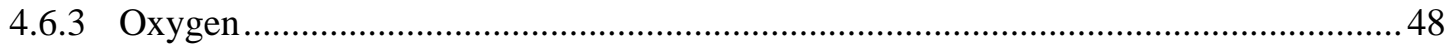

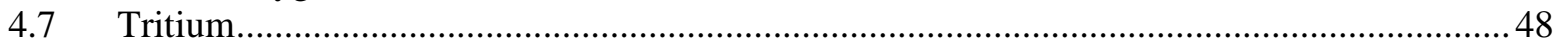

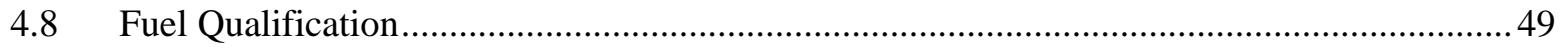

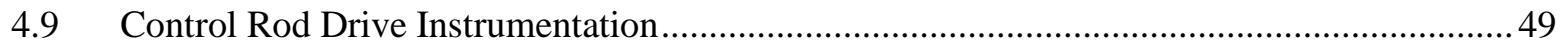

5. DIAGNOSTIC AND PROGNOSTIC TECHNOLOGIES FOR HTGRs........................................51

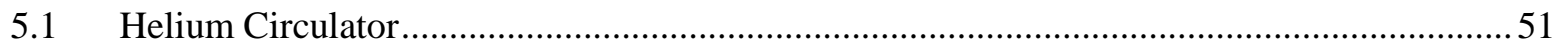

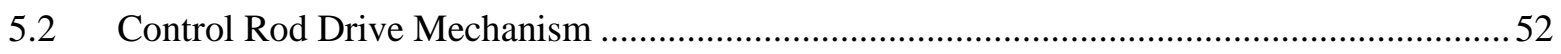

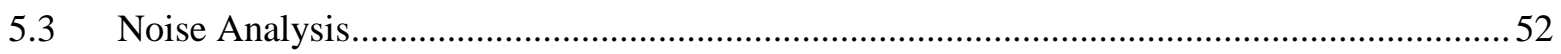

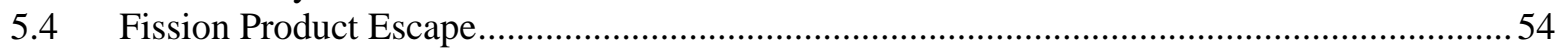

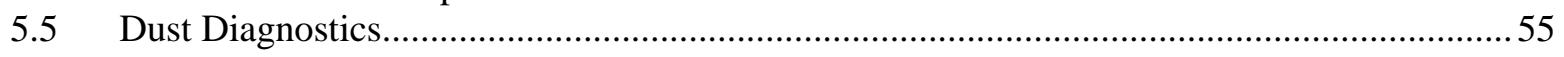

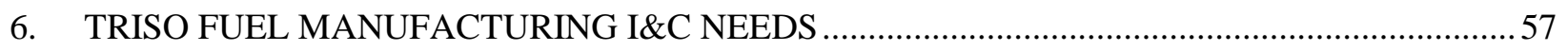

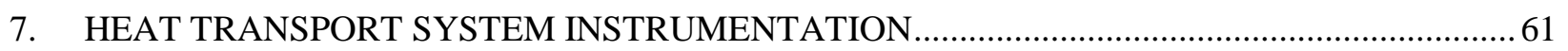

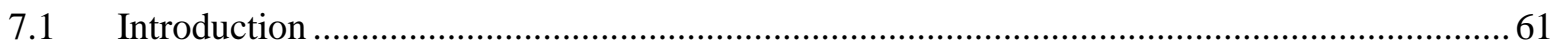

7.2 Process Heat Plant Interface and Heat Transfer Loop Description ..................................... 61

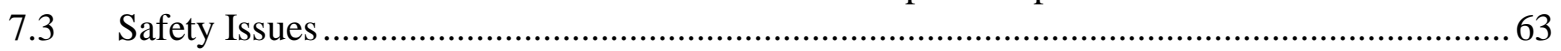

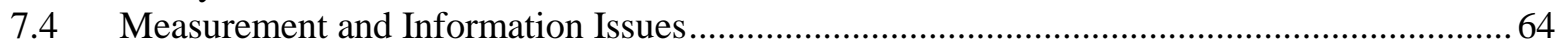

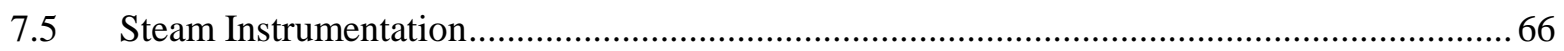

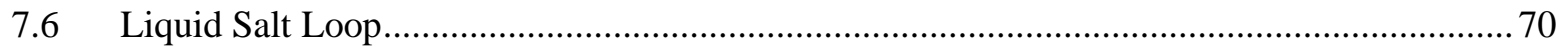

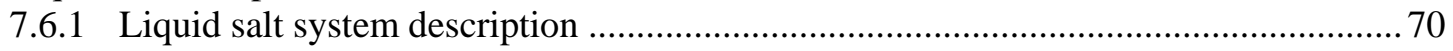

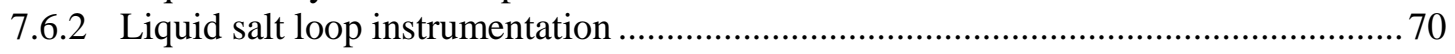

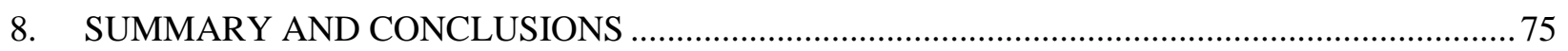

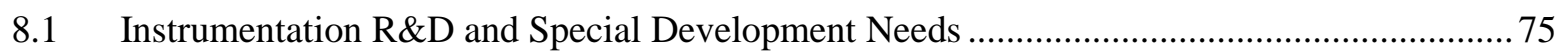

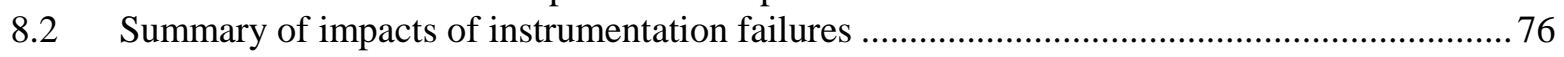

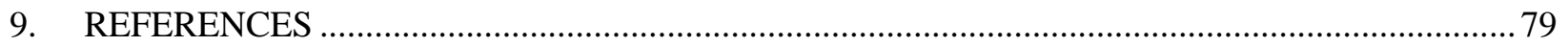




\section{LIST OF FIGURES}

Figure

Page

1 CFD simulation of flow paths and associated temperature distributions for the lower

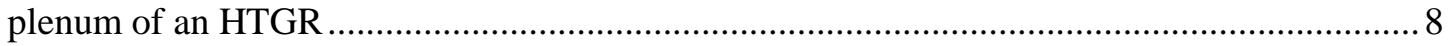

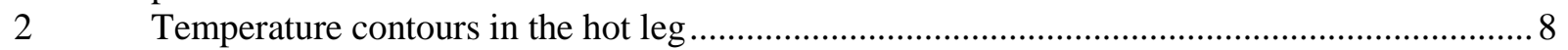

$3 \quad$ Illustration of flow and temperature swirl development ............................................... 9

4 An illustration of the confinement blowout filter and a helium leak detection system ........... 16

$5 \quad$ MHTGR arrangement and water ingress sources........................................................ 19

$6 \quad$ SG isolation and steam water dump system configuration................................................20

$7 \quad$ Typical control system layout for an HTGR steam-electric plant ..........................................26

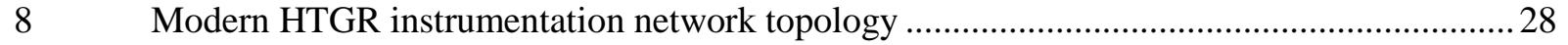

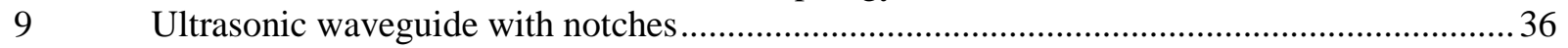

10 Transmitted light spectra through a distributed optical fiber Bragg grating .......................... 37

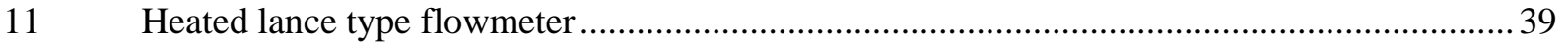

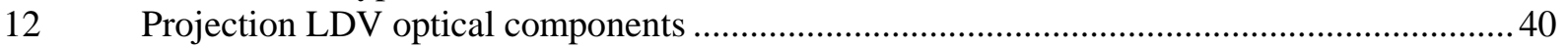

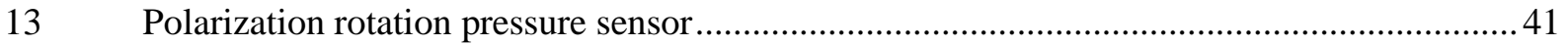

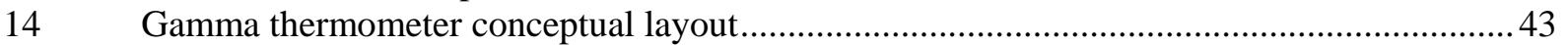

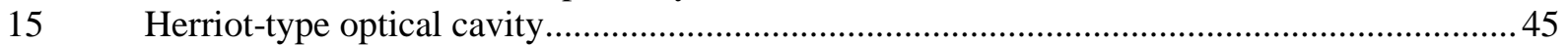

16 High-pressure optical absorption spectroscopy component layout ......................................46

17 Core coolant outlet temperature perturbations at Fort St. Vrain ...........................................54

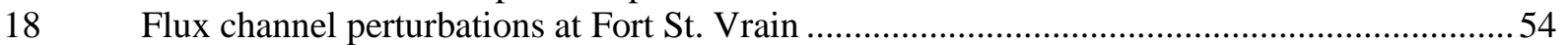

19 Flow diagram of the continuous coating process ..........................................................5

$20 \quad \mathrm{SiC}$ structure as a function of coater temperature...............................................................5

21 Possible configuration option for a liquid-salt heat transfer loop-indirect electrical

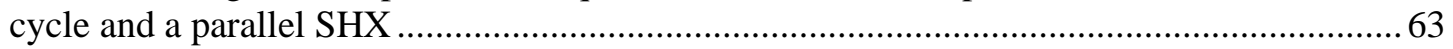

22 Electrical production efficiency as a function of turbine inlet temperature ...........................66

23 Typical once-through steam generator employing a finishing superheater section ...............67

24 Integration of steam related protection systems - steam generator in primary loop ..............69

25 An ultrasonic thermometry system including a notched waveguide ..................................... 71 



\section{LIST OF TABLES}

Table

Page

$1 \quad$ Manufacturing process phenomena identified by the PIRT panel...........................................5 57

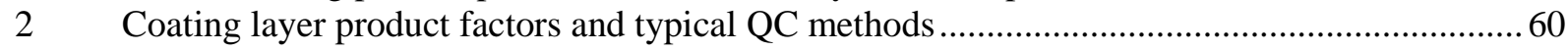

3 Summary of normal operation measurement aberration impacts ............................................ 77

$4 \quad$ Summary of accident scenario measurement aberration impacts ............................................. 78 



\section{ACRONYMS}

\begin{tabular}{|c|c|}
\hline AGR & advanced gas reactor (DOE program) \\
\hline $\mathrm{AOO}$ & anticipated operational occurrence \\
\hline ATWS & anticipated transients without scram \\
\hline AVR & Arbeitsgemeinschaft Versuchsreaktor \\
\hline BAF & Bacon anisotropy factor \\
\hline BDBA & beyond design basis accident \\
\hline CFD & computational fluid dynamics \\
\hline CFR & Code of Federal Regulations \\
\hline CTE & coefficient of thermal expansion \\
\hline DBA & design basis accident \\
\hline D-LOFC & depressurized loss-of-forced circulation \\
\hline DOCXO & double oven controlled crystal oscillator \\
\hline DOE & U.S. Department of Energy \\
\hline ESA & electrical signature analysis \\
\hline FP & fission products \\
\hline GA & General Atomics \\
\hline GRSAC & graphite reactor severe accident code \\
\hline HTGR & high-temperature gas-cooled reactor \\
\hline HTR-10 & high temperature reactor-10 MW (China) \\
\hline HTR-10GT & HTR-10 adapted for gas turbine PCU \\
\hline HTTR & high temperature engineering test reactor (Japan) \\
\hline $\mathrm{I} \& \mathrm{C}$ & instrumentation and controls \\
\hline IAEA & International Atomic Energy Agency \\
\hline IC & integrated circuit \\
\hline IHX & intermediate heat exchanger \\
\hline IR & infrared \\
\hline JNT & Johnson noise thermometry \\
\hline LDV & laser Doppler velocimetry \\
\hline LED & light-emitting diode \\
\hline LOFC & loss of forced circulation \\
\hline LSHT & liquid salt heat transfer \\
\hline LWR & light-water reactor \\
\hline MHTGR & modular high-temperature gas-cooled reactor (DOE 1980s design) \\
\hline MPFD & micropocket fission detector \\
\hline MSRE & molten salt reactor experiment (ORNL) \\
\hline NGNP & next generation nuclear plant \\
\hline NRC & Nuclear Regulatory Commission \\
\hline OFDR & optical frequency domain reflectometry \\
\hline ORNL & Oak Ridge National Laboratory \\
\hline PBMR & Pebble Bed Modular Reactor (South Africa) \\
\hline PBR & pebble bed reactor \\
\hline $\mathrm{PCU}$ & power conversion unit \\
\hline PHX & process heat exchanger \\
\hline PIRT & phenomena identification and ranking tables \\
\hline P-LOFC & pressurized loss of forced circulation \\
\hline PNNL & Pacific Northwest National Laboratory \\
\hline PRV & pressure relief valve \\
\hline PSID & preliminary safety information document \\
\hline
\end{tabular}




$\begin{array}{ll}\text { QC } & \text { quality control } \\ \text { R\&D } & \text { research and development } \\ \text { RCCS } & \text { reactor cavity cooling system } \\ \text { RPV } & \text { reactor pressure vessel } \\ \text { RTD } & \text { resistance temperature detector } \\ \text { SC-MHR } & \text { steam-cycle modular helium reactor } \\ \text { SCS } & \text { shutdown cooling system } \\ \text { SG } & \text { steam generator } \\ \text { SHX } & \text { secondary heat exchanger } \\ \text { SSC } & \text { system, structure, and component } \\ \text { SysML } & \text { systems modeling language } \\ \text { T/H } & \text { thermal hydraulics } \\ \text { TRISO } & \text { trilayer isotropic (particle fuel) } \\ \text { UHS } & \text { ultimate heat sink } \\ \text { V\&V } & \text { verification and validation } \\ \text { VHTR } & \text { very high temperature gas-cooled reactor } \\ \text { VS } & \text { vessel system }\end{array}$




\begin{abstract}
This report provides an integrated overview of measurements and instrumentation for near-term future high-temperature gas-cooled reactors (HTGRs). Instrumentation technology has undergone revolutionary improvements since the last HTGR was constructed in the United States. This report briefly describes the measurement and communications needs of HTGRs for normal operations, maintenance and inspection, fuel fabrication, and accident response. The report includes a description of modern communications technologies and also provides a potential instrumentation communications architecture designed for deployment at an HTGR. A principal focus for the report is describing new and emerging measurement technologies with high potential to improve operations, maintenance, and accident response for the next generation of HTGRs, known as modular HTGRs, which are designed with passive safety features. Special focus is devoted toward describing the failure modes of the measurement technologies and assessing the technology maturity.
\end{abstract}





\section{INTRODUCTION}

This report summarizes the findings of a Nuclear Regulatory Commission (NRC) sponsored hightemperature gas-cooled reactor (HTGR) measurement and instrumentation systems evaluation research project. The project was focused on providing an integrated overview of the state-of-the-art in measurement and instrumentation technologies for near-term future, modular HTGRs.

The object of this research project was to provide NRC staff with (1) insights and knowledge about instrumentation used in other high-temperature reactors either operating or that have operated, and what is currently considered state-of-the-art; (2) evaluation of process heat instrumentation required to operate in high-temperature environments; (3) information to assist NRC in developing criteria to assess the qualification of new instrument hardware and embedded software; and (4) input for developing the bases for possible new regulatory guidance to assist in the review of a Next Generation Nuclear Plant (NGNP) license application.

The report begins with a description of the technology required for safety-related measurements during normal HTGR operation. The following section is structured in terms of postulated accidents and how the instrumentation system is configured to acquire and transfer information in support of accident avoidance and mitigation. The measurement technology, sensitivity, and time response characteristics of the instrumentation necessary to respond to accidents and anticipated operational occurrences (AOOs) are also identified in this section. The report then provides an overview of the technological underpinnings of a modern instrumentation architecture for HTGRs. A primary report emphasis is on providing a description of current and emerging sensors with high potential to be useful at HTGRs. Particular emphasis is placed on describing the known instrumentation failure vulnerabilities and assessing the measurement environmental survivability.

Both accidents and plant component or structural failures often have precursor indicators that, if measured, can provide advance warning. The technologies and methodologies for providing advanced warning of future failures as well as the current plant health status are the subject of the diagnostics and prognostics section of this report. The report then provides a description of the instrumentation and controls requirements for manufacturing trilayer isotropic (TRISO) fuel. The final report technical section describes the instrumentation system for a process heat transfer system connected to an HTGR. The report concludes with a summary of HTGR instrumentation development needs and a summary of the impacts of instrumentation failures on HTGR safety.

The licensing basis and criteria for HTGRs are still being decided and are beyond the scope of this report. However, HTGRs have fundamental physics differences from light-water reactors (LWRs), and their safety and licensing will need to reflect the differences between the reactor classes. The approach taken in this exploratory report is to describe the potential performance and known vulnerabilities of new and emerging reactor instrumentation to support HTGR operation, accident response, and maintenance and to not make any judgment as to the adequacy of any particular architecture or sensor to perform a safety function. Therefore, nothing in this report should be construed as an endorsement or implied approval of any instrument or architecture. Moreover, as the topic area of new instrumentation and issues associated with its application to HTGRs is vast, this report will only identify new instrumentation deployment issues at an overview level while providing a description of new sensing technology at somewhat greater depth.

A companion project for the NRC focuses on the licensing issues for advanced control and protection systems that would be unique to modular HTGRs (as compared to LWRs), particularly in view of their inherent safety features. ${ }^{1}$ 


\section{HTGR MEASUREMENT OVERVIEW}

An HTGR's instrumentation system extends from the sensor elements through the local information processing and the communication network through the control or safety decision point to the actuation device. In essence, the instrumentation system functions as the power plant's nervous system over its entire lifetime under the full range of adverse conditions it may experience. The system performance requirements, aging, maintenance (including periodic replacement), installation, access requirements, and post-severe accident survival all need to be considered as part of the design and safety evaluation process. The objective of this report is to provide a holistic vision of measurement and instrumentation at HTGRs employing best of breed for the new and emerging instrumentation technologies to enable seeing longterm operational and safety consequences of design phase instrumentation decisions.

\subsection{SAFETY INSTRUMENTATION REQUIREMENTS}

This section maps the components and functions of an HTGR's instrumentation system to its performance and safety requirements. The overarching goal of any nuclear safety system is prevention of large, off-site release of radionuclides. The instrumentation system supports this goal by providing accurate, timely plant status information under both normal and accident conditions both to the plant operators and to its automatic safety systems. The instrumentation system is also responsible for transporting control decisions to the plant's actuators as well as keeping a record of both the plant status and the control decisions. The HTGR's instrumentation system goal is to provide the process information necessary to both maximize power production and to preserve the plant investment value. The selection and design of the particular sensors and networking technologies that embody an HTGR's instrumentation system thus arise from an amalgam of the component environmental tolerance requirements and the information requirements to safely and efficiently operate the plant.

Nearly all of the conceptual underpinnings relating to the division of a nuclear power plant's instrumentation into safety-related and nonsafety-related systems transfer directly from LWRs to HTGRs. Safety-related instrumentation is generally used in the protection systems to ensure a timely and appropriate response to an accident or AOO. Much as in LWRs, a combination of safety-related and nonsafety-related instrumentation is employed during normal operations. For example, control rod position monitors (safety-related) are employed by the control system (nonsafety-related) in performing a power level transition.

The performance requirements for an HTGR's instrumentation system arise from its functional requirements, which in turn derive from the plant's physical characteristics and potential accident scenarios. The instrumentation system's basic safety function can be expressed in how it supports the plant's three fundamental safety functions:

1. confinement of radioactive material,

2. control of the core reactivity, and

3. removal of the heat from the core.

The heat removal function can be fulfilled by various design alternatives, but generally three independent systems are common in HTGRs:

1. nominal heat removal path, that is, the primary and the secondary heat transport systems, the power conversion unit (PCU), and the ultimate heat sink (UHS);

2. shutdown cooling system (SCS), which is used to remove post-shutdown decay heat if the primary system is not functioning; and

3. reactor cavity cooling system (RCCS), which is typically an air (or water) natural circulation cooling system intended to provide the majority of decay heat removal for loss-of-forced- 
circulation (LOFC) accidents, as well as to keep the reactor cavity below $\sim 100^{\circ} \mathrm{C}$ to prevent damage to the cavity concrete during normal operation.

The RCCS is generally identified as a passive safety system and is designed to be operational at all times (i.e., during normal as well as abnormal conditions). In some RCCS designs, operation during normal conditions utilizes forced cooling but falls back on natural convection in loss-of-power situations. The heat removed by the RCCS during normal operation should be minimized to reduce parasitic losses, but it needs to be adequate to meet the post-shutdown decay heat needs, primarily to prevent overheating of the reactor pressure vessel (RPV).

Initiating events often challenge more than one safety function at a time. For instance, primary system pressure boundary breaks directly challenge confinement of radioactivity. However, depending on the size and location of a break, it can also challenge the core heat removal capability. The instantaneous reactor power is a key safety parameter. The reactor power has both neutronic and thermal aspects. Measurements of the two aspects of the reactor power are employed as instrumentation cross checks.

Another commonly used method to determine the instrumentation system requirements is based on providing the information necessary to respond to the dominant phenomena in the event sequence. Example events include

1. primary system breaks,

2. loss of primary system heat sink,

3. air ingress events,

4. water ingress events,

5. reactivity transients,

6. depressurized loss of forced cooling (D-LOFC),

7. pressurized loss of forced cooling (P-LOFC),

8. turbine trip, and

9. station blackout.

The instrumentation system's design needs to include sufficient ruggedness and independence to continue to function under adverse conditions imposed by severe accidents. Much as with LWRs, an HTGR's instrumentation system is arranged into divisions to enable cross checking the performance of multiple sensors and measurement methods, thereby avoiding spurious trips and providing an indication of the health of particular sensors.

\subsection{NORMAL OPERATION}

The purposes for safety-related measurements at HTGRs during normal operation are to confirm that the plant parameters remain within design limits and that plant systems, structures, and components (SSCs) remain capable of responding correctly to accident sequences. Since HTGRs are thermal power plants, the focus of the parameter measurements is on confirming proper heat balances throughout the plant subsystems. The SSC monitoring function confirms that the major radionuclide release barriers remain in place and that both safety-related equipment is functioning as intended (e.g., that the control rods' drive mechanisms position the rods as intended) and accident mitigation equipment remains ready to respond (e.g., power is available to the secondary cooling system). Additional monitoring is performed to assess the amount of radioactive material leaking from the plant (e.g., noble gases from the helium cleanup system) and to map dose and/or contamination levels within the plant. The plant security status is also continuously monitored.

The plant monitoring requirements change during refueling. The fuel handling process needs to be monitored to ensure that fuel is not mechanically damaged during handling and that worker dose is minimized. The decay heat from used HTGR fuel needs to be rejected to the environment. Recently removed fuel may require active cooling to avoid fuel failure. If active cooling is used, the cooling system 
will require safety-grade power. However, unpressurized, below-grade fuel storage vaults would not have a strong mechanism to cause release of the radionuclides from even failed fuel to the environment. Given the large decrease in decay heat with time, the function for any active cooling systems for fuel that has been removed from the reactor for at least several months would be to avoid overheating the surrounding structural concrete (preserving the plant value) rather than avoiding failure of the fuel coating layers.

\subsubsection{Background}

A modular HTGR's core heat transport design is fundamental to achieving the reactor's passive safety objectives. The inherent safety features are the high-quality ceramic-coated particle (TRISO) fuel, the single-phase inert coolant (helium), and the reactor's post-shutdown decay heat removal features consistent with TRISO fuel temperature design limits. The core's features of a combination of low-power density, large size and heat capacity, high thermal conductivity, and large fuel thermal margins result in very slow progressions of postulated core heat-up accidents. As a result, the design can allow very long times to provide safety-significant responses to loss of all shutdown cooling mechanisms. Under such conditions, core heat removal is accomplished via heat transfer from the core to the noninsulated via conduction, radiation, and (if helium coolant is present) convection, and from the vessel to the reactor cavity and RCCS by radiation and convection.

A primary design characteristic of modular HTGR cores is the limitation of rated thermal power (and power densities) to small fractions of those typical of LWRs. While this difference may give safety advantages to HTGRs, the in-core instrumentation in HTGRs is much less extensive and informative. In pebble bed reactor (PBR) cores, where the pebble fuel is continuously recirculated, it is virtually impossible to measure fuel temperatures and localized flow rates. Measurements within prismatic (stationary) HTGR cores are also difficult because of the hostile, very high in-core temperature environments, some beyond the range where sensors can operate reliably. Thus, fuel temperatures must be inferred from external measurements and calculations, or after the fact from dummy balls equipped with melt-wire sensors to infer maximum exposure temperature during a pass through the core.

Fuel temperature calculation uncertainties are due to both the variations in localized fuel power densities and the uncertainties in the localized coolant flow rates and temperatures. In both types of cores, there are typically steep flux gradients at the fuel-reflector interfaces. In pebble bed cores, there are wide variations in individual pebble power densities and burnup since they are recycled (approximately six times), and in pebble locations (e.g., they can either traverse the core near the hot center or near the cooler side reflectors). (Note that current PBR designs have cylindrical cores with no central reflector.) Recently noted concerns about pebble flow uncertainties are due to the reduced pebble friction (in helium) at higher temperatures, which tends to make the recirculating pebbles in the central regions flow faster than those in the cooler periphery, thus exacerbating the central power peaking concerns and increasing the uncertainties of core performance predictions. ${ }^{2}$

Localized core flow uncertainties are significant in both types of cores. That is because of the increase in helium viscosity with temperature, which tends to reduce the coolant flow to the hotter areas of the core (a positive feedback effect). In addition, the variable spacing between blocks (side reflector in the PBR and the central and side reflectors plus the fuel blocks in the prismatic cores) leads to uncertainties in the "bypass flow," which is defined as the core helium flow that does not directly cool the fuel elements. Bypass flows (which cannot be measured) are estimated to be between 5 and 15\% of the total. Gap variations between blocks are due to thermal gradients and the warping caused by irradiation of the graphite.

Thermal gradients in HTGR cores are relatively large. The coolant mean-temperature rise across the core at full power $\left(\sim 400^{\circ} \mathrm{C}\right)$ is about a factor of 10 higher than that for LWRs. Spatial variations in coolant outlet temperatures are also quite large (up to $\sim 200^{\circ} \mathrm{C}$ or more) owing to variations in radial coolant flows and power densities (especially for cylindrical cores). 
Determining the mixed mean primary coolant temperature for an HTGR is technically challenging because of the inadequately mixed cooling streaming and swirling within the piping. Lack of fully mixed primary flow is deleterious both to the downstream structural alloys as well as to performing the primary heat balance measurements. The Fort St. Vrain reactor included variable orifices for the core's 27 radial regions to attempt to equalize the coolant outlet temperatures to minimize the mixing problems; such orifices are not present in the current designs.

Thermocouples installed at Fort St. Vrain, High Temperature Reactor-10 MW (China) (HTR-10), and High Temperature Engineering Test Reactor (Japan) (HTTR) in the reflector blocks were useful in estimating core thermal performance..$^{3-5}$ The extrapolations from these "ex-core" measurements to estimated fuel temperatures require measurements (and estimates) of nuclear power distributions and coolant flow in addition to a comprehensive core thermal hydraulics $(\mathrm{T} / \mathrm{H})$ online simulation.

Temperature distribution measurements in the bottom reflector or core support blocks (such as were installed in Fort St. Vrain) can be used to refine estimates of fuel temperature distributions during normal operation. In addition to the proximity problem with ex-core temperature measurements being far from the fuel, there is typically a relatively large time lag involved with sensors imbedded in the large graphite blocks.

Unlike LWR vessels, the RPVs for HTGRs are mostly uninsulated in such a way that in long-term LOFC accidents, the afterheat can be removed by the RCCS, and that the pressure vessel steel temperature remains below design limits. The RCCS may not be necessary to prevent overheating of the fuel during accident conditions, as its unavailability would only cause a slight increase in peak fuel temperature. However, it is necessary to prevent long-term overheating of the reactor vessel and possible damage to or failure of reactor cavity structural elements and reactor supports. Hence, the normal operation steady-state heat loss from the HTGR RPV is a larger fraction of the nuclear power than is the case for LWRs, and so the RCCS heat removal measurement is crucial in determining the actual reactor thermal power output.

In several instances, the performance of RCCS designs have been found to be difficult to predict with regard to total heat removal capabilities as well as to estimating local temperature distributions in the reactor cavity. ${ }^{6,7}$ In its passive operational mode, the RCCS coolant flow and temperature distributions are expected to be quite varied and difficult to measure.

\subsubsection{Measurement of neutronic variables}

The heat balance calculation should start with measurement of neutronic power generated in the fuel, along with means of estimating gamma heating elsewhere. The measurement is typically used as a support variable in the feedback control of reactor power. A typical device used for this purpose in LWRs is the fission chamber. Challenges associated with the use of this technology include drift and degraded operation at above normal conditions. Gamma thermometers offer an alternative technology that can be adapted for power measurement purposes at HTGRs.

Total neutronic power is typically derived from measurements by all of the flux monitors along with a model for the core flux distribution, fuel composition, and geometry. Single local power measurements are potentially misleading because they do not capture the spatial variations in neutron flux. Spatial variance in the neutron flux is a larger concern for HTGRs since the very good moderation provided by graphite and the lower heat transfer of helium can result in local temperature spikes leading to fuel thermal challenges.

A typical protection signal is the ratio of reactor fission power to primary helium flow, which is a complementary signal to helium coolant temperature rise across the core. This ratio signal requires a very reliable measurement of helium mass flow. No commercial technology currently exists for direct measurement of this flow. Instead, it is typically calculated by measuring the coolant pressure and temperature and the speed of the circulator, along with the differential pressure across the circulator. 
Another typical protection signal is obtained from the turbine/generator system. A trip of either the turbine or the generator, commonly called a loss-of-load event, may require a trip of the reactor, although for some designs the plan is to "ride it out" and control the power and flow to reduce to a house load value. This capability is feasible because of the inherent control mechanisms and slow thermal response of the core.

Depending on the reactor design, a trip of the turbine/generator system might disengage the secondary and primary heat transport systems by closure of the main steam isolation valve and remove heat via the SCS, which is generally proposed as a nonsafety system.

The generated nuclear power should match the amount of heat transferred to the primary heat transport system in a calorimetric calculation, which requires that primary helium temperatures at the reactor inlet and outlet be measured as accurately as possible along with helium flow rate. Issues related to accurate measurement of these variables are discussed in the next section.

\subsubsection{Measurement of process variables}

Mixed-mean helium coolant temperatures can approach $850^{\circ} \mathrm{C}$ at the core outlet. The local helium temperature profiles in the outlet plenum have significant deviations from the average - due primarily to nonuniform heat-up in the core as well as flow stratification effects - that create technological challenges in accurate determination of the mean core outlet temperature. Furthermore, measurement or estimation of maximum local outlet plenum temperatures is necessary to determine potentially deleterious effects of high temperatures (including gradients and fluctuations) on critical components downstream, such as an intermediate heat exchanger (IHX), gas turbine, or steam generator (SG), plus any connecting piping where the hot helium could exceed the hot duct temperature rating.

Recent studies have been made of nonuniformities of the coolant temperatures and flows in the lower plenum and those well into the hot leg where coolant temperatures at any measurement plane can vary significantly both spatially and temporally.

Computational fluid dynamics (CFD) analyses can reveal the expected severity of the temperature profile nonuniformity, as shown in Fig. 1, for the lower plenum of the NGNP. ${ }^{8}$ Streamlines in Fig. 1 represent the family of curves that show the direction that hypothetical fluid elements would take (exiting to the left), and the color coding represents a temperature distribution that could span several hundred degrees Celsius.

The wide temperature variation of the primary helium as it exits the lower plenum and traverses the hot leg is shown as a CFD contour plot in Fig. 2. The variation in helium temperature shown as it first enters the hot leg (contour plot on the right) is approximately $70^{\circ} \mathrm{C}$, as read from the color scale (max-min). This variation diminishes, but does not vanish, as the gas flows through the pipe. 


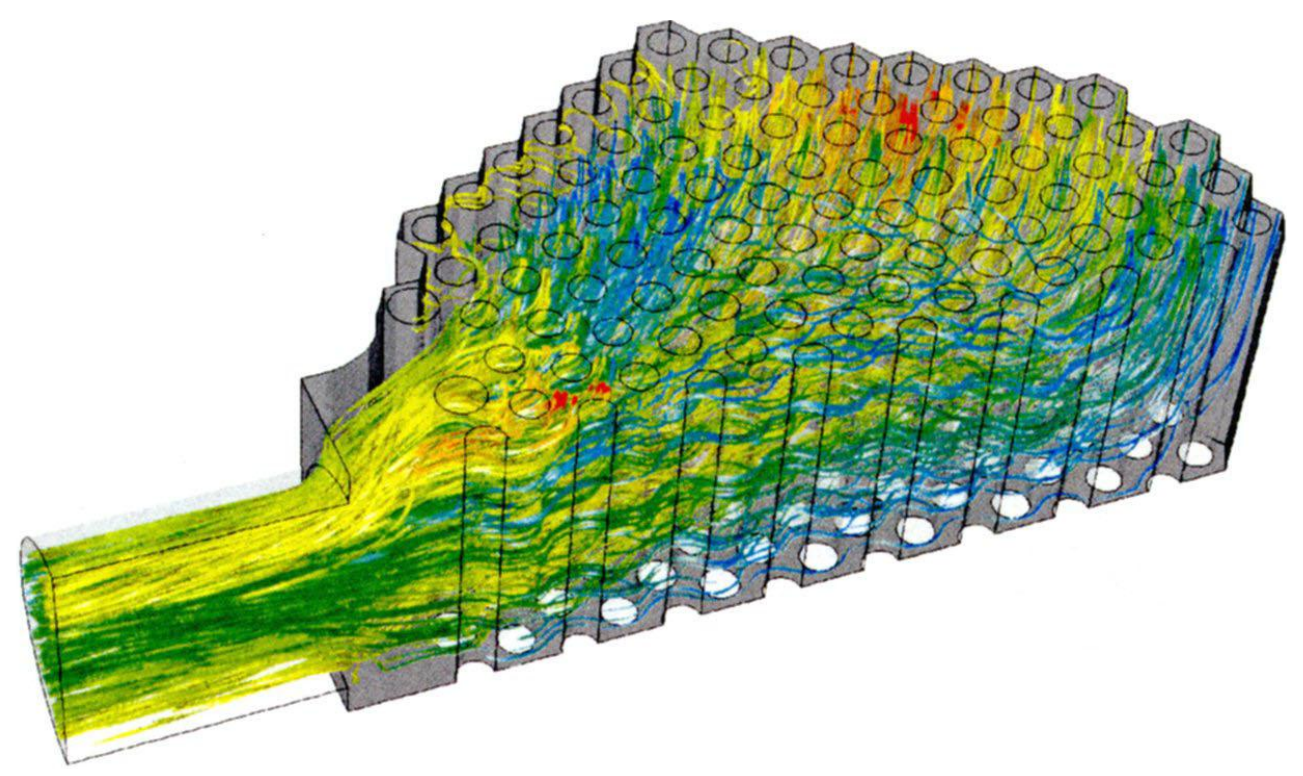

Fig. 1. CFD simulation of flow paths and associated temperature distributions for the lower plenum of an HTGR. ${ }^{8}$
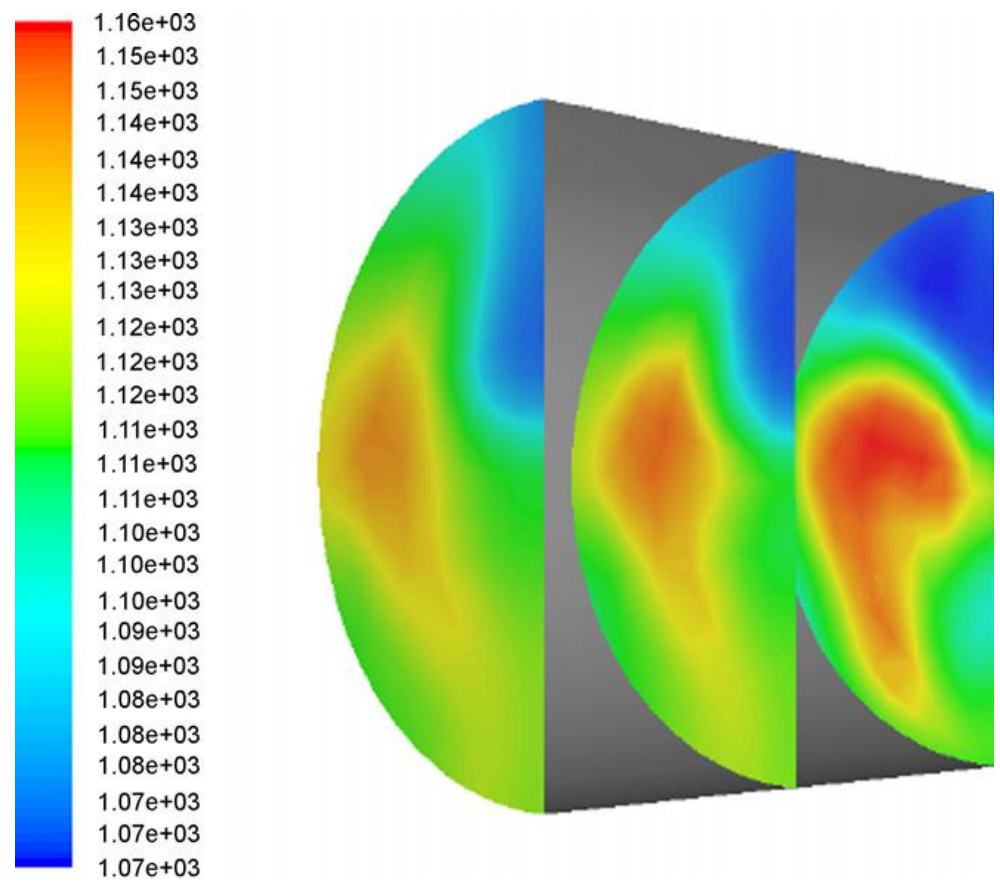

Fig. 2. Temperature contours in the hot leg. The three contour plots represent the entrance (right), the midpoint, and the exit (left) of the outlet pipe of 1.565 -m length. ${ }^{8}$

These projected temperature distribution variations demonstrate the need for multiple temperature measurements in the hot duct and lower plenum. Mean temperature calculations must also account for variations in flow velocities. A discussion of the technology options for temperature measurement, including distributed temperature measurement, is provided in Section 4.1 of this report. 
In addition to spatial variations, flow may exhibit temporal instabilities, such as swirling and shifting with time, as illustrated in Fig. 3. This may require measurements at multiple locations and employing spatial and time averaging techniques to obtain representative values.

On the secondary side, similar needs arise for heat balance calculations to compare with those of the primary loop. For comprehensive calculations for SG designs, heat transfer in the feedwater heaters needs to be taken into account, which includes proper measurement of coolant inlet and outlet enthalpy, along with a measurement of feedwater flow rate.

Typically, turbine manufacturers specify a narrow band of steam temperature at the turbine inlet. This measurement has been used in HTGR designs in the past as a feedback control variable for reactor power. Therefore, measurement of the steam temperature at the outlet of the SG should be carried out by a series of redundant safety-grade temperature sensors.

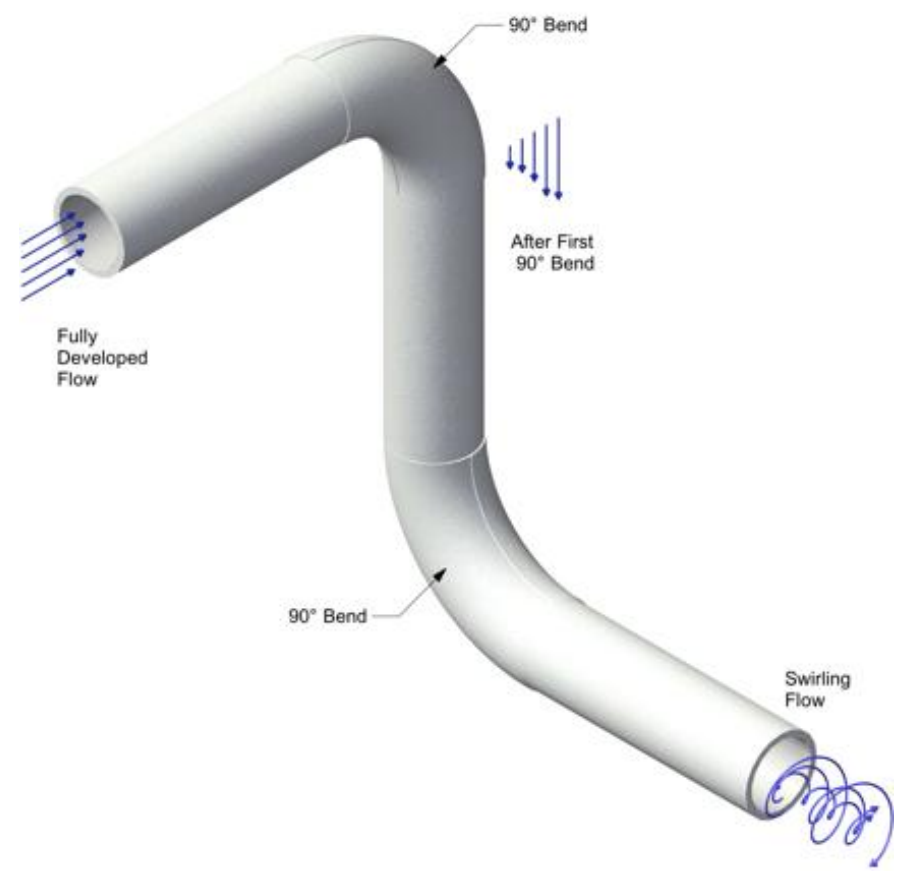

Fig. 3. Illustration of flow and temperature swirl development.

Another issue for temperature measurement in the primary coolant is the mechanical integrity of sensing elements. The primary helium flows at very high velocities and, consequently, creates high mechanical forces on components in the flow path. The temperature sensors are mounted in thermowells that extend into the primary flow path. The primary flow produces both static and dynamic loads on the thermowell body, including vibrations due to vortex shedding. At operational flow velocities, the frequency of the vortex shedding, $f_{s}$, is related to the fluid velocity by the dimensionless Strouhal number:

$$
f_{s}=\frac{\omega_{s}}{2 \pi}=N_{s} \frac{V}{D}
$$

where $D$ is the tip diameter of the thermowell, $V$ is the velocity of the fluid, and $N_{s}$ is the Strouhal number (roughly $\sim 0.2$ for the high Reynolds number) of primary flow. ${ }^{9}$ A thermowell design goal is to ensure that the vortex shedding frequency remains well below the natural frequency of the thermowell probe. 
CFD analyses, supported by experimental verification and validation $(\mathrm{V} \& \mathrm{~V})$, are useful in gaining insight on how measurements can be most accurately correlated to determine a mean primary coolant temperature.

Instrumentation specifications for the secondary heat transport system would be different for a Brayton cycle power conversion system. However, these differences are mostly operations-related details; toplevel requirements are obtained by fundamental thermodynamic principles. Therefore, reliable, accurate measurement of process variables at the inlet and outlet ports of a cycle is a requirement.

Additional instrumentation is generally used to check equipment health status and to provide redundant data for cross correlation purposes. For example, a sudden variation in a process variable, if credible, would be registered by more than one sensor. Some processes have different time constants; therefore, certain amounts of delay can be observed between different sensors as a result of transport times or associated dynamics.

\subsubsection{Helium leak detection}

Helium is one of the most mobile gaseous species because of its low atomic number. Helium may leak out during normal operations at low rates, most likely through seals used in mechanical junctions.

Helium has a lower density than air. Hence, helium from small leaks from the primary system will collect in the dome of the confinement or compartments. Helium concentration monitors installed at high elevations within the confinement volumes should be effective in confirming small leaks. Sensitivities around $1 \mathrm{ppm}$ should be sufficient for detecting minor leaks. Atmospheric helium concentration monitors with 0.1-ppm sensitivity are commercially available.

\section{$2.3 \quad$ ACCIDENT MONITORING}

Accident and post-accident monitoring provides critical feedback on plant conditions to enable proper corrective and mitigating actions, ultimately to avoid or minimize release of radioactivity.

Accident monitoring focuses primarily on the availability and performance of heat removal systems. For the more severe accidents that involve radioactivity, mapping the movement and escape of contamination would also be a primary focus.

Depending on the accident type, event sequences, and equipment and system conditions, different systems - such as the main secondary heat transport system, SCS, or RCCS - could take the lead role in removing the decay heat from the reactor core.

For breaches of the primary heat transport system, a mapping of the transport of radionuclides within and outside the confinement is needed. Augmented with nuclide identification using spectroscopy, this capability would provide useful and timely information.

HTGRs have distinct design differences versus LWRs that impact the design requirements for accident and post-accident monitoring. Key differences, from the safety instrumentation standpoint, are the primary coolant and the confinement building instead of the containment.

The principal motivation, which also drives the technical basis for determining the critical variables necessary during an anticipated operational occurrence or a postulated accident, is not to dump all the data to operators but rather to provide them with a comprehensive picture of the state of the system to help make informed decisions, particularly under undue stress of accident conditions.

An additional safety task in an accident condition is to initiate a reactor trip upon detection of a credible anomaly in plant operation, mainly to prevent recriticality later in the accident progression sequence. As noted before, there is less emphasis on the scram, since for loss-of-cooling accidents the fission process is effectively terminated by the strong negative temperature coefficients of reactivity. 
The plant monitoring system should provide redundant indications for trip status, such as control rod drive mechanism positions, reserve shutdown system trip status, reactor power, reactor period, etc. In general, there would be a need for information about the accident progression, such as the following:

- coolant chemistry,

- chemical reactions between graphite and air/steam,

- formation of gases and aerosols containing fission products (FPs),

- estimates of fuel temperatures, and

- damage to support structures.

This report section provides a high-level walk-through for instrumentation needs from an operator's perspective for each accident as the event progresses. New instrumentation is also proposed that could provide insight about the progression of an accident. For instance, acoustic emission monitoring has long been suggested as a feasible method to identify the location of breaches in pressure boundaries or to pinpoint a troubling component or components within the containment or reactor cavity. Incorporating new technologies early into the design of the overall instrumentation and control (I\&C) system could help with accident mitigation by providing means for timely intervention, especially considering the very long time scales associated with HTGR accident sequences. In considering the instrumentation performance during accident sequences, it is important to consider the equipment environmental qualification and performance requirements for surviving the conditions that could develop.

The subject of post-accident monitoring is treated extensively in NUREG-0737. ${ }^{10}$ A detailed "HTGR" explanation of how these requirements were met at the Fort St. Vrain reactor is in a Public Service Company of Colorado document available in the NRC Tomoye database. ${ }^{11}$

Experience from major reactor accidents indicates that collection and analysis of credible information is the most critical task in responding to the accident - and reliable instrumentation is the medium for that.

HTGR accident scenarios have been described and analyzed extensively. A summary description of these accidents and event sequences can be found in International Atomic Energy Agency (IAEA) SRS No. $54 .{ }^{12}$

\subsubsection{Anticipated operational occurrences}

Anticipated operational occurrences are those deviations from normal operation that are expected to occur several times during the life of the plant. These may include, for example, loss of power to all circulators, tripping of the turbine or generator, isolation of the main condenser, and loss of off-site power. A long-term loss of power to all circulators is discussed in Section 2.3.2. Since the plant conditions are not significantly altered during AOOs, the instrumentation needs are essentially the same as those noted previously for normal operation.

\subsubsection{Turbine trip and loss of load}

Measurement needs for a steam-cycle design's balance of the plant side are similar to those for the PWRs, except that the temperatures are higher. Because a turbine trip requires dumping the steam into the condensers, the reactor may also be tripped and the primary system isolated from the secondary loop. In some designs, reactor power would be sustained but decreased to cover house load. Measurements of interest on the secondary side are the process variables for the steam into the condenser and the status of safety pressure relief valves (PRVs).

\subsubsection{AOO reactivity events}

"Less severe" AOO reactivity events are those in which a manageable amount of excess reactivity, either positive or negative, is accidentally or inadvertently introduced. Typical initiators causing these events are 
1. control rod or rod bank withdrawal;

2. inadvertent control rod movement, including a control rod drop;

3. accidental reactor shutdown;

4. unexpected increase or decrease in primary heat removal rate;

5. compaction of a pebble bed core caused by an earthquake;

6. leak in heat transfer tube(s) in a SG or other water-cooled heat exchanger that could result in a minor water or steam ingress into the core; and

7. fuel loading error.

\subsubsection{Heat removal accidents-pressurized loss of forced circulation (P-LOFC)}

This general category of accidents has one major event sequence that should be taken into account for design basis: long-term pressurized loss of forced circulation in which the helium circulators stop while the primary system remains pressurized.

A long-term loss of primary coolant flow would be rapidly detected by several of the plant process instrumentation systems. For the case of plant designs with the SG in the primary loop, the instrumentation system should provide the operators answers to the following example questions (note that this example list would be different for designs with an IHX or a direct-cycle gas turbine):

1. What caused the failure?

2. Did the plant trip properly upon accident initiation?

3. Was any SCS operation initiated, and what are the prospects for start-up?

4. What portion of the primary cooling system is not functioning properly?

5. What is the response of the primary pressure - is it approaching the relief valve limit?

6. Did the SG isolation valves (secondary side) close?

7. Has any noticeable plant damage occurred (e.g., causing a loss of primary heat sink, or is there moisture ingress from the SG or SCS)?

As the accident progresses, additional information should be provided:

1. estimated core temperatures;

2. estimated reactivity balance (approach to recriticality?);

3. reactor vessel and vessel support temperatures, particularly in the upper regions;

4. RCCS status and heat removal rate;

5. reactor cavity concrete temperatures;

6. primary system pressure;

7. confinement atmosphere temperature and gas composition;

8. electrical power bus status; and

9. evidence of water ingress into the primary system.

Note that for the P-LOFC, with no primary coolant flow, core coolant outlet temperature sensors (in the lower plenum) would not provide any direct information about core temperatures.

There are two major groups of events or event sequences that lead to a P-LOFC: (1) a reactor shutdown with a failure of the SCS (or other shutdown cooling mechanism) to provide forced cooling or (2) a station blackout that results from a long-term loss of off-site power and auxiliary power sources. The first group includes events that result in actuation of the reactor protection system, which typically stops or reduces the primary helium circulation intentionally to avoid overcooling. The second group of events includes loss of grid load or failures of the primary helium circulating equipment (i.e., helium circulators or turbomachines).

The primary concern with loss of circulation is the core and primary system heat-up transient. The advantage of being at pressure is that the primary helium inventory will enter a natural circulation mode 
within the core as the core heats up, which will help equalize the core temperatures and with maximum temperatures appearing near the top of the core.

Many of the measurement needs for P-LOFCs are similar to those for normal operations. Because there is an additional mode of effective heat transfer compared to a D-LOFC - namely, the primary helium in natural circulation mode - fuel temperatures will remain well below safety design limits.

Elevated temperatures are of particular concern for metallic structures and equipment. Those include the primary system pressure boundary, the reactor vessel, control rod sleeves, and the core barrel. Reliable measurement of the temperatures of these structures and components is important, especially for postaccident time-at-temperature analyses. These calculations are critical in assessing the potential impact of such temperature increases on structural integrity and code limits.

Depending on the heat removal conditions seen by the entire primary system and the actions taken (or not) by the helium inventory control system, a long-term primary pressure increase may occur.

For prolonged LOFC accidents, reactor temperatures eventually rise to levels where RCCS heat removal is crucial. The RCCS is generally proposed as a passive, safety-grade system. Heat rejection by radiation from the outer surface of the reactor vessel is the dominant heat transfer mode, but natural circulation of air in the reactor cavity is also important and tends to concentrate heat in the upper regions.

In this heat transfer process, a crucial factor is the thermal emissivity of the reactor vessel and the RCCS opposing surfaces. Certain online measurements of emissivity are feasible: (1) emissivity measurement on the outer surface of the reactor vessel, which is indicative of the effectiveness of radiating heat off the surface and (2) temperature measurements on the outer surface of the vessel and on the surface of the RCCS used in heat balance calculations for the RCCS. In addition to these, airflow rate in the stacks connected to the RCCS provides an indication of how effectively the heat is being rejected to the atmosphere- the UHS for the RCCS.

For emissivity measurements, radiation pyrometry, most likely an IR pyrometer, can be used. For reliable pyrometry measurements, care must be given to the RCCS atmosphere. The presence of dust or gases absorbs a portion of optical energy, which might result in the misreading of surface emission. To overcome this challenge, ratio pyrometers can be used, taking measurements within narrow bands at multiple wavelengths. By taking the ratio of emissions at two temperatures, the effect of variation of surface emissivity with temperature cancels out. This technique also compensates for any intermediary material that might be present in the optical path, such as dust and other gases.

\subsubsection{Primary system rupture accidents}

\subsubsection{Depressurized loss of forced circulation (D-LOFC)}

Many of the monitoring needs for a D-LOFC accident would be similar to those for the pressurized LOFC case. For D-LOFC, there would be an additional concern for air in-leakage to the primary system that could result in long-term oxidation of the core graphite (see Section 2.3.4).

The D-LOFC is a design basis accident (DBA) with failure of the primary system pressure boundary. Therefore, instrumentation functional requirements are drawn from the needs for monitoring the accident progression as well as the regulatory requirements to quantify the risk to the health and safety of the public.

In a D-LOFC accident, it is assumed in the typical reference case that, in addition to an LOFC, the primary helium inventory is lost to the point that the primary system is depressurized to atmospheric pressure. D-LOFC conditions may arise from primary pressure-containing equipment failures, such as leaks or piping ruptures that are not isolatable. The opening of primary system safety PRVs (without reclosure) may also lead to D-LOFC conditions. 
Variations of the D-LOFC include scenarios in which the leak is isolated and the resulting pressure is greater than atmospheric, thus setting up some natural circulation flows within the core. (With only atmospheric pressure helium, natural circulation within the core has no noticeable effects on core temperatures.) Another variable of much interest is the size of the leak, which determines the rate of depressurization. Rapid depressurization event consequences may include an unfiltered discharge of the primary system inventory into the atmosphere as well as damage to equipment outside the primary system from a hot helium jet or from piping whiplash. Impact of the large momentum transfer and the resulting forces on safety-related equipment will need to be accounted for in the structural evaluation of the postulated accident sequence. As helium leaks into the reactor cavity and the confinement, temperatures in these volumes will initially rise significantly with certain extremely hot spots before it completely mixes.

The major consequence of long-term D-LOFC accidents is the core heat-up and potential radioactivity release (prompt and delayed) into the confinement and, eventually, into the environment. During the course of the accident, the maximum fuel temperature reaches its peak value within a few days, followed by a prolonged decline. Maximum fuel temperatures are generally expected near the midpoint of the core. The major design features of modular HTGRs (maximum power, core diameter, etc.) are limited to ensure that the peak fuel temperature does not exceed the design value (typically $1600^{\circ} \mathrm{C}$ ).

During the initial depressurization process, much of the circulating activity may be released along with the leaking helium. Depending on the break size and location, graphite dust containing fission products from failed fuel as well as any ${ }^{137} \mathrm{Cs}$ and other isotopes plated out onto colder portions of the loop may also be released. The large prompt helium releases are followed by slower releases into the confinement. In current designs, these discharges would pass through charcoal filters before being released to the environment.

Maximum attainable temperatures in the cavities and the confinement should be estimated from use of thermodynamic equilibrium models. Based on the calculations with reasonable engineering margins, requirements for equipment qualification should be written for certain safety-related instrumentation to withstand the anticipated conditions - i.e., pressure, significant forces, and temperature. Maximum and final process parameters will be a function of the primary helium inventory, the core mass and temperatures, and the ratio of total primary system volume to total cavity and confinement volume.

Cabling requirements for safety-related instrumentation would be determined on the basis of predicted consequences of postulated events, as per requirements by IEEE Standard 323-1974. Class 1E equipment cabling practices should be adopted for any component or system that is identified as potential safetyrelated instrumentation during a postulated accident.

\subsubsection{Nuclear measurements}

The most critical parameter to be monitored during a D-LOFC is the radioactivity levels in the reactor cavity, confinement, and site periphery. Measurement at multiple locations may be useful in identifying the location of the leak. Activity trends might also be a confirmatory indication of approximate size of the breach.

Qualified air monitors used in the operating reactors monitor the activity in the containment atmosphere. However, qualification requirements for the HTGR confinement atmosphere will be different from those for LWR containment. Some equipment may need to be designed with larger thermal margins to withstand localized temperature transients following a major depressurization event.

Typical air monitors do not provide spectroscopic information that can be used for isotopic analysis, which would be useful in monitoring accident sequences involving fuel failures. 


\subsubsection{Process measurements}

During a D-LOFC, availability of in-core temperature information is of particular importance, primarily because much of the safety-related parameters are linked directly to temperature, such as TRISO fuel integrity. During the course of the event, core temperatures rise, though slowly, well beyond the levels expected during normal operations. Some of the instrumentation used during normal conditions might fail because of the core heat-up. Although direct in-core temperature measurements are likely not available, it is advisable to have some related temperature instrumentation (such as in the reflectors) available to withstand the extreme conditions to provide means of estimating in-core parameters during the transient.

In addition to core temperature instrumentation, means should be provided to monitor the temperature in the cavity - both reactor and the primary coolant systemPCS. Because of the excessive forces and subsequent heat released during a depressurization accident, concerns about the availability of the instrumentation apply, as mentioned earlier. The equipment intended for accident and post-accident monitoring in the reactor cavity, confinement, and site vicinity should be designed to withstand the conditions that might arise within reasonable assumptions during a DBA. Instrumentation for safetyrelated functions is expected to be qualified to stricter requirements to be determined by accident analyses.

Pressure is the key parameter in a D-LOFC for confirming depressurization and potential breach of the pressure boundary. Pressure is most likely measured at multiple locations within the primary system as well as within the reactor cavity and the confinement. Following a breach of the primary pressure boundary, pressure transducers within the cavity and the confinement may also register shock waves. Depending on the break characteristics and the instrumentation design, it may be possible to obtain insight as to the approximate location of the leak.

\subsubsection{Confinement air filter measurements}

During a rapid depressurization, the confinement building will experience a sudden increase in pressure. Depending on the design, excess pressure will most likely open a flapper valve to the environment. Blowout filters (Fig. 4) could also be instrumented with a radiation monitoring system — with or without spectroscopic capabilities. Spectroscopic capabilities would provide additional means for tracking movement or escape of contamination. Rate counters with identical energy windows at the inlet and outlet of the filter can be used to determine its effectiveness.

\subsubsection{Acoustic emission monitoring}

A major depressurization process will manifest itself as sudden departure from nominal values in the process variables. Monitoring these variables provides a direct and reliable indication as to the existence of an anomaly. However, determining the location of the leak may not be possible with the instrumentation specifically intended for monitoring the plant variables.

One potentially viable method for (1) confirming a breach and (2) locating the leak is through acoustic transducers. Discharge of high-temperature helium into the cavity with a large pressure differential creates very high-frequency acoustic waves. Furthermore, at the onset of a breach, the initial release should create a strong pressure wave - a shock wave - that should be easily registered by pressure transducers as well as accelerometers mounted on the components. The approximate location of the pressure source might be determined by cross correlation of the readings from multiple sensors and triangulation.

Even if the leak were small, it should create very distinct, high-frequency acoustic waves easily detected by the same method. Noise amplitude analysis would most likely not lend itself to determining the approximate size of the leak.

Leak position sensing could be accomplished in a number of ways, and transducers mounted on the primary piping should help create a baseline for nominal operation. On-pipe transducers are also useful to 
monitor flow-induced noise, which can provide data for detecting potential loose parts within the heat transport loop. The proximity of the sensors to the leak should impact the amplitude of the signals. Hence, amplitude comparison among sensors made available for this purpose should provide an indication as to the approximate location of a leak.

Another method for position sensing is to employ a time-of-flight approach, where the time shift of the waveform is measured by using one transducer as the reference signal source. Other transducers are used with respect to that reference signal to determine the amount of shift in a signature waveform. The approximate location of the wave source, potentially a leak or a failed component with a distinguishable noise characteristic compared to the baseline spectrum, can be calculated with the information from multiple transducers by triangulation.

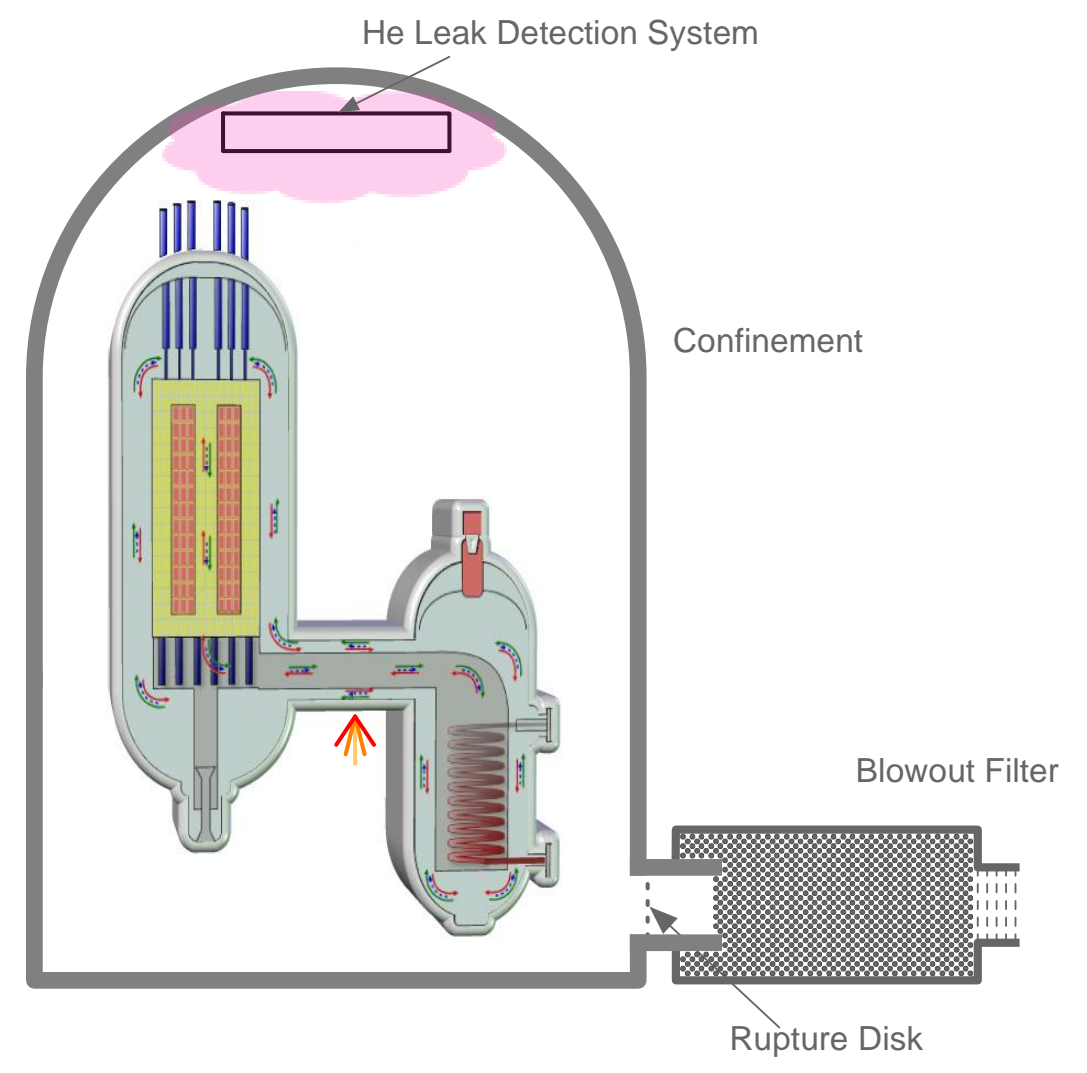

Fig. 4. An illustration of the confinement blowout filter and a helium leak detection system. ${ }^{13}$

\subsubsection{Air ingress}

Key factors in air ingress accident scenarios are the net airflow rate into the reactor vessel and core and, ultimately, the availability of fresh air (oxygen) over the course of the accident. The net airflow through the core is strongly dependent on the buoyancy forces due to differential temperatures and the flow resistances in the core and at the break(s). Predictions of the availability of "fresh air" ingested into the vessel and core need to account for the RPV being in a cavity or confinement building (vault), where fresh air in-leakage is limited and the discharged helium and gaseous products of an accident would collect and mix and become components of the gas for subsequent core ingress. 
For a single break or opening in the primary system, calculations and experiments have shown that there may be long delays before a sustained, significant net air inflow into the core is established. The main responsible phenomenon is the persistence of a helium "bubble" in the top area of the vessel, which inhibits recirculation flows within the core. Experiments and analyses by JAERI ${ }^{14}$ and others have shown that this bubble may be effectively maintained in the vessel for days. For idealized experimental conditions, these predictions have proven quite accurate. However, for more realistic break situations, actual conditions would be complex and could result in large uncertainties in the time for a significant ingress flow to start. The major uncertainty factors include size and location of the break(s), the core temperature distribution, the temperature and composition of the gas outside the primary system that provide the cold leg driving force for the natural circulation, and other types of perturbations (such as operator actions) to the system likely to occur in the days following a major event such as a D-LOFC. This process involves air diffusion into the helium bubble and, potentially, a density-gradient-driven stratified flow effect as well for larger break scenarios. ${ }^{15}$ Because of the uncertainties, ingress flow start times in these analyses are usually inputs treated parametrically.

For a much less likely case of a double break that allowed outside access to both the top and bottom of the core, this chimney-like configuration would promote a higher net air ingress flow with minimal delay.

Once a net air ingress flow is established, oxidation would typically begin in the lower part of the core or in the bottom support and reflector areas. However, for the low flow rates expected, oxygen could be depleted even before reaching the active core area. In some scenarios, however, oxidation would occur in the lower part of the active core for higher ingress flow rates and for cases where the lower reflector has cooled sufficiently and no longer oxidizes. Structural damage from low-temperature (chemical regime) oxidation may be considerable in the lower plenum, depending on the delay in the start of air ingress. Hence, this start time is a major determinant of the potential accident consequences.

Variation in the time delay for a net air ingress flow typically has little effect on peak fuel temperatures, which occur higher up the core. Even with no mitigation, the oxidation rate would eventually decrease on account of limitations in available oxygen.

While $\mathrm{CO}_{2}$ is the principal oxidation product with its oxidative heat deposited in the graphite, carbon monoxide can be formed in higher-temperature reactions of the $\mathrm{CO}_{2}$ with graphite $\left(\mathrm{CO}_{2}+\mathrm{C}=2 \mathrm{CO}\right.$, the Boudouard reaction). Since this is an endothermic reaction, ignoring it is "conservative" when predicting peak core temperatures, but its omission may lead to an underprediction of the amount of graphite consumed and, thus, a greater potential for fuel damage in the hotter part of the core.

Studies have shown that core survival could be in jeopardy if there is very long-term easy access to fresh air after a D-LOFC. ${ }^{16}$ Thus, prediction of damage to the hot core and support structures that encounter the oxygen requires refinement of design data and further analysis, as well as post-accident monitors designed to determine the extent and nature of damage to the core and support structures. It is important that for long-term air ingress accidents, the ultimate availability of fresh air is considered and limited.

\subsubsection{Analytical measurements}

Much of the basic instrumentation requirements discussed under the D-LOFC also apply to air ingress scenarios. Because depressurization is prerequisite to air ingress, measurement needs are also similar. In addition, analytical methods should provide information about the extent and nature of the graphite oxidation. Reaction products (e.g., carbon dioxide and carbon monoxide) as well as potential fission gas releases to the reactor building (confinement) would need to be monitored to help guide accident mitigation efforts. Measurement of airborne concentrations of these species should provide insight into the progression of these events. Technologies suitable for primary system and confinement gas purity monitoring are described in Section 4. 


\subsubsection{Steam/water ingress}

\subsubsection{Background}

The NRC preapplication review of the modular HTGR (MHTGR) in the 1980s as documented in NUREG-1338 (Ref. 17) and the extensive supporting documentation provided by DOE in the Preliminary Safety Information Document (PSID) for the Standard MHTGR ${ }^{18}$ provide thorough documentation of the multiyear regulatory review of a 350-MW(t) plant similar to that currently considered for the NGNP. It is applicable to NGNP in that a dominant risk is from steam/water ingress via steam generator (SG) tube leaks or breaks.

For moisture ingress events, the major risk evaluations would, as with other accidents, focus primarily on dose at the site boundary, radioactive release from the reactor building, and worker dose. Secondary risk evaluations for moisture ingress events would be for loss of structural integrity of the graphite or composite reactor internals, release of primary system contaminants to the reactor building, explosive gas concentrations, and fission product mobilization. A comprehensive safety evaluation of moisture ingress was completed recently and forms the basis for much of this section. ${ }^{19}$

If one adopts the assumption that the only feasible means for fission product escape to the environs in a moisture ingress accident is via operation of the primary system PRVs, then the leading critical parameter in the accident sequences is primary system pressure. Simultaneous depressurization events due to breaks in the primary system, considered to be independent of water ingress, are usually judged to be beyond the usual beyond design basis accident (BDBA) probability.

Primary system pressure is affected by the amount of steam (or water) ingress, reaction gas generation, system temperatures (e.g., core heat-up), and the timing of various elements of the sequence. For cases where relief valves open on high pressure, cycling of the valves would impact the amount of gas release and the dose involved.

Typically the cores of modular HTGRs are under-moderated, so that the additional moderation introduced by moisture ingress increases the reactivity and thus can cause rapid power increases. In addition, a reduced neutron leakage from the core reduces the worth of control rods as well as reserve shutdown system effectiveness. Even so, with a very hot core, any moisture ingress would be in the form of lowdensity steam, which should have only small effects on reactivity.

There is also the need to consider "chronic" degradation of graphite resulting from low-level concentrations of moisture in the primary system during normal operations. Such long-term degradation may affect the integrity of structural supports and thus exacerbate the consequences of structural impacts during severe accidents.

\subsubsection{Ingress event descriptions}

Steam/water ingress events are assumed to be primarily caused by SG tube leaks or breaks, but also possible would be leaks in other water-cooled heat exchangers in the primary system such as in the SCS. Figure 5 shows the possible sources of water ingress, the dominant ones being from the SG since it operates at a pressure higher than the primary helium coolant. The figure implies the dependency of SG event sequences and accident outcomes on the SG leak location, since water (from the feedwater end) or steam (or both) may be injected. 


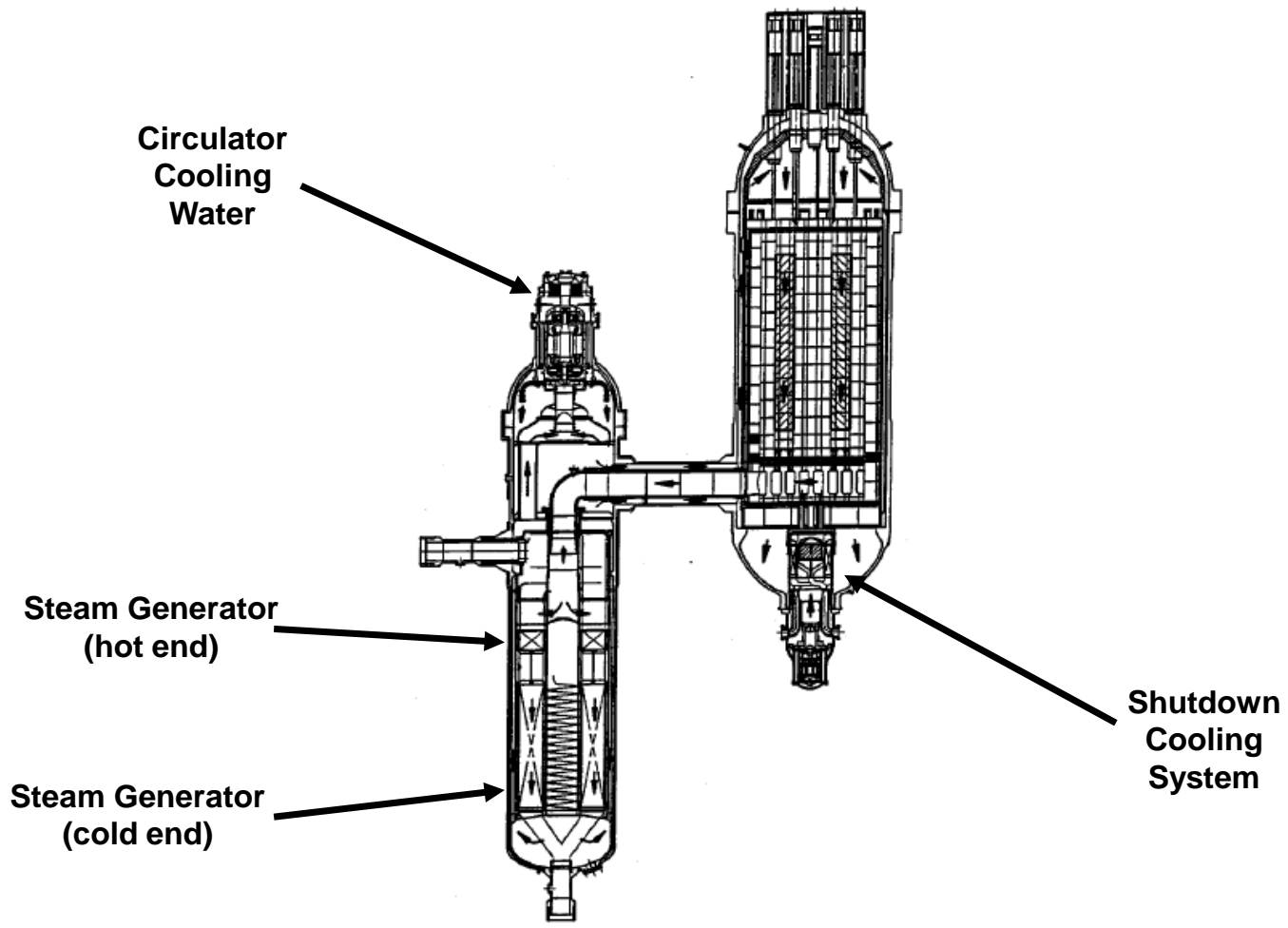

Fig. 5. MHTGR arrangement and water ingress sources. (From Ref. 19)

The SG is also equipped with secondary side isolation and dump valves. A typical SG isolation and dump system configuration is illustrated in Fig. 6. Reactor trips are accompanied by closing the feedwater and main steam isolation valves and opening the dump valves to drain the remaining water inventory from the SG. The dump valves are reclosed when the secondary pressure has dropped to less than the primary coolant pressure. Draining the excess water from the SG prevents additional water from entering the primary via vaporization of remaining water in the tube bundle.

In ingress scenarios where it is assumed that nonsafety-grade moisture monitors (per MHTGR design) operate and successfully activate the SG isolation valves, thus cutting off the water ingress source, the results are a modest amount of total water ingress with very little effect on reactivity, core temperature, water gas generation, and graphite oxidation. On the other hand, scenarios that assume failure of a moisture monitor trip action ultimately rely on a high primary system pressure to scram (and potentially for subsequent safety valve actuation), which also activates the SG isolation. In this case, the safety valve actuation would maintain the system pressure within design limits but at the cost of releasing fission products (FPs) to the environment. A continuing pressure rise causing repeated openings of the relief valve(s) would continue to maintain a "safe" pressure but would continue to release FPs. In a variation of this scenario in which the high-pressure trip point is not reached, there would be a reliance on the operator to manually scram the reactor and actuate the SG isolation and dump valves.

Events involving moisture ingress during shutdown and refueling modes of operation could have a greater impact on reactivity than those during normal operation. With moisture in the liquid form, more moderation could be occurring than with high-temperature steam, where the density would be much lower. Moisture monitors also may not be able to detect the ingress and conditions associated with the presence of moisture in the liquid form (e.g., saturation levels do not indicate the status of water concentrations). 


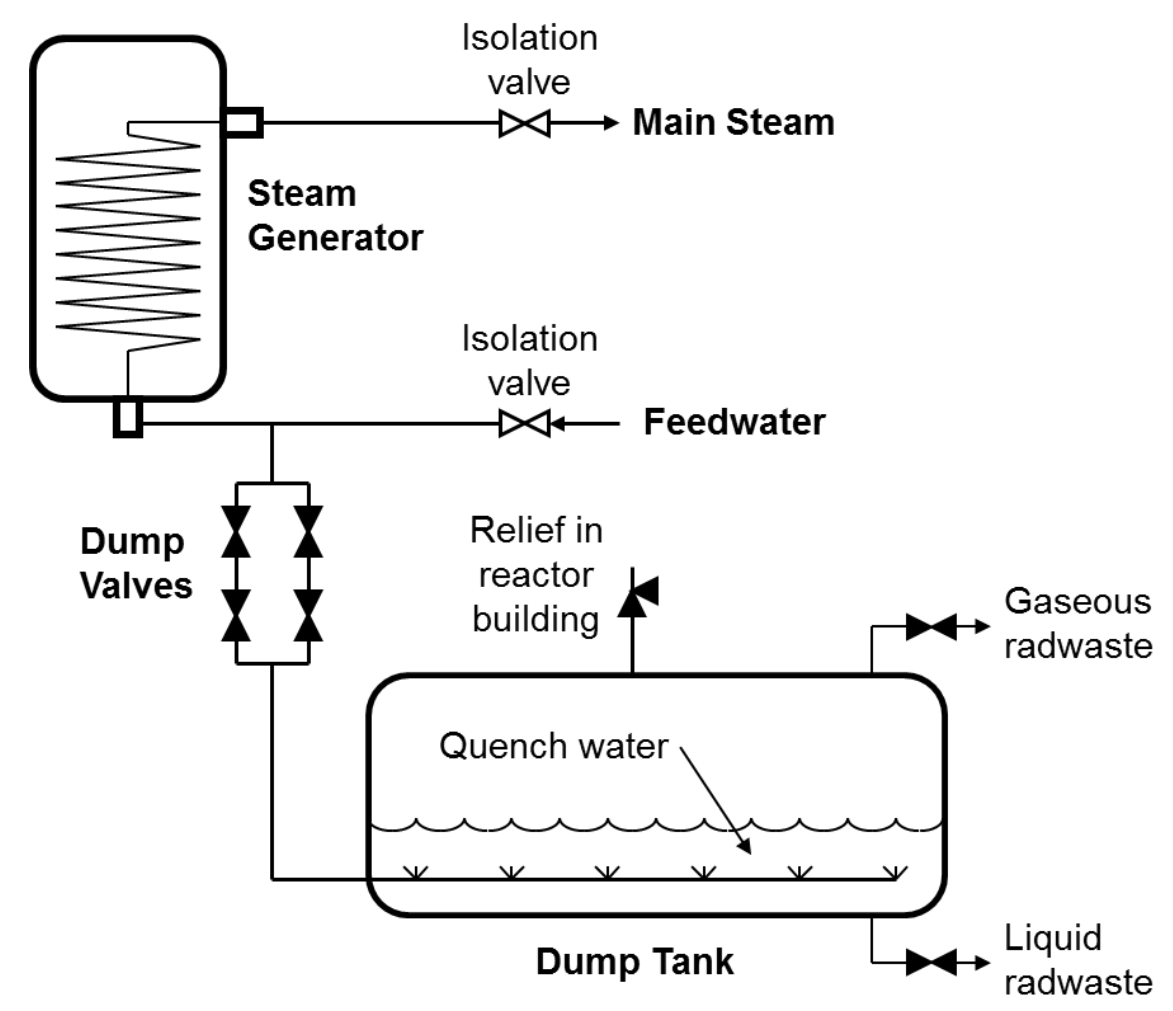

Fig. 6. SG isolation and steam water dump system configuration. (From Ref. 19)

In the events and situations noted, there are cases where changes in operating conditions (or model assumptions) could have significant effects on predictions of total water ingress and total FP releases. For long-term accident sequences especially, the possibilities for operator actions need to be factored in (where "intuitive" or prescribed interventions may or may not be beneficial). For such long-term, potentially complex accident scenarios, it is important for the instrumentation to provide both the automated systems and the operators with reliable and accurate information.

The essential information should be collected and analyzed to enable the $\mathrm{I} \& \mathrm{C}$ system and the operators to estimate and track

1. moisture levels in the primary;

2. core and primary system coolant temperatures, flow, and pressure;

3. reactivity effects of steam/water ingress (increased reactivity with under-moderated core);

4. reduction of control/shutdown rod worth;

5. scram (and reserve shutdown system) action;

6. reactor pressure vessel (RPV) pressure relief system activations and response;

7. plant protection and control systems (safety and nonsafety) response;

8. confinement atmosphere conditions (temperature, pressure, composition);

9. confinement release characteristics, including dose;

10. SG isolation and dump system operation;

11. graphite oxidation/corrosion products; 
12. fission product releases from fuel and graphite; and

13. potential for explosive gas mixtures in both the RPV and the reactor building.

\subsubsection{Applicable instrumentation}

A steam/water ingress accident requires reliable moisture monitoring in the primary system. Although a major in-leakage could also be detected from a sharp increase in the primary loop pressure, there are other causes of pressure increases so it would not necessarily indicate moisture ingress. Depending on the scale and location of the leak, it may also be detectable by acoustic sensors. Moisture ingress can also cause an increase in the core reactivity related to added moderation from the hydrogen, although small leaks are not anticipated to produce measureable reactivity changes. No observable reactivity changes were recorded during the Fort St. Vrain reactor operation in spite of the numerous ingress events. Calculations indicate, however, that gross in-leakages could cause reactivity increases that would be readily detectable by power range fission chambers. ${ }^{20}$ Additionally, a side effect of water entering the core could be a release of tritium that has been chemisorbed into the core graphite.

Moisture monitoring will likely be performed either with a mechanical resonance or capacitive-type gauge connected to a gas sampling tube (to lower the gas temperature and pressure) or preferably by an online, infrared absorbance spectrometer. Descriptions of the sensor options are included in Section 4.

In general, the hot graphite of the core is expected to react with all of the trace oxygen, moisture, and carbon dioxide in the coolant to form carbon monoxide and hydrogen. The hydrogen, in turn, could react with cooler graphite to form $\mathrm{CH}_{4}$. The moisture detection system needs to be sensitive to $\sim 1 \mathrm{ppm}$ of moisture, and periodic off-line analysis of primary coolant contamination helps to keep track of the reactions occurring during normal operation.

The recent HTGR moisture ingress evaluation notes that ppm levels of moisture could be a chronic problem at HTGRs, but indicates that further research and development (R\&D) is advised to estimate the effects on core materials and lifetimes. ${ }^{19}$ However, with a properly functioning helium cleanup system, even the large amount of moisture that can potentially be present in new fuel or reflector block loadings can be removed relatively rapidly (hours).

Water-steam leaking into a helium environment will have an acoustic signature as the steam flow induces vibration in the leaking crack. The intensity and frequency of the acoustic signature will vary if the crack enlarges and the steam flow increases over time. The leak's acoustic signal can be detected by attaching a high-temperature strain gauge to the surface of the primary piping near the SG and reading out the strain gauge at a few tens of kilohertz.

A rise in the loop tritium level resulting from flushing the chemisorbed tritium from the core graphite would be observable in the helium cleanup system. In the most likely form of the helium cleanup system, a side stream of primary coolant would be oxidized by flowing it over a copper oxide bed to form tritiated water. Next, the tritiated water would be adsorbed onto a microporous synthetic zeolite filter, referred to as a molecular sieve dryer. The filter would be removed from the flow path and heated to drive off the water. Finally, the water would be condensed in a cold trap and analyzed for tritium content most likely by use of a scintillation cocktail. The tritium collection process inherently takes time; tritium would not be detected until the filter is exchanged and analyzed, likely some hours after the water ingress begins. However, tritium detection may be a useful indicator of small-to-moderate water ingresses.

\subsubsection{Summary}

Typically in safety studies, the dynamic effects of water ingress into an operating or shutdown core are considered of high importance. The 1986 MHTGR PSID included several DBA and BDBA versions of steam leaks and tube breaks, with and without safety system intervention, including scram, turbine trip, and isolation and dump valve closures. The DBA scenarios resulted in modest power increases from reactivity increases, maximum fuel temperatures well within material limits, and the expectation of no 
fuel failure occurrences. The consequences of BDBA events (with only safety systems responding) were more significant, with more water entering the primary system leading to more graphite oxidation.

The primary PRV cycles resulted in releases of radionuclides. However, the PSID analysis concluded that the oxidation and the total dose to the environs would be well within limits. There are variations in the BDBA sequence (from the PSID) that could lead to more oxidation and dose; consequently, sensitivity studies, with variations in both sequence assumptions and models used, are recommended. This will require a systems accident code capable of simulating phenomena associated with moisture ingress being used to acquire a better understanding of the potential consequences of moisture ingress events and to optimize the design of mitigation systems in the process.

Fission product releases would result mainly from removal of FP deposits from primary system surfaces and from chemical reactions with the FPs and graphite. Moisture ingress would have no significant effect on intact fuel particles, only on defective particles in which the kernels are exposed. Releases to the environment would occur only upon opening the relief valves. There is a need for more data and improved modeling for decontamination factors for the reactor building.

For the long-term case, low levels of moisture present during normal operating conditions are a significant concern, as oxidation rates and the physics of diffusion-controlled oxidation are not well understood. Additional R\&D would be required to accurately calculate the oxidation rates, the effects on material performance, and the mechanisms controlling the oxidation behavior at high temperatures and in low-moisture environments. Long-term structural damage would be a consideration as it may affect "initial conditions" in the evaluation of significant moisture ingress accidents.

\subsubsection{Reactivity events and anticipated transients without scram (ATWS)}

Anticipated transients without scram (ATWS) events are usually those that are AOOs followed by the failure of the reactor trip portion of the protection system specified in General Design Criteria 20 of Appendix A to Code of Federal Regulations (CFR) Part 50.

A failure to scram involves initiating events that call for a scram. Typical ATWS initiating events considered for HTGRs are

1. loss of off-site power,

2. loss of heat sink,

3. loss of forced cooling under pressurized or depressurized conditions,

4. withdrawal of one group of control rods,

5. compaction of a pebble bed core caused by a safe shutdown earthquake, and

6. ingress of water or steam into the core (causing a positive reactivity insertion).

High-level requirements for HTGR reactivity control will vary depending on design features such as the balance of the plant characteristics of the power plant (i.e., steam cycle vs gas-turbine-based power conversion system). A discussion of the safety aspects and consequences of reactivity events is found in IAEA SRS No. $54 .^{12}$

HTGRs are typically furnished with two active reactivity shutdown systems that are diverse from the reactivity control system, which functions as a power regulation system. The first shutdown system actuates automatically, inserting sufficient negative reactivity into the reactor typically by inserting control rods into the core or into the reflectors depending on the design. The second shutdown system has a diverse actuation mechanism that dumps neutron-absorbing balls into the core. The second shutdown system can be actuated either manually or automatically in the event that the first shutdown system fails. Both systems should have sufficiently black reactivity to render the reactor subcritical.

In an ATWS event sequence, when a reactor protection parameter reaches its trip point, a scram signal is initiated and sent to the reactor protection system, which actuates a series of protective actions, such as 
dropping the control and safety rods, stopping the primary helium circulators, closing a blower flap, and isolating the secondary system (by closing the main steam isolation valve in a steam-cycle design).

Furthermore, the excellent reactivity-temperature feedback, coupled with the very high thermal inertia of the core components (primarily a large graphite mass), provides inherent protection against the deleterious potential of an ATWS event and allows for long delay times in case there is a need for manual operator actions, such as insertion of the absorbing balls into the side reflector.

High-level instrumentation requirements for ATWS mitigation - similar to those for PWRs and BWRsshould include a diverse signal route from sensor output to final actuation device, which will de-energize the coils on the reactor shutdown rods. This is a safety-grade system. A diagnostic system that predicts reactivity based on power history, temperatures, control/safety rod positions, and calculated xenon poisoning levels would be useful for monitoring any approaches to recriticality.

Note that control rod ejection events due to control rod housing failures may also be associated with a primary system rupture; however, such events are omitted from consideration in modular HTGRs by design. 


\section{MODERN HTGR INSTRUMENTATION ARCHITECTURE}

HTGRs have low power density, high-temperature ceramic cores, a large thermal margin to fuel damage, no potential for primary coolant phase-change accidents, strong negative reactivity thermal feedback, no requirement for auxiliary power in case of long-term station blackout accidents, and inherently slow accident progression scenarios. As such, HTGRs will require significantly different safety measurement capabilities than would an LWR. The differences will inevitably be reflected in the instrumentation system architecture. While general design principles such as high quality, diversity, and defense-in-depth remain requirements for any reactor, the much larger time and temperature margins inherently afforded by an HTGR to respond to any accident may, in addition to altering the instrumentation, affect the allocation of responsibility for safety response from equipment to operator or even to a remote expert.

Unlike LWRs, HTGRs have no credible accident scenarios that require a rapid response. All known loss of core coolability accidents evolve slowly. HTGRs have no known mechanisms to rapidly overpressure the primary coolant pressure boundary, and even a postulated control rod ejection accident would only lead to local fuel damage before the inherent negative thermal reactivity feedback mitigates the accident. The longer time afforded for communication means that no obvious imperative exists for any signal to have direct point-to-point wiring. Indeed, the timing requirements for an HTGR's digital communications network can be significantly relaxed from those for an LWR. Given the large time (days) for accident response at an HTGR and the resultant ability to manually perform safety system actuation in the event of a communications system failure, separating the digital control network from the safety network may no longer be necessary. The continuous use of the control network provides online, albeit limited, functionality and end-to-end testing of the communications network. This may result in a higher reliability automatic system, while the manual backup provides the defense-in-depth ordinarily provided by the separation of the control and safety systems.

To preserve the passive decay heat removal capabilities, HTGR prismatic cores are limited to roughly $600 \mathrm{MW}(\mathrm{t})$ in size. Because of their relatively smaller thermal power ratings, HTGR cores are more likely, than would be the case for LWRs, to be grouped together to provide a larger amount of electrical power from a single site. Indeed coupling two 250-MW(t) cores together to feed a single steam turbine in the initial demonstration plant (with the intent to couple together several or even many modules for commercial operation) is the approach being taken by the Chinese HTGR program. ${ }^{21}$ Having multiple reactors, perhaps constructed at different times and possibly collocated in a single containment (or confinement) feeding a single turbine drastically alters the plant instrumentation architecture. As the recent accident at Fukushima Daiichi has so dramatically shown, co-locating reactors and sharing services between them means that the impact of a severe accident at one reactor needs to be considered in the safety analysis of its neighbors. The newly reemphasized instrumentation architecture issues (including basic questions such as how far to locate the control room from the containment) are beyond the scope of the current effort. Hence, this report does not address non-HTGR-specific instrumentation architecture issues and is instead limited to the technologies embodying a modern (redundant, diverse, separated) HTGR-relevant digital communications network.

A representative I\&C system layout for an HTGR with a steam cycle is shown in Fig. 7. The figure includes process measurement variables and locations (i.e., temperature, pressure, differential pressure, and flow rate) that provide a continuously updated portrait of the plant status. The figure does not include the safety-grade RCCS, which must also be considered in the overall heat balance calculation during normal operation. 


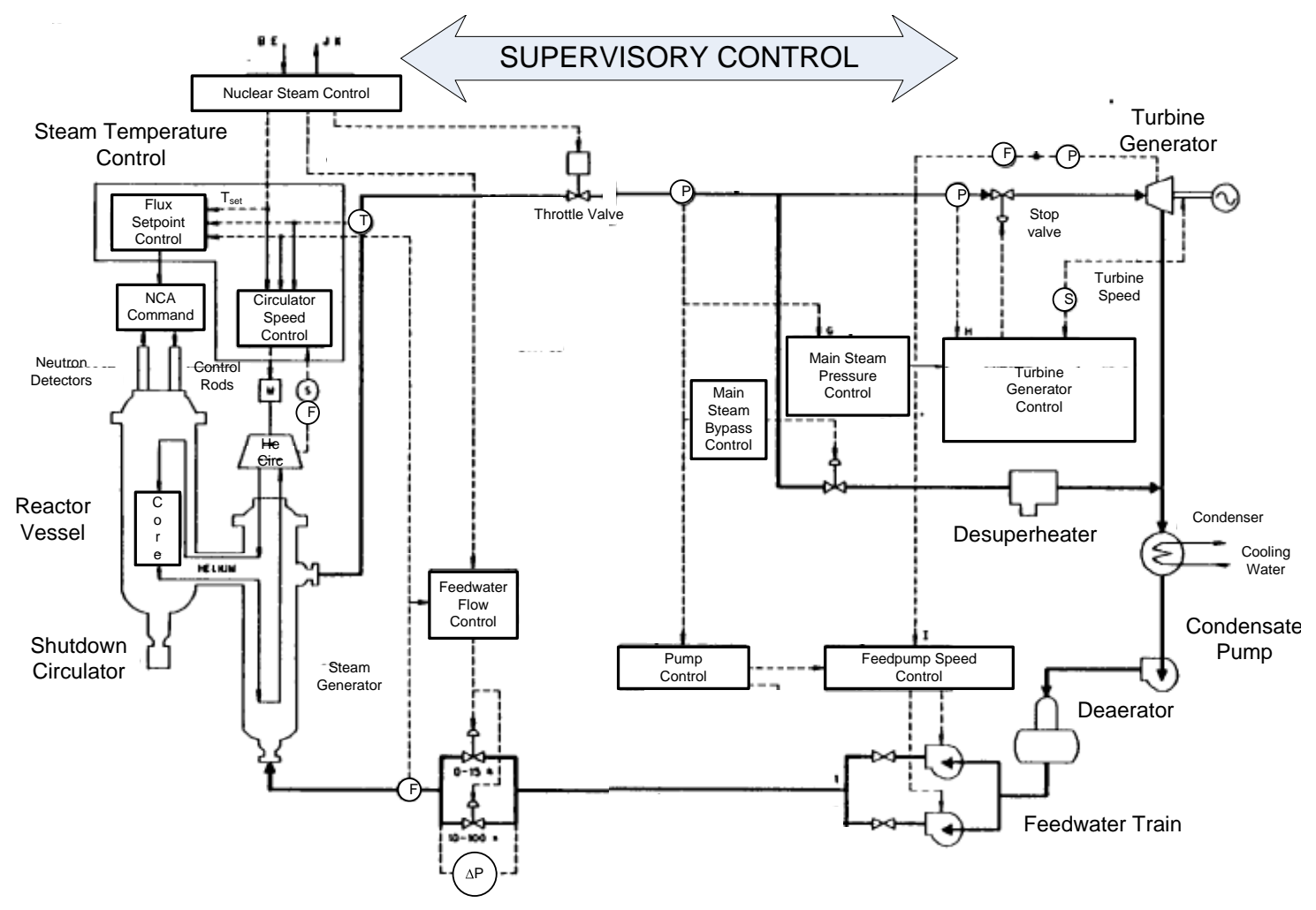

Fig. 7. Typical control system layout for an HTGR steam-electric plant.

(F, flow sensor; $\mathrm{P}$, pressure; $\Delta \mathrm{P}$, differential pressure; $\mathrm{S}$, circulator/turbine speed) (Ref. 22)

\subsection{CONCEPTUAL DIGITAL NETWORK TOPOLOGY OVERVIEW}

The basic HTGR instrumentation network topology derives from the purpose of the instrumentation system and, hence, is closely analogous to that of other safety-significant industries and prior nuclear power implementations. Evaluation of instrumentation system architecture details that are not specific to HTGRs is beyond the scope of this report. More general modern nuclear power digital networking architectural information is available in NUREG/CR-6991. ${ }^{23}$

Network information flow begins with transducers that feed information into signal processing electronics, which in turn are interconnected into a network access point. The network access point is a component of a digital signal network that communicates information from sensors to data loggers and control/decision points as well as transmits instructions from the decision points to the plant sensor and actuation systems. The basic network layout for any safety-significant industrial plant is a redundant collection of high-speed connections. The classical sensing topology is to provide wiring to each sensor as wiring provides a robust, durable means of providing power to the sensor and a high-reliability signal path to the sensor.

The communications network in LWRs is segregated between safety and control systems. Given the much larger time response available for an HTGR, the safety and control functions may be comingled with the human operators providing the diverse backup. Equipment health measurements may also be transmitted over the communications network. Transmitted instructions to the sensor system could be a query for nonstandard reported information such as the amount of drift compensation currently being applied or an instruction to perform a self-calibration. The communication network also includes the 
interconnection to the system actuators. As the communications network needs to support post-accident sensor communication, the network electronics will need to have appropriate environmental tolerance.

A conceptual illustration of a portion of a potential advanced HTGR network topology demonstrating the architecture features, described in the following sections, is shown as Fig. 8. Two of the typically four redundant communication networks that would be anticipated in a future HTGR are shown in the figure. A wired-ring topology has been selected as the sensing network backbone. Figure 8 shows the network layout impact of several candidate advanced technology concepts. Much as in LWR instrumentation channels, the sensors themselves may be common to multiple instrumentation networks. Communication path diversity is increased by connecting sensors via both wired and wireless means. Wireless is only shown in a containment (confinement) technology to minimize the potential for external intrusion. System actuators are shown connected to an IEEE 1901 type power line communication network. ${ }^{24}$ Safety actuators are connected to multiple communications networks for redundancy. Safety sensors are shown connected to multiple networks to enable voting. Diagnostic sensors may be connected to one or more networks. Local environment power scavenging is shown supporting both wired and wireless sensor communication networks. Wireless network access points are shown to address more than one sensor.

\subsection{REDUNDANCY, DIVERSITY, AND SEPARATION}

A major portion of the rationale for redundant instrumentation networks is to maintain the capability to operate when any single component has failed. Since highly reliable operation is as valuable to an HTGR as any other power plant, its instrumentation redundancy will closely resemble that of an LWR or other large industrial facility. In contrast, it is anticipated that the much larger time allowance for accident response provided by an HTGR may enable the system diversity to be provided more extensively by human operators. Human thought patterns are diverse from digital instrumentation systems and the many hours to few days available to take safety actions at an HTGR allows human-based action to be highly effective in performing correct safety functions, provided the humans have access to correct information about the system.

The basis for the physical separation requirements for signal paths is to avoid vulnerability to commoncause failures such as fires or local flooding. The physical pathway separation requirements within any single HTGR reactor module will closely resemble those for a single unit LWR. However, with the additional depth of integration between multiple smaller HTGR modules (much as with other technology small, modular reactors), logical and physical separation between the signals and signal pathways between different HTGR reactor modules is also necessary.

\subsection{WIRELESS}

Laying communications wiring during plant construction is not especially costly or difficult. Further, in most deployment scenarios, a wire (or optical fiber) based communications path provides a defined communications path with higher bandwidth than is readily achievable with a wireless network. Moreover, wireless communications within power plant environments (with their large reflective metal structures and strong electromagnetic emissions) are much more technically restricted than in milder environments. In addition, the cyber intrusion vulnerability is greater for a wireless network. Hence, a fully wired communications network would, on initial consideration, appear to be technologically preferable. However, wireless communications networks (especially when coupled with environmental power scavenging) provide aging, flexibility, diversity, and severe accident survivability capabilities that cannot be matched by a wired system. 


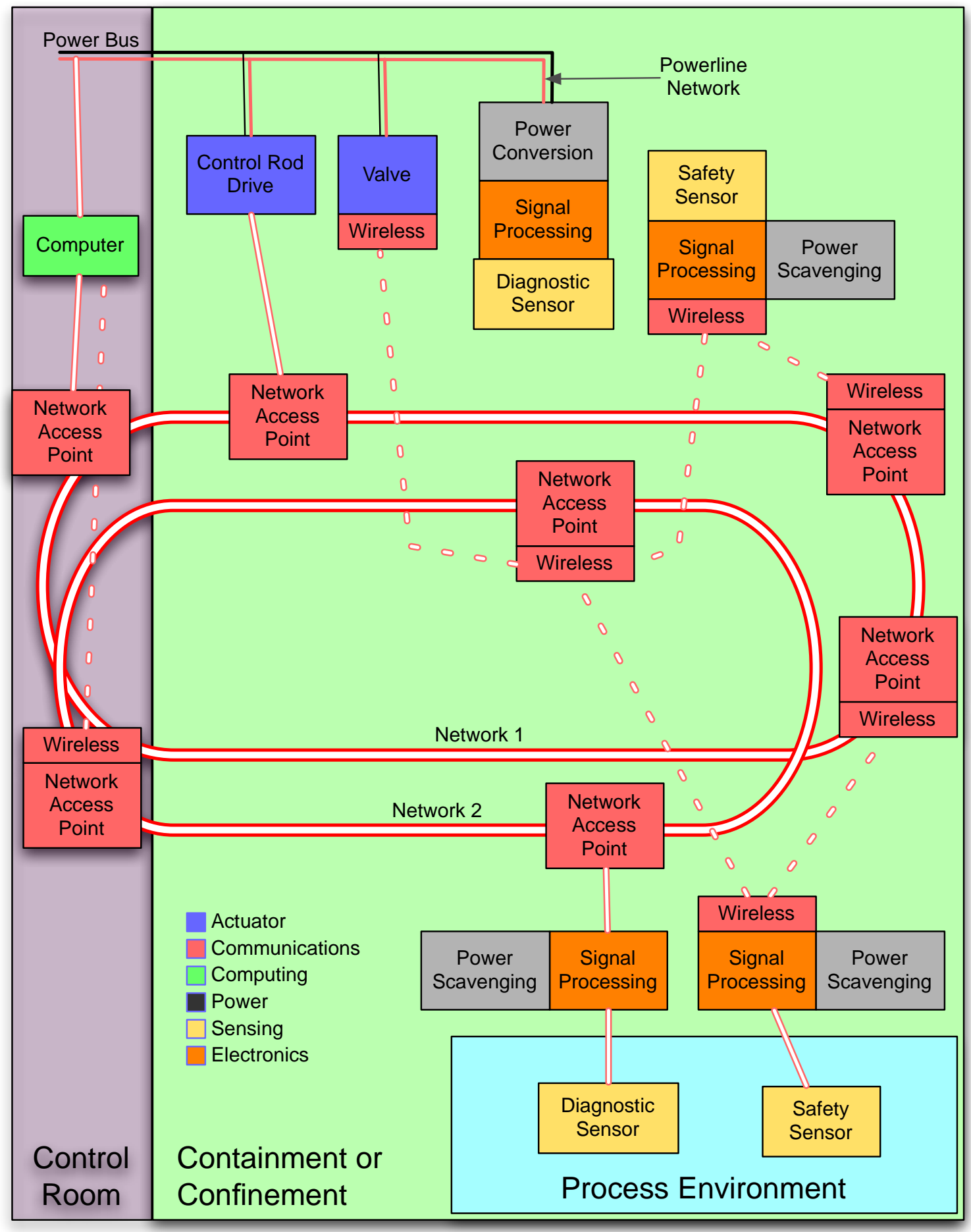

Fig. 8. Modern HTGR instrumentation network topology.

To provide protection from fire and/or mechanical damage, communication cables are embedded within protective materials, making cable removal and replacement expensive and difficult. The organic insulators used in nearly all electrical communication cables degrade under plant environmental 
conditions over time. Note that metal-clad glass optical fibers do not depend on organic materials and, hence, do not have the same aging concerns, making metal-clad glass optical fiber networking a potentially advantageous, albeit initially more expensive, network physical layer. Embrittled cables can fail suddenly when subjected to severe accident conditions (e.g., being shaken by an earthquake). This failure vulnerability cannot be diagnosed from cable electrical properties measured at the cable ends. Cable replacement technology and cable health diagnostics are, thus, current LWR sustainability issues. Wireless data transmission by avoiding cables altogether offers a potential solution to cable aging issues.

As a rule, the amount of information being gathered and communicated about industrial processes increases with time, resulting in continually increasing data networking demands. Further, digital components tend to become obsolete much more rapidly than their analog counterparts. Thus, nuclear power plant instrumentation networks need to be designed for upgrading and replacement (likely more than once) over the plant lifetime. Component and structure monitoring for diagnostics and prognostics is becoming progressively more common. Over time, it is likely that additional measurements, potentially only used intermittently, will be added to the HTGR. Deploying additional wiring at an HTGR is both expensive and potentially disruptive of normal operations. Wireless networks, in contrast, offer the potential to rapidly reconfigure the instrumentation network in response to evolving demands.

Even with protective layers, wires are more vulnerable to fires and mechanical or radiation damage than wireless communication paths. Moreover, wireless networks can be designed for ad hoc reconfiguration routing around damaged segments. Hence, wireless networking provides a unique potential for higher assurance communications under severe accident conditions.

Lacking full control over the communications path, wireless networks are more vulnerable to cyber intrusion or unintended electromagnetic disruption than a wired network. Partially mitigating the vulnerability, many wireless communications technologies are inherently short range, and the reactor containment (confinement) both provides considerable electromagnetic shielding and is physically distant from uncontrolled space. However, some plant systems are located nearer the plant boundaries and may involve longer-range wireless communications technologies. A longer-range, spatially distributed networking is much more vulnerable to cyber attack than a short-range wireless instrumentation network deployed only within plant buildings.

Overall, future HTGR network architectures are likely to consist of a mixture of wired and wireless networking. The wired network is likely to consist of high-bandwidth cabling with wireless network access points distributed along its length. The additional accident response time inherently provided by an HTGR is anticipated to eliminate all point-to-point wiring connections to the control room. The wired network may be an all ceramic and metal configuration designed to last the life of the plant or may be designed for periodic replacement. Powered actuators (e.g., control rod drive motors) are likely to route their communications over their associated power lines. Individual sensing elements remain likely to have a wired connection to the nearest environmentally benign area where their measurement electronics will survive, as electronics remain the most environmentally sensitive component in the instrumentation system. Higher-temperature-tolerant electronics are under development to support a number of industries. Some of the high-temperature-tolerant electronics technologies are also more tolerant of higher radiation doses. Consequently, the severe accident survival of local instrumentation electronics packages will improve over time, and the first-stage electronics will progressively be located closer and closer to the transducer.

\subsection{INSTRUMENTATION POWER SCAVENGING}

Wireless instrumentation networks lack an obvious means to supply instrumentation power. Instruments, however, only require small amounts of power, and the combination of batteries with power scavenging from the local environment has the potential to enable truly wireless instrumentation. Alternatively, electrical- and optical-wired networks can provide instrumentation power over the same wires used for 
communications. In particular, IEEE's recent 1901 broadband power line standard should be considered for endorsement for use at nuclear power plants. Optical power networks may be especially useful under flooding conditions, as optical fibers cannot be shorted out.

Batteries without automatic recharging would be an ongoing maintenance burden at nuclear power plants. In addition, batteries may be in a near-discharged state just prior to an accident-when the demand placed upon them would be greatest. Under normal operating conditions, power plants provide an energy-rich environment that can be harvested to provide instrumentation power. Solar cells can be employed to collect ambient lighting. Both mechanical vibration and airflow are also widely available energy sources. The large electromagnetic fields near motors similarly can be exploited for instrument power.

Thermopiles can also be employed to harvest the energy inherent in the temperature difference between the process piping and the ambient environment. In short, during normal operations local batteries can be recharged by one of several alternate methods through scavenging power from the ambient environment.

In a post-severe-accident environment, however, power scavenging would be technically challenging as the power harvesting devices need to directly couple with a local environment that is no longer well controlled. Given the relatively small power needs of instrumentation, however, dedicated local batteries (recharged under normal operating conditions via power scavenging) could be sized to provide several weeks of data before running down.

\subsection{AGING AND OBSOLESCENCE}

The sensors, measurement electronics, and communication network components all age and either need to be designed to perform acceptably for the entire plant life or, more likely, to be replaced. At the most fundamental level, instrumentation system aging is an expression of the inevitable entropy increase (atomic rearrangement) of the system components and materials over time. The higher temperatures of an HTGR cause more rapid aging of the sensor materials and, thus, necessitate the use of more durable materials. Sensor aging mechanisms are specific to the particular sensor, and a mechanistic discussion is provided along with the sensor descriptions later in this report. The electronics environment, in contrast, in an HTGR is likely to be either the same as that for an LWR or, near the primary piping, less severe from the lack of ${ }^{16} \mathrm{~N}$ decay gamma rays. The digital signal processing technologies employed in control room type environments in an HTGR are likely to be nearly identical to those used in any other modern industrial plant.

In combination with aging, instrumentation system components become commercially unavailable with time as suppliers change and upgrade their product offerings. HTGR instrumentation systems are more likely than LWRs to rely on standard industrial safety-grade control electronics because the reactor inherent passive safety relaxes the system performance requirements. Use of standard components, instead of the bespoken production common for LWR safety system electronics, changes the system obsolescence paradigm.

At an LWR, once production of a particular, qualified digital component or system has ceased, specialized nuclear power specific qualification of a replacement system or component is required. As the replacement component or system is likely to have different characteristics or technologies than its antecedent (e.g., embedded software or different generation digital logic), qualification of the replacement component is generally both time consuming and expensive. Obsolescence avoidance strategies, such as lifetime stockpiling or dedicated remanufacturing of outdated components, do not allow LWRs to take advantage of the continuously improving digital system capabilities (such as built-in health diagnostics or automatic recalibration) that have demonstrably improved the reliability of safety-significant control systems over the past few decades. In other words, the safety system qualification process at LWRs limits application of improved, albeit more complex and difficult to qualify, digital instrumentation technology, resulting in lower system reliability than might otherwise be achieved with the enhanced diagnostics available in modern digital instrumentation. 
At an HTGR, in contrast, the major issue for instrumentation system upgrade is preservation of the objectives and requirements of the original instrumentation system design. Use of modern design description languages such as the Systems Modeling Language (SysML) or compliance with the ISO 10303 AP-233 standard on systems engineering data representation in the original plant design specifications is anticipated to alleviate the difficulty in tracing design intent. Simply put, the inherent passive safety of HTGRs means that the human operators provide diverse and timely backup to all required safety actions, greatly reducing the potential impact of any software or hardware errors and, thereby, reducing the required rigor of the instrumentation system qualification process. Thus, HTGRs are anticipated to be able to make much more extensive use of digital system improvements as they become technologically available, resulting in a higher net instrumentation system reliability than is typical at an LWR.

The lifetime of digital systems is becoming progressively shorter and shorter as the speed of technological progression increases. Analog instrumentation had often been available for a decade or more, while digital instruments often have had a model lifetime of just a few years. As most instrumentation components have lifetimes much shorter than the major plant structures, they need to be designed for replacement several times during the plant's operating life. One of the key lessons learned from LWR life extension efforts is that cable replacement is difficult and expensive. While HTGRs are expected to have much less cabling than older LWRs because of their network instrumentation configuration and use of wireless, the network cables will need to be designed for replacement. This means that the mechanical and fire protection layers over the cables need to be removable or the cables routed through conduit. Further, as cable cracking and embrittlement may not be observable from the cable ends and tends to occur locally at points of peak environmental stress, cable test coupons should be deployed along with the cabling to allow periodic destructive testing of cable samples.

The built-in automatic sensor and electronics recalibration possible in modern digital instrumentation is more important to apply as outage intervals are extended. In modern, high-reliability electronics, measurement standards are becoming more commonly embedded within the electronics to provide higher measurement confidence and to extend the calibration intervals. For example, an embedded band-gaptype voltage reference circuit ${ }^{25}$ provides a high-confidence voltage level to a measurement circuit that can periodically be automatically switched into the measurement path to recalibrate the amplifier and analogto-digital conversion circuitry. Similarly, a time (or frequency) standard can be provided either wirelessly or over the network to compensate for any drift in the measurement electronics timing. Temperaturecompensated crystal oscillators periodically recalibrated with a local GPS-type (double-oven-controlled crystal oscillator [DOCXO]) timing signal provide very good local time measurement stability. ${ }^{26}$ Indeed this is the timing maintenance configuration used in the commercial cell phone network. A realistic goal for digital measurement instrumentation is to have an external recalibration interval longer than the lifetime of the technology, avoiding manual recalibration altogether.

\subsection{DEPLOYMENT AND ACCESS ISSUES}

The combination of the higher temperatures and the high-pressure characteristic of an HTGR makes deploying primary system instrumentation technically challenging. Of particular note is the relatively large mechanical shift between the core and the vessel caused by the differential coefficient of thermal expansion (CTE) between the graphite moderator and the metal pressure vessel. In essence, the motion of the core would provide large lateral stresses on any sidewall penetrations limiting measurement access to above and below the core. Additionally, access to the hot inner annulus of annular primary piping (hot inside, cooler outside) is restricted by the mechanical shifting of the inner piping as the reactor heats up.

The thick vessel and piping walls make ultrasonic access to the primary loop technically difficult (a potential work-around for the ultrasonic access issue is described in Section 4.1.4). Similarly, a fully qualified optical penetration into primary piping does not currently exist and, as the CTE of fused silica 
and sapphire are much less than that of steel, any optical penetration will most likely be provided at the end of a standpipe extending to a lower temperature environment.

\subsection{DECISION AID TOOLS}

While the high degree of passive safety inherent to HTGRs limits the demands on the operators, human error on the part of an HTGR's operating or maintenance staff remains a potential source for accidents. Operators taking the correct actions are also central to preventing accidents from escalating and to mitigating the consequences of any accidents that do occur. Decision aid tools can support the plant staff by ensuring that relevant information is readily available. For example, an electronic job notepad can monitor its location in the plant, thereby increasing the confidence that a maintenance worker is performing work on the correct piece of equipment. Electronic notepads can also provide much more graphical detail on component maintenance procedures than their paper counterparts. The added support is especially important for infrequently serviced components where the plant staff may have less familiarity with the maintenance procedures.

Emergency operations procedure manuals provide guidance to the plant operators on how to respond in the event of an accident. Emergency operations procedures have traditionally been paper based and, as a procedure-based system, provide limited insight into the physical processes occurring in the plant. Electronic alternatives to paper manuals have begun to be used in many industries. A key advantage to electronic manuals is that their recommendations can be continuously updated as an accident evolves by tying the recommendation engine into a plant simulation. Further, the plant status information can be displayed in an easier-to-understand format, such as an augmented reality temperature overlay onto a view of the reactor vessel.

The major purpose of HTGR accident progression simulators is to support operator decision-making by projecting the outcomes of alternate recovery actions. Thus, a premium is placed on having correct physics models for accidents and on correctly interpreting sensor information under degraded conditions. HTGRs in general and especially the pebble bed modular reactors (PBMRs) have few in-core sensors. Employing a simulator coupled with ex-core sensors (inlet and outlet temperatures, flux, rod positions, coolant flow rate, pressure, as well as the gas composition both within vessel and containment, etc.) could provide assurance that any particular recovery action would produce the intended result. Given the slow accident progression scenarios characteristic of HTGRs, the operators (or outside experts) would be able to perform reasonableness checking on the simulation results before a need to take action develops.

Techniques for accommodating degraded sensors need to be part of any accident response support simulator. Under accident conditions, sensing elements, the transducer electronics, and the communications hardware, etc., may be operating outside their qualified bounds. Being able to interpret the received signals and the characteristic changes in the signals if the sensors are stressed enables the best available data to be fed into the accident simulation. The Graphite Reactor Severe Accident Code, ${ }^{27}$ GRSAC, is an applicable HTGR accident progression simulation code. However, while the model includes default data to fill in for unavailable measurements, the simulation relies upon external data validation.

The accident progression simulation output to the operators would include the anticipated radionuclide releases, the predicted core temperature distribution, the reactivity balance (predicted flux measurement for the measured control rod positions), and the heat balance. For predictive simulations, a major consideration would be optimizing the displays to minimize the chances of misunderstandings. 


\section{NEW AND EMERGING HTGR SENSORS}

This section provides a description of advanced sensing and instrumentation technology that, while not yet ready for deployment at nuclear power plants, offers the potential for substantial performance improvements over currently available technologies. Maintaining awareness of the potential capabilities and limitations of emerging instrumentation technologies is important in that future deployment of these systems may change the degree of, and confidence in, the understanding of the plant conditions and, thus, the safety profile. Additionally, while generally improving on the capabilities of current-generation instrumentation, the new instrumentation has different failure modes and vulnerabilities, and understanding the performance parameters is important to the assessment of the safety impact of emerging instrumentation technology.

\subsection{TEMPERATURE}

Both accurate primary circuit heat balance and in-core temperature measurement for pebble-bed systems remain challenging instrumentation problems. The drift of current-generation thermocouple or resistance temperature detector (RTD) based thermometry at hot, and to a lesser extent cold, leg temperatures would necessitate a larger plant instrumentation margin to avoid unacceptable thermal degradation of the primary circuit materials. Hence, a significant impetus exists to develop and adopt less-drift-prone, higher-accuracy temperature measurement technology.

\subsubsection{Gold-platinum thermocouple}

Existing precious metal thermocouples can be used with care outside high neutron flux regions to provide reasonably high precision temperature measurement (initially roughly $\pm 200 \mathrm{mK}$ above $500^{\circ} \mathrm{C}$ ). Note, however, that the precious metal elements have too high a neutron capture cross section for use in areas with significant neutron flux. For higher stability and precision temperature measurement, the pure element (99.999\%), nonletter-designated $\mathrm{Au}-\mathrm{Pt}$ thermocouple can achieve precision of approximately $\pm 10 \mathrm{mK}$ at temperatures up to $1000^{\circ} \mathrm{C} .{ }^{28}$ Overall, the $\mathrm{Au}-\mathrm{Pt}$ thermocouple is markedly superior to the platinum-rhodium alloy thermocouples in terms of stability, homogeneity, and sensitivity (about double a type $S$ ) and thus appears likely to be the preferred ex-vessel temperature measurement instrument for very high temperature gas-cooled reactors (VHTRs). However, the stability and durability of mechanically rugged, metal-sheathed, mineral-insulated versions of the $\mathrm{Au}-\mathrm{Pt}$ thermocouple have yet to be demonstrated sufficiently for immediate application to safety-important measurements at nuclear power plants. In particular, the coefficients of thermal expansion (CTEs) of gold and platinum are sufficiently different such that the hot junction mechanical interconnection needs to be flexible to avoid stressing the elements. A thin, gold bridging wire has been shown to provide the necessary strain relief. ${ }^{29}$

The largest concerns for replacing RTDs with $\mathrm{Au}-\mathrm{Pt}$ thermocouples are the increased electromagnetic noise vulnerability due to the smaller signal and maintaining proper cold junction compensation. Thermocouple signals are typically around $10 \mathrm{mV}$, whereas industrial RTD signals are at least $100 \mathrm{mV}$. Thus, both better electromagnetic shielding and higher gain, high stability amplifiers are required for thermocouple readout. No standard compensating wire currently exists for Au-Pt thermocouples and, as the thermocouple wire is expensive, the thermocouple itself will likely extend only a few centimeters past the exterior of the insulation surrounding the primary circuit. The temperature at the cooler, proximal end of the thermocouple will thus be required to be independently measured to compensate for its difference from the ice point. As the $\mathrm{Au}-\mathrm{Pt}$ cold junction temperature is likely to be less than $50^{\circ} \mathrm{C}$, readily available thermistors or capsule-type RTDs appear to be capable of measuring the cold junction temperature. Also, while not a significant issue for temperature measurement within large primary piping, the thermal 
wicking down the thermocouple leads also needs to be considered in the measurement system design. Both gold and platinum are good thermal conductors, and thermocouple leads have larger diameters than RTD leads - because of the requirement to minimize the impact of impurities. Thus, a longer immersion depth is required for $\mathrm{Au}-\mathrm{Pt}$ thermocouples as compared to RTDs for accurate measurements.

\subsubsection{Johnson noise thermometry (JNT)}

The impact of the mechanically and chemically induced changes in RTD electrical resistance with time at high temperature can be avoided by instead basing the measurement on a fundamental property of temperature. Johnson noise is a first-principles representation of temperature. Johnson noise results from the vibration of the electronic field surrounding atoms as they thermally vibrate. Since temperature is merely a convenient representation of the mean kinetic energy of an atomic ensemble, measurement of these electronic vibrations yields the absolute temperature.

As a first-principles temperature measurement, Johnson noise is insensitive to the material condition of the sensor and, consequently, immune to the contamination and thermomechanical response shifts that plague thermocouples and resistance thermometers. Commercialization of Johnson noise thermometers has the potential to increase the accuracy of both near-core and primary-loop temperatures with the added benefit of reduced calibration requirements.

JNT is best understood as a continuous, first-principles recalibration methodology for a conventional resistance-based temperature measurement technique. The traditional method of directly measuring temperature from an RTD has unavoidable drift. JNT measurement is applied in parallel to the RTD lead wires of the resistance measurement circuit without altering the traditional resistance measurement circuit. A more detailed overview of the application of Johnson noise to high-temperature reactors was published in 2005. ${ }^{30}$

One significant advantage of JNT is that the actual resistive element is not required to follow a particular temperature-to-resistance curve. This allows consideration of high-stability, high-mechanical-strength alloys or even a cermet as the temperature transducer, likely significantly increasing the lifetime and reliability of the sensor element. While the JNT amplifier electronics restricts the allowable range of transducer resistance shift with temperature to roughly a factor of 3 around the operational resistance of tens or hundreds of ohms, the exact shape of the resistance-to-temperature correspondence is not otherwise constrained apart from the basic requirement for a monotonic change with temperature.

Conventional industrial RTD elements are composed of high-purity, well-annealed platinum in order to achieve a repeatable resistance-to-temperature correlation. However, RTDs are not industrially deployed at temperatures over $850^{\circ} \mathrm{C}$ and are often restricted to temperatures less than $450^{\circ} \mathrm{C}$ for high-accuracy deployments. As the deployment temperature increases, the CTE mismatch between the platinum element and the support structures exerts progressively greater and greater amounts of stress onto the temperature measurement element, shifting its calibration. This is compounded by the softening of platinum at temperatures over $\sim 650^{\circ} \mathrm{C}$ and the overall increase in impurity atom mobility at higher temperatures.

Molybdenum disilicide has been demonstrated as an alternate high-temperature resistor for JNT up to $1600^{\circ} \mathrm{C} .{ }^{31}$ Hot-pressed silicon nitride-molybdenum disilicide composites $\left(\mathrm{Si}_{3} \mathrm{~N}_{4}-30\right.$ vol \% $\left.\mathrm{MoSi}_{2}\right)$ also have useful electrical resistivity for Johnson noise resistive elements as well exhibiting high mechanical toughness. $^{32}$

JNT has three significant sources of potential measurement error that may, in general, be avoided or compensated for by proper design and implementation. However, reviews of JNTs being implemented in safety systems will need to assess the design and implementation methodologies selected to overcome the vulnerabilities. While digital implementations of JNT can compensate for some electromagnetic noise pickup, Johnson noise is a small signal phenomenon. Consequently, severe electromagnetic pickup (as would be anticipated from improperly implemented grounding or shielding) would prevent Johnson noise 
measurement. Also, JNT relies on high gain $\left(\sim 10^{6}\right)$ wide-bandwidth signal amplification. If the amplifier gain shifts over time or with electronics temperature, the JNT would provide an incorrect RTD recalibration. Consequently, the amplifier gain characteristics need to be verified either online or by periodic maintenance. Finally, the intervening cabling between the sensor and the first-stage signal amplification will cause the higher frequency components of the wideband Johnson noise signal to roll off, restricting the allowed upper measurement frequency. Understanding and compensating for any shifts in the cable properties is required for a successful long-term implementation.

Developing a prototype commercial-style JNT is the subject of a U.S. Department of Energy (DOE) small modular reactors project that is currently getting under way.

\subsubsection{Vacuum microtriodes}

Measuring the pebble temperature online in-core is extremely technically challenging. Core temperatures and radiation fluxes are well beyond where semiconductor electronics can function. Vacuum tubes, in contrast, consist entirely of ceramics and metals (which are inherently extremely radiation tolerant) and, thus, have the potential to operate under the severe operating environment of an HTGR core. Vacuum tubes, in fact, have a heritage of core-type radiation environment operation on account of their use in firststage amplifiers for early fission chambers. ${ }^{33}$

The lack of measured pebble-bed core data requires that the pebble flow, neutron flux, and core temperature distribution be conservatively estimated, limiting the achievable reactor core power density. Experience with the Arbeitsgemeinschaft Versuchsreaktor (AVR), a pebble-bed experimental hightemperature reactor, indicated that core coolant temperature simulations significantly underestimated the hot spots in the core. ${ }^{34}$

Several attempts have been made over the years to miniaturize vacuum tubes. Ceramic tubes similar in size to a pencil eraser were developed in the 1970s. Spindt tips-based tubes were developed in the 1990s and have a cavity cross section of $\sim 100 \mathrm{~nm}^{2}$ (Ref. 35). The fundamental element of a vacuum tube is the triode. In order to provide an online, in-core temperature measurement, the microtriode needs to measure the temperature (likely converting an analog voltage into a frequency), amplify the frequency signal, modulate the signal onto a higher frequency carrier signal, and wirelessly transmit the frequency-encoded temperature. These measurement process steps will require a power source, amplification circuitry, and signal transmission circuitry. From a circuit design perspective, four fundamental components are required to perform the measurement function: a resistor, a capacitor, a triode (amplifier), and a rectifier. An electronic oscillator (and, for that matter, any electronic component) can be built from these four fundamental elements.

Vacuum microtriodes are technically the furthest out of the emerging technologies. An estimate of their failure modes and vulnerabilities will need to await further development of the technology.

\subsubsection{Ultrasonic guided wave}

Ultrasonic probe thermometry has been under development since the mid-1960s. ${ }^{36}$ Probe-based ultrasonic temperature measurements have been applied to nuclear reactor core temperature measurements since the late $1960 \mathrm{~s} .{ }^{37,39}$ Ultrasonic probe-based thermometry was first compared to JNT for reactor thermometry in 1974. ${ }^{40}$ Progressive development of high-temperature materials, high-speed electronics, and signal processing methods has pushed the technology forward. Simply put, probe-based ultrasonic thermometry can be deployed in very high temperatures and hostile environments because an electrical insulator is not required and because of its compatibility with refractory alloys.

The most significant unresolved issue for implementing ultrasonic-guided wave thermometry as a general practice in nuclear reactors is the challenge of transmitting the ultrasonic-guided wave through the primary pressure boundary. Solid-state measurement electronics are not compatible with HTGR 
temperatures. The ultrasonic waveguide, however, can extend several meters. Thus, the transduction electronics can be located above the reactor vessel head within a cooled high-pressure helium environment separated from the high-temperature environment by a small-diameter standpipe up to a few meters long. The electrical signals would be the only components that would then need to pass through the pressure boundary.

Guided-wave, pulse-echo ultrasonic thermometry operates by measuring the speed of sound in a metal wire or rod, which is a known function of temperature. The speed of sound in a metal is dependent on the elastic modulus and density. Although both parameters are temperature dependent, the temperature effect on elastic modulus dominates by about an order of magnitude over that of density, which causes sound velocity to decrease with increasing temperature.

By launching a compressional wave down a cylindrical rod waveguide, the transit time can be measured as the wave travels from the launch location to a point of reflection and then returns to the detection location. The temperature can be calculated from the transit time. By creating abrupt impedance shifts (such as notches) at predetermined locations, temperature measurement over multiple zones is made possible. The arrival times of reflections from multiple notches can be measured as shown in Fig. 9. The average temperature between notches can be calculated from timing data.

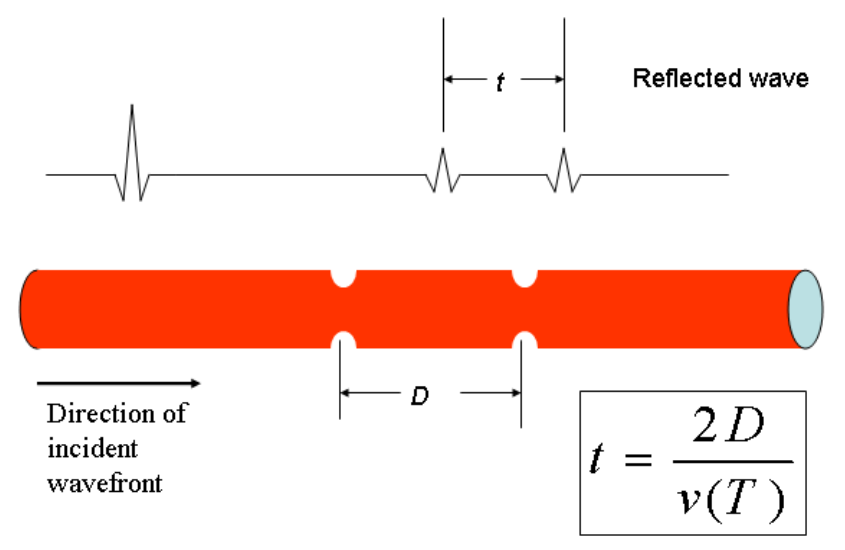

where $v(T)$ is the velocity of sound as a function of temperature

Fig. 9. Ultrasonic waveguide with notches.

Ultrasonic-guided wave thermometry is not immune from drift. The high temperatures and high radiation flux of an HTGR core environment will, over time, alter the mechanical properties of the waveguide and transmute its composition, shifting the recorded temperature. Also, any solid deposits onto the waveguide will cause spurious echoes that can confuse the signal analysis. Additionally, relatively complex algorithms are required to reconstruct the temperature profile from the large number of reflections received from a multiply notched waveguide; thus, software quality assurance will require a comparatively larger effort. The DOE Nuclear Energy Enabling Technologies (NEET) program is initiating a project focused on deploying guided-wave ultrasonic thermometry as a technique for fuel qualification. 


\subsubsection{Distributed fiber-optic Bragg thermometry}

Distributed fiber-optic Bragg thermometry is based upon a series of Bragg gratings arranged along the core of a single-mode optical fiber (Fig. 10). The simplest readout technique for a limited number of gratings along a fiber begins by launching a band (range of wavelengths such as from a light-emitting diode [LED]) of light into the optical fiber. Each grating reflects a specific wavelength within the band. The particular wavelength reflected is determined by the Bragg grating period, with each individual grating having a slightly different spacing. Temperature causes the grating period to shift both by thermal expansion as well as change in the refractive index. A shift in the reflected wavelength thereby corresponds to a shift in the temperature of a particular Bragg grating.

The primary advantages of distributed fiber-optic Bragg thermometry are that the sensor is nonconductive, allowing for deployments in high-electromagnetic-field environments such as pump motors and turbines, and that many sensors can be configured along a single path, enabling the acquisition of a distributed temperature map with a single readout system. This would enable applications such as direct observation of the temperature profile across the primary piping instead of relying on single radius sampling. Note that by properly adhering the Bragg gratings to the piping, the distributed thermometer would transform into a distributed set of strain or vibration gauges, enabling mechanical diagnosis of piping or components.

Optical frequency domain reflectrometry (OFDR) can also be employed to measure the signal from many (thousands of) individual gratings along a fiber. ${ }^{41} \mathrm{OFDR}$ is an interferometric technique requiring an adjustable wavelength, coherent light source. Tunable lasers remain somewhat expensive and have a more limited lifetime than simple, wideband light sources. Consequently, OFDR would only be the preferred readout technique for large sensor arrays.

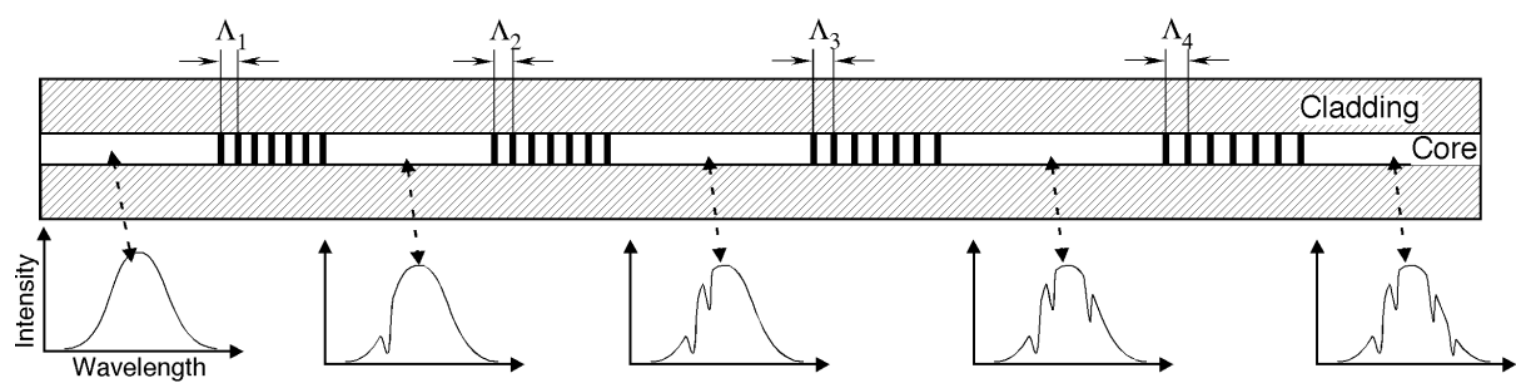

Fig. 10. Transmitted light spectra through a distributed optical fiber Bragg grating.

Distributed fiber-optic Bragg thermometers have been demonstrated to function briefly (a few days) in high (core-type) radiation environments and much longer in more moderate radiation environments. ${ }^{42-44}$ The optics and electronics for distributed fiber-optic Bragg thermometers can be located hundreds of meters from the sensing elements, allowing placement in well-controlled environments at nuclear power plants. For OFDR, in particular, the readout electronics are somewhat more complicated than for competing technologies such as thermocouples requiring more effort in the qualification process. Also, Bragg gratings in standard communication-type optical fibers bleach when exposed to combined high temperatures and high-radiation fields. The grating bleaching vulnerability requires employing less common, custom optical fibers expressly designed for higher temperature, higher dose deployments. This contrasts with RTDs and thermocouples where devices suitable for nuclear power application are substantially the same as for nonnuclear deployments. 


\subsection{FLOW}

Primary helium flow rate is a factor in the measurement of core heat removal. Primary coolant flow is not typically directly measured in HTGRs but instead is inferred from either the turbine-compressor or the helium circulator rotational speed, depending on whether the reactor is directly or indirectly coupled to the turbine. The high-pressure and high-temperature primary flow environment effectively eliminates consideration of all commercial flow meters. However, thermally based flow measurement can potentially be configured to perform under VHTR temperature, pressure, and flow conditions.

\subsubsection{Hot wire anemometry}

Hot wire anemometry functions by running a current through an electrical resistor, connected as a fourwire element, which is exposed to the flow (see www.efunda.com). The voltage across the resistor is measured. Combining the impressed current and the measured voltage yields the element resistance. The resistance is then used to determine the element temperature through a resistance-to-temperature look-up table. The current through the resistor is varied to maintain a prespecified temperature difference from the flow (whose temperature is measured independently). The amount of current necessary to maintain the temperature difference is a direct measure of the heat transfer from the electrical resistor, which, in turn, is a measure of the coolant flow rate.

The electrical element used in conventional hot-wire anemometry is directly exposed to the flow environment, providing high-frequency flow mapping. Primary HTGR flow would rapidly destroy any electrical element that is directly immersed within it. However, sheathed elements, such as a typical RTD, can endure HTGR cold-leg environments, and sheathed, conductive ceramic composite electrical resistors can withstand hot-leg temperatures. Flow measurements made using an RTD as a hot-wire anemometer would have the same response time as would be anticipated when an RTD is used as a thermometer (several seconds).

\subsubsection{Heated lance-gamma thermometer type probe}

A heated lance type flowmeter is conceptually similar to a hot-wire anemometer with a nearby electrical resistance heater taking the place of the current supply and a thermocouple being used to measure the temperature. ${ }^{45}$ An illustration of the concept is shown in Fig. 11. To minimize the impact of thermocouple drift on the temperature measurement, the thermocouple leads can be configured as in a gamma thermometer with one of the junctions thermally insulated from the flow by an annular gas gap. In this case, the temperature difference between nearby thermally insulated and thermally connected thermocouple junctions is inferred by the voltage measured at the ends of the thermocouple leads. The temperature difference between the two junctions is proportional to the heat deposition and the cooling rate. The cooling rate is directly proportional to the temperature difference between the element and the coolant as well as the coolant flow rate. 


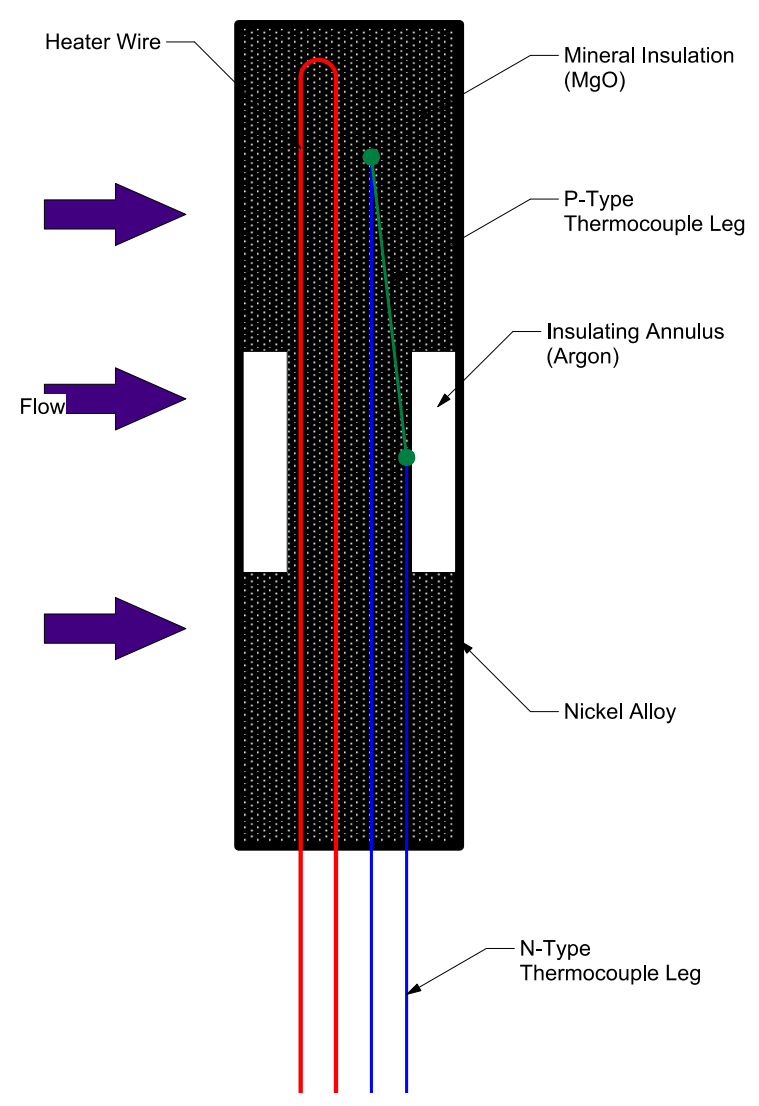

Fig. 11. Heated lance type flowmeter.

The most significant issue for thermally based measurement of the primary flow in HTGRs is that both techniques are point measurements (although multiple elements can be deployed along a single probe). Flow within the primary ducting of most HTGR designs is not fully developed and may not have a stable profile. Hence, a point measurement may not provide a reliable mass flow rate.

\subsubsection{Projection laser Doppler velocimetry}

The motion of graphite dust within the helium coolant can be used to infer the primary coolant mass flow rate. Laser Doppler velocimetry (LDV) has, until recently, been difficult to implement in industrial situations because of the precision optical alignment required. Conventional LDV crosses two beams of coherent laser light in the dust containing primary coolant flow, creating an interference pattern perpendicular to the flow direction. As particles pass through the constructive interference fringes, they scatter light into a photo-detector. The motion of the dust particle as it crosses the fringe pattern causes a frequency shift (Doppler) in the scattered light, enabling calculation of the particle velocity. Conventional LDV requires alignment of two laser beams and good optical access for imaging the beam intersection point.

Projection LDV is relatively new LDV variant that creates the fringe pattern by placing an optical mask within a single laser beam. ${ }^{46}$ Thus, the fringe pattern is projected along the laser beam. As the dust particles cross the fringe pattern, the Doppler shift in their scattered light wavelength indicates their velocity. The detector can be configured coaxially with the laser (as shown in Fig. 12) by employing an 
oval optical mask oriented 45 deg to the circular laser beam. The optical mask would be absorptive on the incident laser side and highly reflective on the return side to direct the scattered light into the detector.

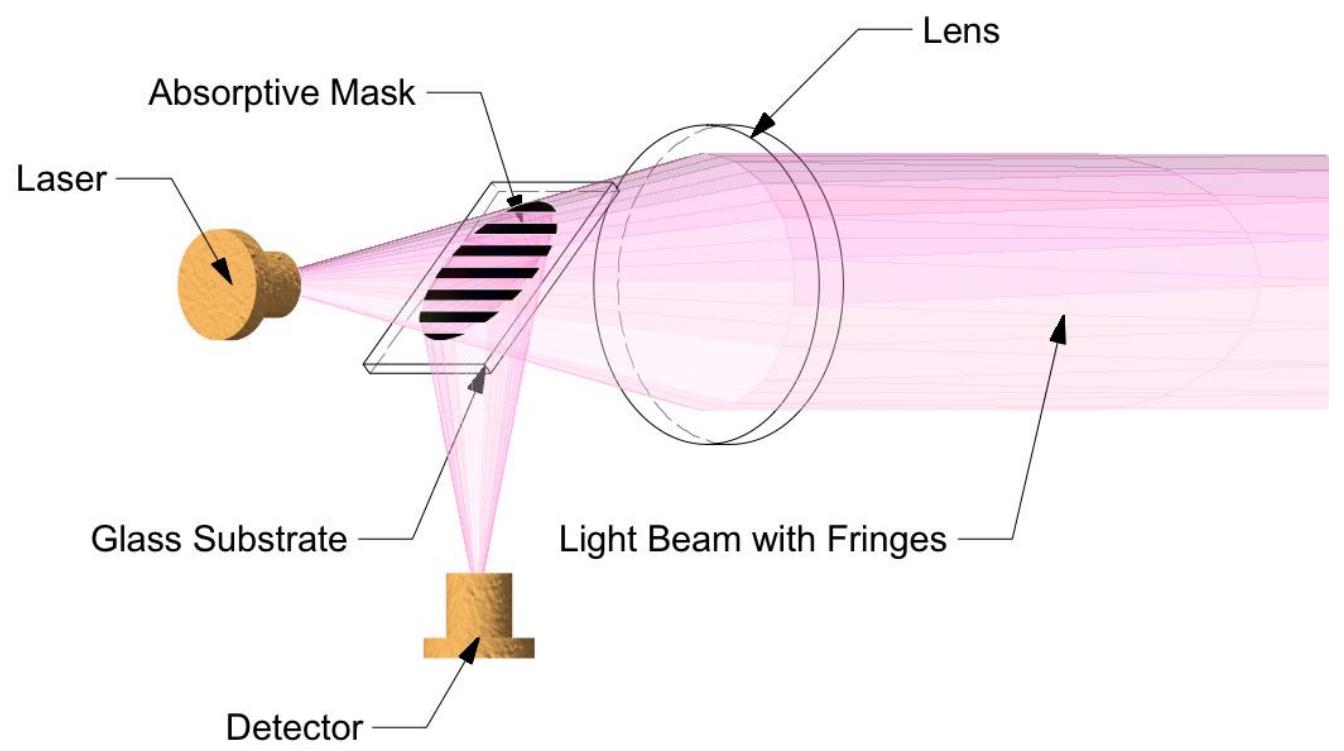

Fig. 12. Projection LDV optical components.

Projection LDV provides a measure of the particle flow across a chord across the flow. Chirping the laser would enable a flow profile to be measured along the laser path. The optical components of the projection LDV system would be located outside the primary coolant, with optical access provided through a highpressure window located in a standpipe to lower the window temperature. The number of scatters could also be counted to provide a measure of the dust level within the coolant.

\subsection{PRESSURE}

Pressure measurements are useful at HTGRs as supporting measurements to confirm proper functioning of the heat transport system. Differential pressure measurement is useful at HTGRs as a corollary measurement to indicate failure of system components or structures. For example, differential pressure measurement across the core could serve as an indication of changes in flow resistance. Pressure is typically measured by converting the pressure into a mechanical deflection, which is, in turn, converted to an electrical signal. For solid (or liquid) elements only, a pressure differential across an element will result in an unbalanced force and, hence, a mechanical deflection. Creating a controlled pressure difference at operating temperature between HTGR pressure and a reference pressure is technically challenging because of the high-temperature mechanical property shifts of structural alloys. While the primary helium itself can serve as the fill fluid for impulse lines running back to more moderate environments where conventional measurement electronics can survive, access concerns frequently make running impulse lines impractical.

\subsubsection{SiCN internally self-referenced composite ceramic}

An innovative approach to developing a differential pressure is to employ a closed-pore ceramic sensor body. The sensor body is deformed by the difference between the internal and external pressure and the electrical resistance; the sensor body is dependent on its strain state. ${ }^{47} \mathrm{~A}$ unique characteristic of polymerderived ceramics is their formability prior to firing, allowing creation of complex shapes with designed 
pore structures. ${ }^{48}$ Polymer-derived ceramic bodies based on these principles are already under development as high-temperature, high-pressure sensor materials focused on power generation. ${ }^{49}$ In this case, the sensor body as a whole can serve as a strain gauge with a nonporous sensor body employed as a sensor reference leg. A particular challenge for this type of sensor is wiring the signals back outside the primary circuit. As the ceramic element and electrical wiring pads are directly exposed to the primary fluid, avoiding shorting the electrical leads (due to carbon dust or metallic deposits arising from evaporation impurities within the structural alloys) becomes a significant technical issue.

\subsubsection{Liquid metal impulse line}

Impulse lines are the most common method to transfer a pressure from a harsh environment to a more benign one where measurement electronics can survive, and indeed a primary coolant impulse line is typically used at HTGRs wherever mechanical access is available. Liquid-filled impulse lines, however, provide both shorter response times as well as an additional isolation barrier to the primary coolant. In order to serve as an impulse line fluid, the enclosed liquid needs to remain in liquid state at both the hot process temperature and the lower measurement temperature. Sodium-potassium mixtures meet the melt point criterion. While the alkali metals can react violently with some materials, the impulse line can have a very small diameter, limiting the amount of material present. High-temperature pressure sensors incorporating a $\mathrm{NaK}$ impulse line are currently available as a special-order item. ${ }^{50}$

\subsubsection{Polarization rotation}

An internally self-referenced pressure sensor can also be realized by the use of a CTE-matched glass and metal sensor assembly. In this case, the glass piece serves as a diaphragm sealing off a cavity in the sensor body (Fig. 13). This type of mechanical configuration has been demonstrated for turbine engine control. ${ }^{51}$ High-temperature application requires matching the CTE of the glass with that of the supporting structure. Aluminosilicate glasses have CTEs that nearly match those of molybdenum alloys, enabling development of a sealed-glass diaphragm-refractory metal system.

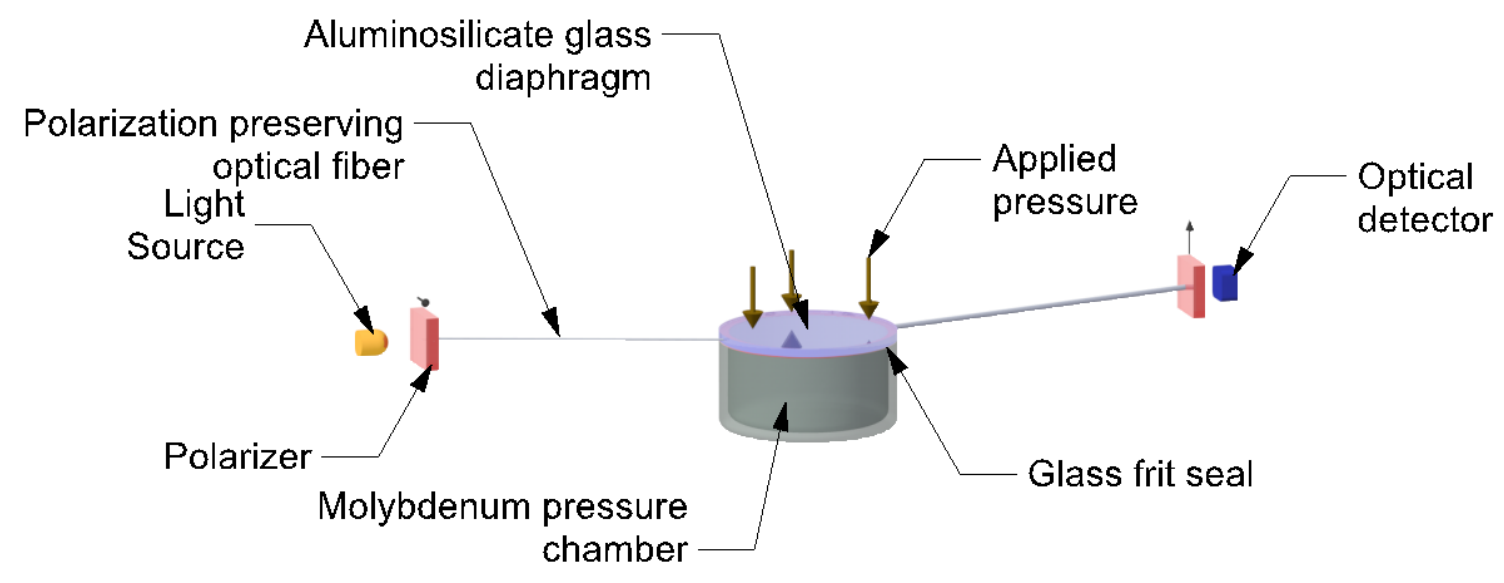

Fig. 13. Polarization rotation pressure sensor.

The pressure-induced stress on the glass causes local realignment of the electric field within the glass, changing the refractive index for light propagation in the direction of net applied stress (birefringence). Placing the measurement glass between a set of crossed polarizers and monitoring the intensity of the transmitted light provides a measure of the polarization rotation and, thereby, the pressure.

A polarization rotation pressure sensor has to overcome a number of challenges to become a reliable pressure sensor in HTGR environments. Although metal-jacketed optical fibers can be brazed into 
standard gland-type pressure seals, polarization-preserving optical fiber penetrations into HTGR-type environments are not yet standard items. Also, a multilayered glass diaphragm and chamber seal will be required as many glasses (including the aluminosilicates) are somewhat permeable to helium at high temperature. A helium leak into the pressure chamber of this type of sensor (such as via helium percolation through either the diaphragm or the glass frit) would be difficult to detect in the measurement signal, leading to progressively larger measurement error with time.

\subsubsection{Extrinsic Fizeau cavity}

The position of a diaphragm between the high-temperature helium and exterior pressure can also be read out optically. Essentially, a Fizeau cavity is formed by the distal end of an optical fiber and the diaphragm. ${ }^{52}$ The diaphragm deflection changes the cavity tuning and, thus, the wavelength-specific reflectivity of the cavity. The large mismatch between the CTE of silica glass and metallic support structures makes maintaining a precise spacing between the diaphragm and the fiber tip with varying temperature challenging. However, a proprietary-graded joint approach to maintain precise alignment between the silica optical fiber and a metallic housing has now been demonstrated to enable widedynamic-range pressure sensing to above $800^{\circ} \mathrm{C} .{ }^{53}$ Similar technology has also been employed for hightemperature measurements in ex-core HTGR-type radiation environments but continues to have measurement drift limitations. ${ }^{54}$

\subsection{NUCLEAR}

Monitoring a fission reactor's neutron flux is a key safety and performance measurement. Neutron flux measurement instrumentation is important for reactor control because it provides unambiguous indication of spatial and temporal levels and variation of neutron flux, guides the operator with respect to the approach to criticality, and provides a measurement of reactor power.

\subsubsection{High-temperature fission chamber}

No suitable neutron flux measurement technology is commercially available that functions at temperatures above $550^{\circ} \mathrm{C}$. HTGRs have core temperatures well above $550^{\circ} \mathrm{C}$. Prior HTGR development programs have demonstrated fission chambers that function up to $800^{\circ} \mathrm{C} .{ }^{55,56}$ However, these detectors are not commercially available. The current design intent for the NGNP is to move fission chambers away from the core and infer core flux conditions from the remote measurements. ${ }^{57}$ Developing fission chambers that are directly usable near the core is a significantly superior measurement approach. Neutron flux can peak sharply within the core, and the peaking has both safety and performance implications. It may be difficult to reconstruct local flux peaking from remote sensors because of the fine spatial structure of the flux profile.

The fundamental processes of fission-chamber-type neutron chambers are not temperature dependent. The failure of fission chambers at high temperatures is most commonly due to metallic deposits, which arise from evaporation of contaminants (or alloy components) from the structural alloy and form across the electrical insulator between the central anode and the wall shorting out the chamber. To overcome the temperature vulnerability of fission chambers, low-outgassing structural materials and high-temperaturetolerant sealing materials and methods need to be devised.

The fissile material of a fission chamber is consumed in the measurement process. The chamber sensitivity thus decreases as the neutron fluence increases. Longer-lived fission chambers combine a fertile with a fissile material, ${ }^{234} \mathrm{U}$ with ${ }^{235} \mathrm{U}$, to extend the chamber's useful period of performance. While the general burn-out characteristics of the fission chamber are known and tracked, the chamber sensitivity is sufficiently uncertain to warrant periodic device recalibration using the heat balance measurements provided by the primary coolant temperature and flow measurement. 
A DOE NEET project to fabricate and demonstrate a high-temperature-tolerant $\left(900^{\circ} \mathrm{C}\right)$ fission chamber has recently been initiated.

\subsubsection{Gamma thermometers}

The local core power distribution is a primary reactor performance and safety parameter. While traveling in-core probes and self-powered neutron detectors are commonly used as local power monitors in LWRs, both technologies would require significant redesign to function at the higher temperatures of VHTRs.

The materials and structures of gamma thermometers are similar to thermocouples and heated lance-type level probes and, as such, are anticipated to be suitable for higher temperature. However, high-

temperature reactors present different chemical environments as well as higher temperatures, and as such gamma thermometers for high-temperature reactor cores require alternate sheath material selection as well as structural reengineering.

Gamma thermometers function based upon the heating of the sensor assembly by gamma rays and the subsequent controlled differential cooling of the sensor body. ${ }^{58}$ Gamma thermometers (as shown in Fig. 14) essentially consist of a series of differential thermocouples embedded within an electrically insulating body. At periodic intervals along the body, annuli of the electrical insulation are removed. A linear electrical heating element is also typically included to enable sensor calibration. The resulting structure is then swaged into a metal jacket. The temperature differential developed between an insulated and an uninsulated thermocouple junction within the body of the sensor is proportional to the rate of local heating by the gamma radiation, which is in turn proportional to the local power generation rate during power range reactor operation. The combination of insulated and uninsulated temperature measurement decouples the sensor response from the coolant flow rate as nearly all of the deposited heat is removed via the coolant flow, yet the two temperature measurement junctions have different thermal flow path lengths to the same flow-cooled surface.

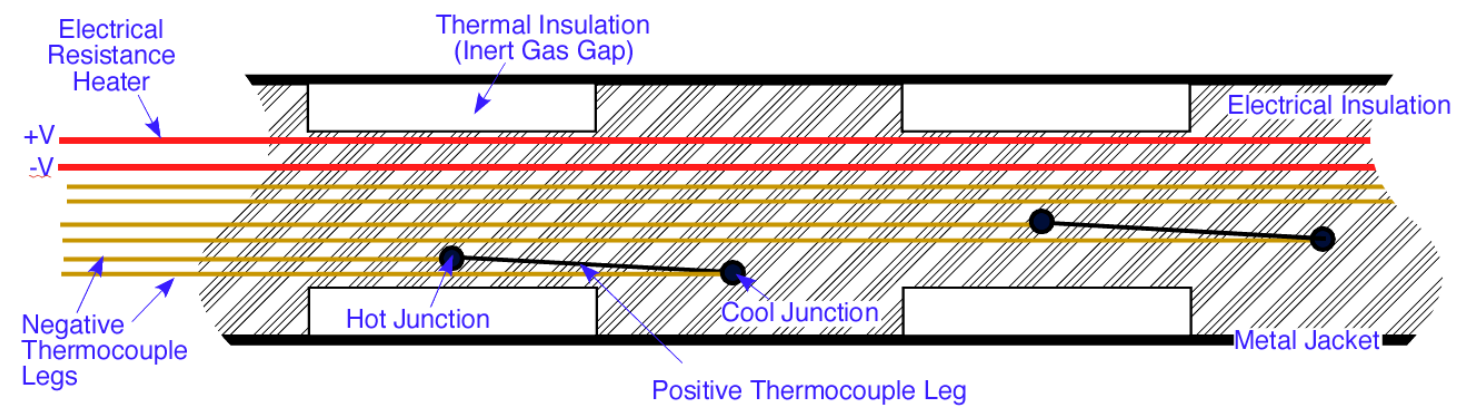

Fig. 14. Gamma thermometer conceptual layout.

Gamma thermometers are anticipated to be reliable sensors, with their largest issues being properly compensating for the neutron component of the heating, pinhole leaks in the outer jacket, and susceptibility to electromagnetic interference in the region between the end of the metal jacket and the signal amplifier. Gamma thermometers have not been demonstrated at the higher temperatures of HTGRs, and the additional radiative heat removal across the insulation will need to be compensated for either in the sensor design (low emissivity coating of the annular gap) or in the sensor calibration by supplemental temperature measurement. 


\subsubsection{Micropocket fission chambers}

Micropocket fission detectors (MPFDs) are pancake-style, highly miniaturized fission chambers that employ sealed alumina plates as their structural backings and coatings of uranium or thorium as their neutron sensitive element. ${ }^{59}$ Typical device dimensions are $0.5-2 \mathrm{~mm}$ in thickness and $1-3 \mathrm{~mm}$ in diameter and are operated with $\sim 200 \mathrm{~V}$ of bias. Multiple chambers can be co-located on the same substrate, providing the ability to subtract leakage current, detect thermal neutrons with enriched uranium, and detect fast neutrons with thorium. ${ }^{60}$ A temperature measurement can also be incorporated into the detector body, enabling controlled leakage current compensation.

While highly promising and composed of materials that are anticipated to be high-temperature tolerant, MPFDs remain to be qualified for the high temperatures and long performance times required for local flux measurements in VHTRs. The DOE NEET program is currently initiating a project to mature the technology in support of fuel qualification testing.

\subsection{PRIMARY SYSTEM GASES}

Primary coolant chemistry monitoring has most commonly been performed off line with a low-pressure, cooled sample of primary coolant. A wide range of technologies is available for off-line measurement of the trace constituent chemistry and moisture content of helium. The chilled mirror technique employed at Fort St. Vrain can provide accurate moisture measurements but is both labor and maintenance intensive. Future helium composition measurements are most likely to be performed through

1. optical absorption spectroscopy,

2. capacitive shift due to water absorption, or

3. vibration frequency shift of a resonant structure resulting from water absorption into a hygroscopic coating.

\subsubsection{Optical absorption}

Water has a well-known optical absorption spectrum in both the infrared and ultraviolet, and trace atmospheric moisture measurements are commonly performed in both wavelength regions. A water or air ingress accident will also result in carbon dioxide and/or carbon monoxide as well as $\mathrm{CH}_{4}$ in the primary helium coolant. All of these combustion gases have infrared absorption signatures, and the particular wavelength bands selected for monitoring needs to avoid overlap to avoid loss of specificity.

Optical absorption measurement is both rapid and sensitive and can thus provide a prompt, unambiguous indication of a major water or air ingress accident or provide a diagnostic indication of small leak initiation. To minimize measurement drift, optical absorption-based measurement is almost always performed in a relative manner, dividing by the simultaneously measured optical absorption at a nearby insensitive wavelength. The measurement sensitivity is largely a function of the optical path length. The effective optical path length can be made large by placing the sample in a Herriott-type optical cavity (Fig. 15) that multiplies the sample path length through multiple reflections. 


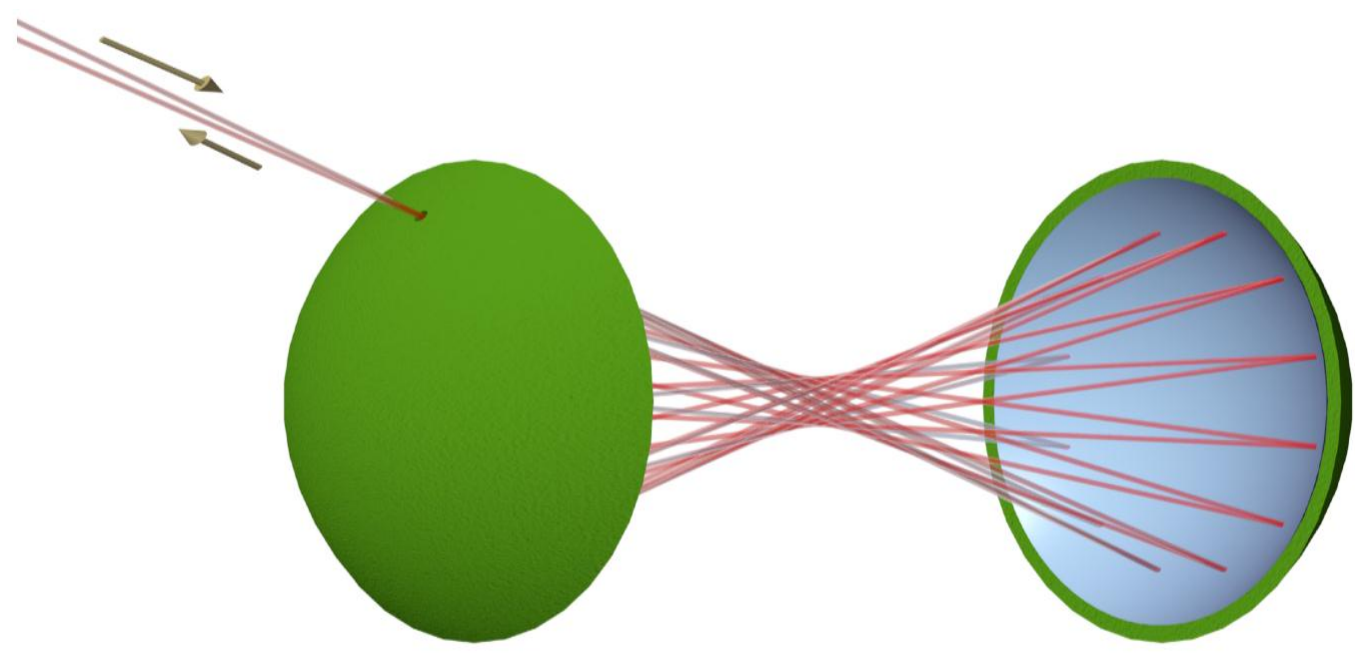

Fig. 15. Herriot-type optical cavity.

Optical absorption spectroscopy can be performed at elevated temperatures and pressures. Performing the optical absorption measurement under primary coolant operating conditions, however, both significantly alters the absorption spectrum and necessitates optical access across the primary coolant pressure boundary. Optical access into an HTGR primary coolant path would either be through a fiber optic port or a small high-pressure window. High-temperature, high-pressure fiber optic ports, which mechanically closely resemble the compression fittings employed for electrical wiring penetrations, are commercially available with either fused silica or sapphire windows. However, as helium is transparent, a small diameter, high-pressure-tolerant window can provide optical access across the primary pressure boundary. Sapphire and fused silica windows are commercially available with significantly higher pressure ratings than would be employed in HTGRs. In most optical penetration designs, in order to reduce the temperature on the window's ceramic-to-metal seal, the window is located on a short pipe flange extending outward from the high temperature process. While both fused silica and sapphire are transparent in the near infrared and ultraviolet, water's ultraviolet optical absorption does not become large until below available fiber optic cut-off wavelengths $(\sim 160 \mathrm{~nm})$. Hence, only the infrared optical absorption spectroscopy appears feasible for an online moisture measurement.

Both temperature and pressure alter the water vapor absorption spectrum. By selecting measurement wavelengths that have different temperature and pressure sensitivities, infrared optical absorption spectroscopy can be configured to provide simultaneous, online measurement of primary coolant moisture content, pressure, and temperature. Nagali and Hanson ${ }^{61}$ have provided an overview of infrared optical absorption-based simultaneous moisture, temperature, and pressure measurement in a high-pressure, combustion-type environment that includes suggested measurement wavelengths $(1.30-1.41 \mu \mathrm{m}$ range). A conceptual layout of a high-pressure-, high-temperature-tolerant optical absorption-based measurement system is shown as Fig. 16. Note that this type of temperature and pressure measurement system will not work without some included moisture and would thus be most useful in post-accident conditions. Adequate system sensitivity would need to be experimentally validated under normal operating conditions. In general, optical absorption-based process condition measurements would be especially useful in post-severe-accident environments, since no sensor element would be required to withstand the primary coolant environment, and the measurement electronics can be backed well away from the reactor. 


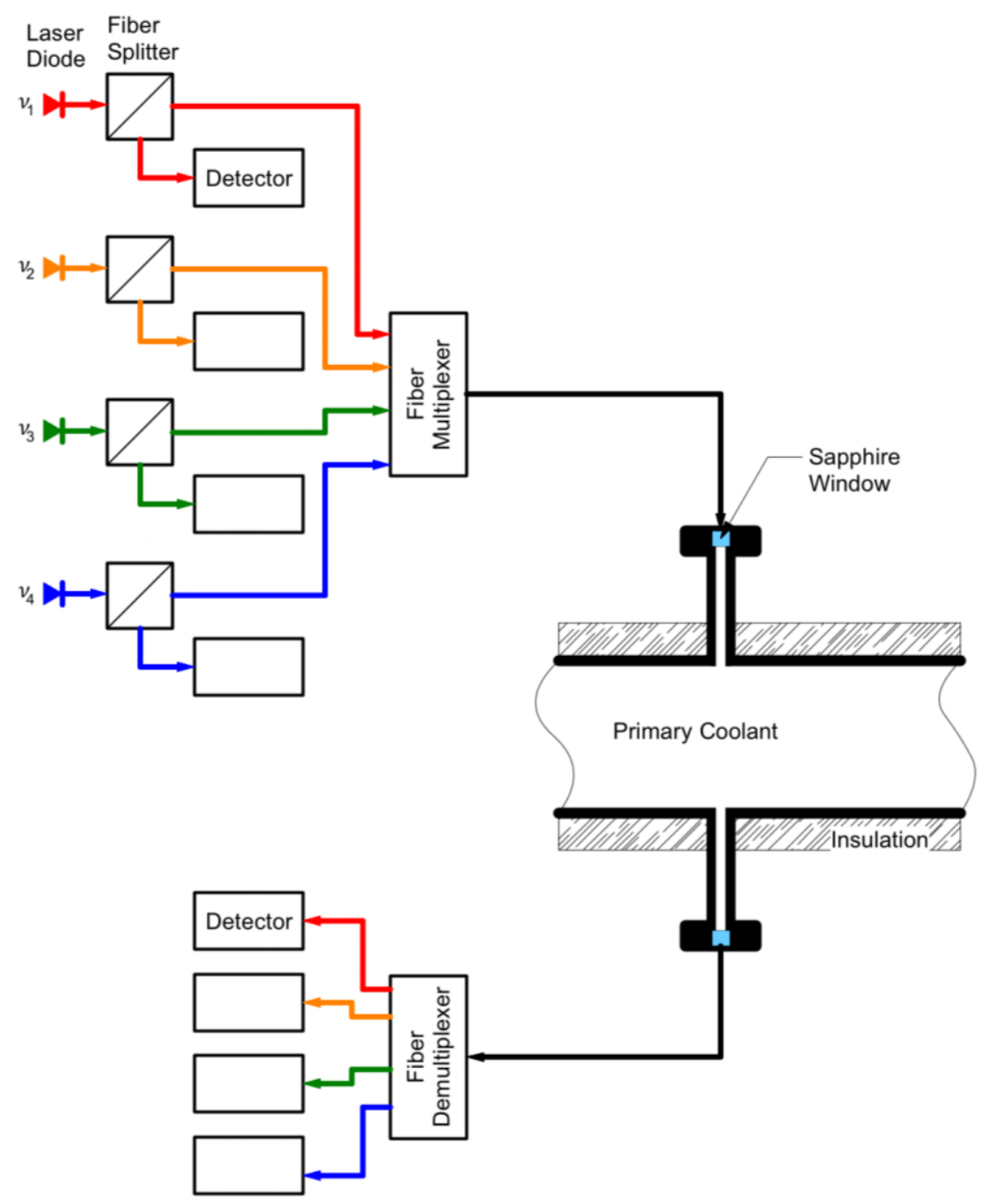

Fig. 16. High-pressure optical absorption spectroscopy component layout.

Optical absorption-based moisture content measurements can also be made on lower-temperature, atmospheric-pressure coolant samples. Primary coolant samples would be extracted by use of a bleed valve attached to a sampling line. At low pressure and temperature, water exhibits several narrow (angstrom) absorption lines in the infrared. To measure the moisture content of a gas sample, a tunable narrow-band laser diode would be tuned across a water absorption line. ${ }^{62}$ The optical attenuation at a wavelength just above or below the absorption line would be used to compensate for measurement drift. Moisture is also strongly absorbing at the Lyman-alpha wavelength $(121.56 \mathrm{~nm})$, and an ultraviolet optical absorption spectrometer employing fluoride glass windows and a hydrogen discharge lamp is another candidate moisture measurement technology for lower pressure and temperature samples.

\subsubsection{Capacitive shift}

In a capacitive shift-type moisture detector, water vapor is adsorbed onto the dielectric layer between a capacitor's two plates. The water changes the effective dielectric constant of the layer, which in turn shifts the capacitance value. In the most common implementation format (including the GE General Eastern model deployed at HTR-10), the capacitor is formed by first oxidizing an aluminum plate to produce a 
few-microns-thick alumina layer. Tubular pores are then formed into the top surface of the alumina layer (typically by combination of anodic oxidation and chemical dissolution). The pore diameter (a few nanometers) is controlled to preferentially admit water molecules. The pores also significantly increase the surface area available for water adsorption, increasing the device sensitivity. A thin $(\sim 30 \mathrm{~nm})$ gold top electrode is deposited onto the structure. Moisture diffuses through the thin gold layer and is adsorbed onto the surface of the alumina.

Capacitive shift-type hygrometers are moderately sensitive to pressure and temperature changes, necessitating a controlled sample environment, and are generally insensitive to combustion gases. Measurement times of a few seconds are possible for high-moisture-content changes and of roughly a minute for low moisture concentrations. Capacitive-type moisture monitors offer only modest accuracy and repeatability and require periodic recalibration. ${ }^{63}$

\subsubsection{Resonant frequency shift}

Piezoelectric quartz tuning forks exhibit high-stability resonant oscillation. A moisture sensor can be formed from the tuning fork by coating it with a hygroscopic polymer (e.g., cellulose acetate) ${ }^{64}$ Moisture absorption into the polymer increases the tuning fork's mass, thereby shifting its resonant frequency. A matched set of tuning forks is employed to provide drift compensation by maintaining the duplicate turning fork in a dry atmosphere at matched temperature and pressure. While mechanically resonant structures are more common, surface acoustic wave-type humidity sensors have also been built and also function based upon the shift in the acoustic properties of the sensor with water absorption into a surface film. Measurement response time is determined by the adsorption characteristics of the polymer and ranges from a few seconds for large shifts to roughly a minute for small shifts. Measurements are sensitive to temperature and pressure, necessitating control of the measurement environment. Parts per billion measurement sensitivities are possible with resonant frequency-type measurements.

\subsection{CONFINEMENT GASES}

Measuring the confinement gas composition is primarily of interest following accidents and as an indicator of helium leakage. Monitoring combustion by-products both in confinement and within the primary coolant loop supports the monitoring of accident progression. Monitoring the oxygen content of the confinement provides an indication of how much additional graphite combustion can occur following a loss-of-pressure accident. The spatial distribution of the gases needs to be taken into account in the measurement design. The helium will rise to the top of the confinement, and the amount of mixing of the other gases will depend on the specifics of the accident. Likely, multiple measurements of gas composition at multiple elevations will be necessary.

\subsubsection{Helium}

The resonant frequency of a tuning fork directly shifts with the density of the surrounding gas. As the density of the containment gas directly varies with helium concentration, a gas density measurement provides a surrogate for helium concentration measurement. A matched set of tuning forks would be employed to provide drift compensation. The matched fork would be located in matched pressure and temperature air or nitrogen environment (i.e., within a sealed, helium-impermeable bellows), providing compensation for the confinement pressure and temperature shifts. Measurement response time of resonant frequency devices is short, and $0.2 \%$ system sensitivity has been demonstrated. ${ }^{65}$

\subsubsection{Combustion products}

Monitoring the carbon dioxide and carbon monoxide in a post-depressurization accident would provide indication of the amount of air ingress as well as a general tracking of the accident progression. 
Measuring the ratio of $\mathrm{CO}_{2}$ to $\mathrm{CO}$ would give information about where in the core the oxidation is taking place. Combustion diagnostics at both high and low pressure across a wide range of temperatures can be performed online by infrared optical absorption spectroscopy. Both carbon monoxide and carbon dioxide can be observed simultaneously along with moisture. Infrared absorption measurements can be quite mechanically and thermally robust, with measurements being made in atmospheres as aggressive as a coal-fired power plant combustion chamber ${ }^{66}$ and a full-sized, natural gas burner. ${ }^{67}$ The instrumentation necessary to perform the measurement is much the same as that necessary for the infrared optical absorption-based moisture measurement described earlier. Infrared absorption measurement times are small, and typical measurement sensitivities are $\sim 100 \mathrm{ppm}$. Performing combustion measurements within the primary coolant boundary (or in-core) would require ensuring optical access across the primary coolant pressure boundary in a post-accident environment. Monitoring of combustion products in confinement can be performed with reasonably available, well-known hardware.

\subsubsection{Oxygen}

The confinement environment following a severe accident may contain several gas species as well as moisture droplets and carbon particles. Maintaining specificity of the measurement of a mixed, aggressive environment is key to selecting the most advantageous measurement technology. Infrared optical absorption spectroscopy is especially effective at selecting out oxygen from the interfering species. All of the other conventional oxygen analyzer technologies have some cross sensitivity to interfering gases that may be present in confinement in a post-accident scenario. A molecular oxygen absorption band near $760 \mathrm{~nm}$ has been shown to provide $0.1-1 \%$ oxygen measurement under fire-suppression conditions. ${ }^{68}$ The measurement configuration for a fiber optic coupled, tunable laser diode, oxygen infrared absorption spectroscopy measurement system closely resembles that for either moisture or combustion product measurement.

\subsection{TRITIUM}

Tritium contamination is regularly measured as part of nuclear plant environmental release monitoring. Measurements can readily be made in helium, air, and/or water using well-established techniques. The "NGNP Contamination Control Study" tritium, and classical instrumentation is anticipated to be suitable for tritium measurements at nextgeneration HTGRs.

Tritium concentration measurement in helium would most readily be performed by placing the helium sample into an ion chamber or flow-through-type proportional counter. If additional contamination with other radioactive species is suspected, the helium sample would first need to be passed through a liquid nitrogen cold trap to plate out the radioactive noble gasses. An instrument for the measurement of tritium within air would be similar to one for measuring tritium in helium. Established procedures (filtering, electrostatic precipitation, etc.) need to be followed for compensating for smoke, aerosols, moisture, and/or gamma-ray fields. ${ }^{70}$ In a high background area, such as an HTGR containment following a severe accident, a gamma-insensitive flow-through ion chamber would likely be required for an accurate tritium concentration measurement. $^{71}$

Tritium measurement in water would most likely be performed by dissolving the sample into a liquid scintillation cocktail and measuring the resulting scintillation light with a photomultiplier tube. Both environmental and medical tritium contamination monitoring in aqueous solutions is commonly performed by use of this scintillation cocktail method. ${ }^{72}$ Alternatively, the water suspected to contain tritium can be electrically separated into hydrogen and oxygen and a flow-through-type ion chamber employed to count the tritium in the hydrogen. 


\subsection{FUEL QUALIFICATION}

The particular TRISO fuel intended for use at the NGNP is currently undergoing qualification testing through the DOE Advanced Gas Reactor (AGR) program. ${ }^{73}$ In-fabrication, in-core, and post-exposure testing are all under way. Measuring the parameters of the fuel qualification environment is technically challenging because of the high levels of radiation, high temperatures, and small spaces available. Several of the sensors described in the preceding sections are likely candidates for deployment for fuel qualification. Most fuel property measurements are made by post-irradiation examination using classical laboratory techniques. Similarly, the fuel test conditions are confirmed off-line by use of melt and flux wires. However, irradiation temperature and neutron flux are typically measured online. The micropocket fission chambers described previously may enable improved local neutron flux measurements as compared to current self-powered neutron detector techniques with their known temperature sensitivity. ${ }^{74}$

JNT has been shown to be advantageous for fuel temperature measurements in-core since it is fundamentally immune from radiation-induced shifts in the sensor value. ${ }^{75}$ While type-N thermocouples are generally stable and reliable to temperature measurements of $1000^{\circ} \mathrm{C}$, fuel qualification temperatures often are performed at higher temperatures to simulate accident conditions. A particular challenge for fuel qualification thermocouples is the small-diameter wire required. The small wire diameter increases the technical challenge of the wire drawing, increases the surface area to volume ratio making the wires more vulnerable to corrosion, and makes the wires more vulnerable to grain growth across the thin wires.

Additionally, the electrical resistivity of insulators decreases by about one order of magnitude per hundred degrees above $1000^{\circ} \mathrm{C}$. The $0.1 \mathrm{MoPt}-5 \mathrm{MoPt}$ thermocouple developed by the Dragon reactor project in support of irradiation experiments would also be useful for fuel qualification testing at temperatures up to $1700^{\circ} \mathrm{C}^{76}$ Molybdenum-niobium alloy thermocouples have also demonstrated good high-temperature, high-neutron flux performance. ${ }^{77}$ However, niobium and its alloys are particularly vulnerable to oxygen-induced embrittlement (at concentrations as low as $1 \mathrm{ppm}$ ). ${ }^{78}$ Consequently, radiolytically liberated oxygen from the oxide electrical insulators is a concern for long-term thermocouple survival. Also, pure niobium tends to exhibit grain growth and consequent wire cracking. $\mathrm{Nb}-1 \mathrm{Zr}$ alloy is commonly used to avoid the rapid grain growth. Additionally, molybdenum becomes brittle at ambient temperature after being exposed to high temperatures, which can be a concern for welded thermocouple junctions or cyclic testing. The recent use of lanthanum oxide dispersion strengthened molybdenum has decreased the thermocouple vulnerability to molybdenum's loss of ductility. ${ }^{79}$

\subsection{CONTROL ROD DRIVE INSTRUMENTATION}

Due to the tall HTGR core format, full-height control rods do not fit within the primary vessel when extracted from the core. To avoid the need for the control rods to penetrate a pressure boundary, the rods retract partially into standpipes located above the vessel. To minimize the required standpipe height, the control rod leaders need to be either flexible, telescopic, or both. In Fort St. Vrain the control rods were attached to a cable and drum drive system with the control rod motors located at the top of the standpipes to lower the motor temperature. The rods had an electromagnetic clutch that could be depowered to allow the rods to fall into the core under gravity. ${ }^{80}$

Both control rod position and cable tension need to be monitored to provide evidence that the control rod is at its specified position and that it remains capable of moving when called upon. For a cable and drum system, the simplest form of position sensor is an absolute shaft encoder. Both electromagnetic and optical absolute shaft encoders are widely available. Alternatively, the amount of cable remaining on the drum can be measured with capacitive gauges. The position of the top of the control rod could also be directly measured by coherent laser radar with optical access to the top of the standpipe provided through a high-pressure window. Cable tension is measured to demonstrate that the control rod is free to move. Too low a tension indicates that the rod is resting upon an obstruction, and too high a tension indicates 
that the movement system is wedged and the rod may not drop when released. Cable tension is measured by monitoring the amount of force necessary to deflect the cable with a pulley and strain gauge apparatus. Similar information can be derived from shaft torque sensors on the drive motor. Several different styles of torque gauges are commonly in use in industry. 


\section{DIAGNOSTIC AND PROGNOSTIC TECHNOLOGIES FOR HTGRS}

Advanced instrumentation technologies can provide information necessary to assess a plant's current "health" and predict the remaining useful life of the plant's SSCs. Diagnostics and prognostics techniques, however, are becoming ubiquitous in industrial systems. Some diagnostic techniques, such as lubricating oil condition and contamination monitoring, have been widespread throughout industry for several decades. This section provides a descriptive overview of the instrumentation and methodologies for diagnostics and prognostics as they might apply to HTGRs and does not attempt to address the more general issues associated with applying the technologies to nuclear power plants in general or other industrial SSCs.

Active components are particularly amenable to integration with instrumentation in that the sensor data obtained can support control as well as diagnostics and prognostics. Overall, integrating advanced controls and instrumentation deeply into nuclear power plant components offers the potential to profoundly improve their capabilities, performance, and maintainability.

The recent reports by Pacific Northwest National Laboratory (PNNL) staff provide a good general foundation on the application of instrumentation to component and structure health and to remaining useful life estimation. ${ }^{81-83}$ Material prognostics are especially important at HTGRs since at the higher temperatures the structural alloys have a greater tendency to creep under load, and careful monitoring and consequent adjustment of operating conditions can significantly extend the life of expensive, difficult-toreplace structural components.

Diagnostics and prognostics techniques can also be applied to the instrumentation system itself to increase confidence in the measurement values and to provide an estimate of remaining useful life. For example, an increase in the measured noise on an instrument's signal likely indicates a degradation of the sensing channel rather than a process variable shift. The recent textbooks by H. M. Hashemian provide a good review of the use of signal variance as a measure of instrumentation system health. ${ }^{84,85}$

\subsection{HELIUM CIRCULATOR}

The helium in the primary circuit of an HTGR needs to be kept very clean, and conventional oillubricated bearings are a potential source of contamination. Also, bearing maintenance within the primary pressure boundary is both expensive and time consuming. The helium circulator for Fort St. Vrain was the source (especially its seals and bearings) of much of the plant's reliability problems. ${ }^{86}$ Modern HTGRs are consequently likely to adopt active magnetic bearings. The HTR-10GT (which is a version of the HTR-10 adapted for a gas turbine PCU) helium circulator has already made this design choice by employing high-temperature, active magnetic bearings controlled with a multiaxis, high-speed feedback scheme. ${ }^{87}$

The development of high-temperature materials technologies over the past few decades was a key enabling technology for instrumentation to more intimately couple into the helium circulator to support active control. Additionally, development of high-speed, fault-tolerant computing and controls technology was necessary for the advancement to active management of circulator performance; this technology was unavailable for the HTGRs of the 1960s and 1970s.

The basis of active magnetic bearing suspension is varying the drive current to electromagnets as a result of rotor displacement measurements. Shaft horizontal and vertical positions are independently measured at each radial bearing-motor set. Rotor position is measured either by monitoring the change in the resonant frequency of a driven coil located near the rotor resulting from a shift in position of the magnetic rotor material or by use of a Hall effect-type sensor. 
An HTGR helium circulator shaft will rotate rapidly under normal, at-power conditions. The combination of turbulent fluid motion and rapid impeller rotation results in multimode shaft vibrations with frequencies up to roughly $10 \mathrm{kHz}$. Complicating the measurement interpretation, even minor imperfections in the impeller balance or in the rotor position sensor targeting can result in rotational instability (i.e., the control system itself can enhance the inherent oscillations).

The relative and absolute motions of the circulator rotor are the primary measured parameters for both the control and diagnostics system. Rotor rotational characteristics are computed from the measured force and position data. Flaws within the circulator structure or operations are impressed onto its rotational characteristics. System models are used to correlate the measured rotational characteristics with a particular flaw. Once a flaw has been identified, the control system is called upon to adapt to degraded operating conditions. A prognostic model for flaw progression can also then be employed to predict the component remaining useful life. Fault-tolerant active magnetic bearing control design remains an active development area $^{88}$ as does active magnetic bearing-based fault detection in centrifugal pumps. ${ }^{89}$

Fault-tolerant control can be combined with system diagnostics to improve overall circulator reliability. For example, the circulator active magnetic bearing control would typically be powered by three-phase power supplies. For any one radial bearing, each phase could control the rotor position along axes separated by $120 \mathrm{deg}$. Since position control need only be supplied on the $x, y$ axes, in any one radial bearing control, any one of the power supplies is redundant. Thus, if one of the power supplies were to fail, the other two phases of the magnetic bearing control power supply system could maintain control of the rotor position, provided that they were sized appropriately and that the I\&C system could respond rapidly enough to recognize the problem. This would both avoid a rotor crash and enable online system repair by hot-swapping a working third phase into the power supply rack.

\subsection{CONTROL ROD DRIVE MECHANISM}

HTGR control rod drives are substantially different than those for LWRs. The taller core and desire for a less than full core height standpipe above the vessel, along with the lower density and compressibility of the coolant, combine to create substantially different design requirements. As the environment at the top of the standpipe, where the control rod drive motor is located, is inert and relatively low temperature, the motor, clutch, drum, and instrumentation can be fabricated from traditional materials. As electrical signature analysis (ESA) can be applied without deploying additional instrumentation outside a wellcontrolled environment, it is the most likely technique to be employed to observe the onset of mechanical changes to the control rod drive system. ${ }^{90}$ The central premise of ESA is that mechanical changes to an electrically powered system, such as clutch slippage or changes in shaft torque (rod jamming), will be impressed onto the higher frequency components of the motor current and voltage. As such, ESA is a general diagnostic technique (that was originally developed at Oak Ridge National Laboratory [ORNL] under NRC sponsorship ${ }^{91}$ ) with widespread applicability to any electrical-motor-operated component.

\subsection{NOISE ANALYSIS}

Noise analysis has been applied to a wide variety of reactor designs, and the results have sometimes been useful in obtaining information about system operation that would otherwise not be available. Perhaps the most common current use deals with monitoring vibrations of rotating equipment, where changes in the noise spectrum characteristics can be attributed to various degradations, such as bearing wear, and can usefully be applied to maintenance or replacement scheduling. Likely candidates for this application in HTGRs would be the control rod drive motors (noted in Section 4.2) and the circulators (or the gas turbine for the Brayton cycle designs). Today's noise analyzers are fast, cheap, reliable, and abundant.

The signal typically obtained from noise analysis is the product of two elements: the source of the noise and the characteristics of the process or system (and sensor) between the source and the measurement. For example, if bubbles in a reactor core coolant are the noise "source," the ensuing reactivity fluctuations 
and their effect on the neutron population (and the flux sensor) are the "filter" between the source and the measurement. The filter characteristics are functions of the void coefficient of reactivity and other thermal-hydraulic processes. In some cases then, it may be difficult to "back out" the desired information.

One useful variation on noise analysis makes use of forced perturbations on the system, which then can allow the analysis to characterize the measured response as system behavior without the uncertainty of the size or nature of the perturbation. Such tests can usually be done without significant "interference" with system operation (which is often a requirement in commercial power plants), since this information can usually be obtained with small perturbations. For example, tests using small variations in control rod and steam valve positions over time have been run on operating PWRs. The resulting information is in the form of the frequency response of the system. Examples are the reactivity-to-power and reactivity-to-core outlet temperature characteristics. These are linearized functions and will typically change with such parameters as power level, coolant flow, and burnup. By comparisons of the measured frequency responses with the theoretical models, useful information can be obtained to help with model validation. Because of the differences between the response times of various phenomena, which can be seen in frequency response results, parameters can be inferred that would not be evident in the analysis of steadystate measurements.

The use of several types of perturbation signals allows for trade-offs in experimental difficulty and accuracy of the information obtained. The use of pseudo-random binary sequences (PRBS) has the advantage of generating perturbations with many known distinct frequencies, where at these frequencies the signal-to-noise ratio would be high (and thus, hopefully, the results "clean"). A comprehensive study and implementation of these options was performed for the ORNL Molten Salt Reactor Experiment (MSRE). ${ }^{92}$

Historically (in HTGR history, at least) the most unusual case of reactor noise occurred in 1979 at Fort St. Vrain, where large periodic variations were observed in core coolant outlet temperature and flux detector signals (see Figs. 17 and 18). ${ }^{93}$ The mystery was solved when it was determined that the cycles were due to fuel blocks tilting (back and forth). The cyclic nature was due to thermal expansion and cooling variations from bypass flows from adjacent blocks along with varying radial pressure drops. The effect in Fort St. Vrain was exacerbated by differences in core regional flow orifice settings, which resulted in high lateral pressure drops. Current modular HTGR designs do not have regional orifices, so the lateral pressure drops would be small; however, in NGNP designs, the active core is ten blocks high (vs six high for Fort St. Vrain), making it more prone to wobbling. The newer cores have design features (e.g., supports) to inhibit wobbles. 


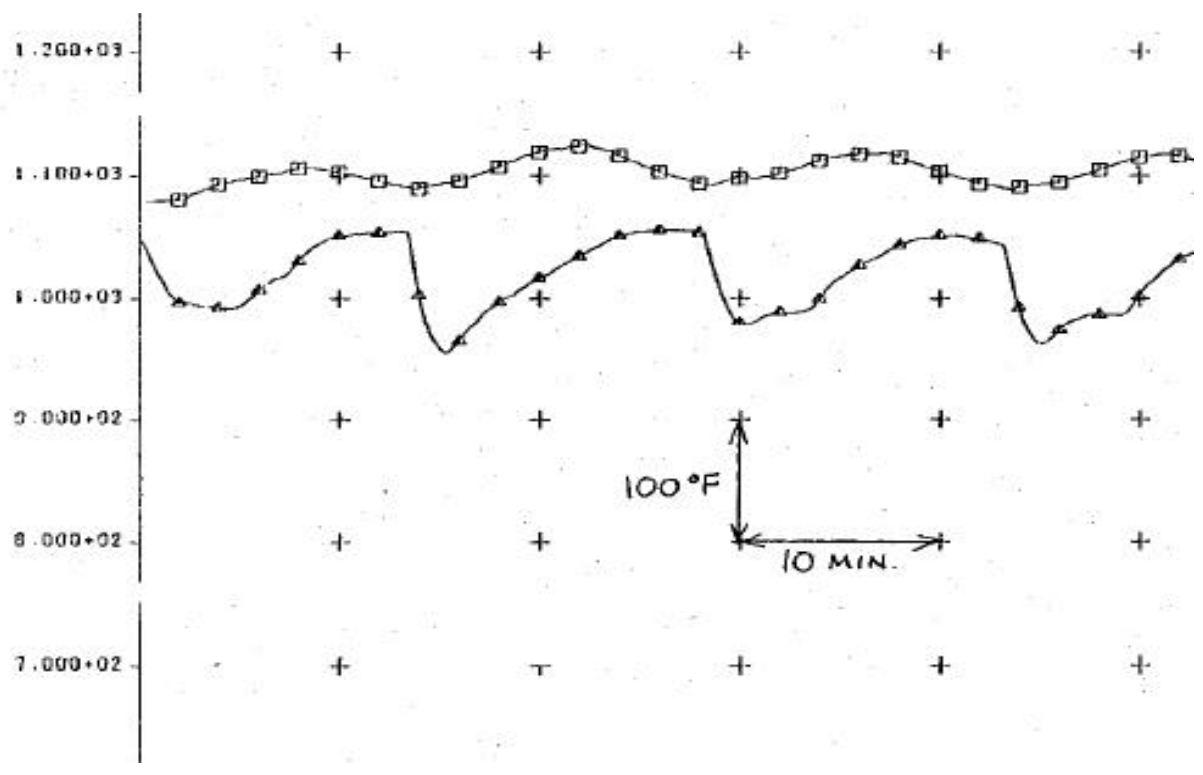

Fig. 17. Core coolant outlet temperature perturbations at Fort St. Vrain.

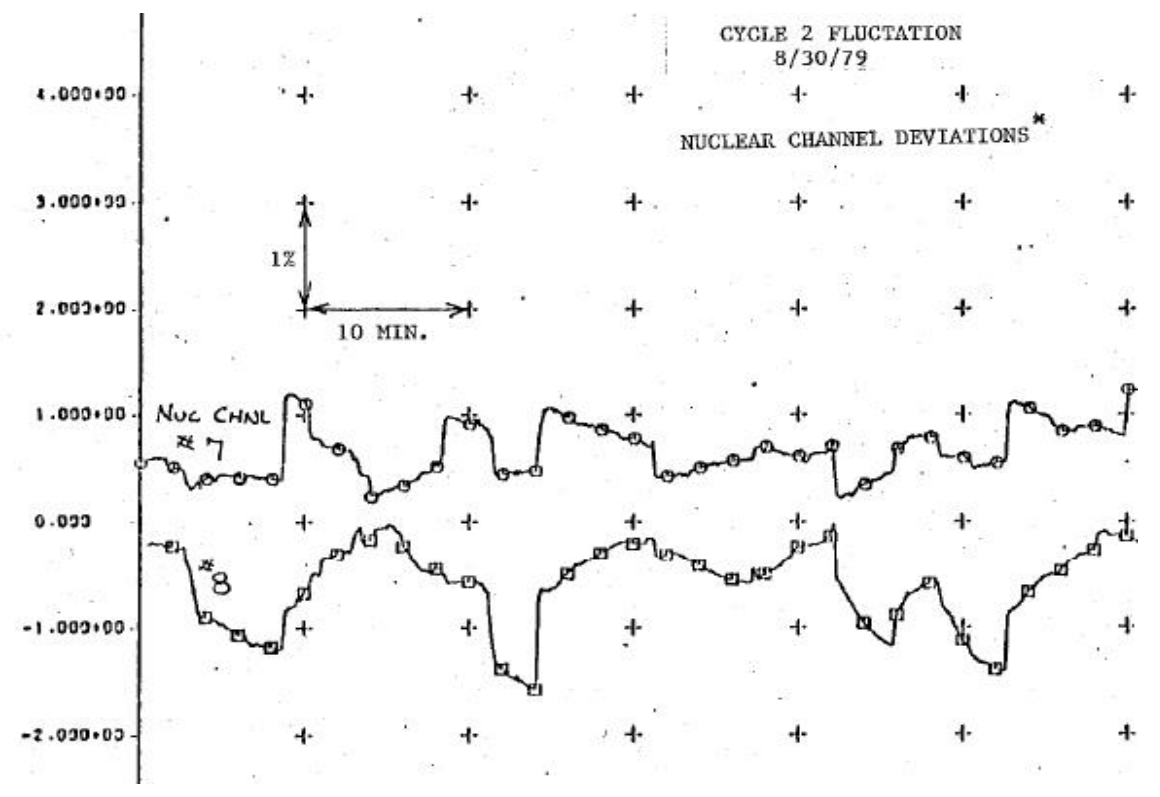

Fig. 18. Flux channel perturbations at Fort St. Vrain.

\subsection{FISSION PRODUCT ESCAPE}

Some of the fission products will escape the TRISO fuel. The degree to which FPs leak is a potentially important diagnostic both to ensure the quality of deployed fuel as well as to ensure that the primary coolant remains sufficiently clean such that a depressurization accident does not excessively contaminate the confinement, filter system, or environment. While some of the FPs released from the fuel will adsorb 
onto the nearby graphite, the released FPs may also be transported in the graphite dust suspended in the primary coolant or as a vapor mixed with the primary coolant.

Dust particles can be removed from the primary flow by use of electrostatic precipitators, much as coal ash is stripped from the flue gas emerging from coal combustors using electrostatic precipitators. ${ }^{94}$ The gamma intensity and spectrum of the deposited particulate layer would then serve as an indicator of FP leakage. Iodine-131 and ${ }^{133} \mathrm{Xe}$ will both circulate as gases in the primary coolant. The ${ }^{133} \mathrm{Xe}$ will be trapped in the cold trap of the helium cleanup system. The ${ }^{131} \mathrm{I}$ will tend to plate out on the cold surfaces. However, the boiling point of iodine is only $184.3^{\circ} \mathrm{C}$. Consequently, a significant amount of the iodine will evaporate and circulate. Iodine will also be removed by the cold traps in the helium cleanup system. Measuring the radionuclide content of the helium cleanup system cold trap is, thus, a measure of the fuel failure fraction.

Cesium, which has a higher vapor pressure than most other FPs, would preferentially transport in vapor phase. The boiling point of cesium is $671^{\circ} \mathrm{C}$. Consequently, the cesium would tend to plate out either in the colder sections of the SG or in the cold leg. Performing gamma detection and spectroscopy on the inlet section of the cold leg would provide an indication of the amount of cesium leakage from the fuel. The cesium may form a friable layer on the surface of the cold leg and, thus, be releasable during a severe depressurization accident. Consequently, measurement of the cesium concentration plated onto the cold leg would be a useful measurement of whether the coolant contains an unacceptable level of contamination.

\subsection{DUST DIAGNOSTICS}

An earlier report ${ }^{1}$ summarized the dust measurement issues in HTGRs (primarily PBRs), noting that from a safety standpoint, the concern is mainly about how much contaminated dust would be released to the environment in rapid D-LOFC accidents. For low-pressure containment designs, a rapid discharge of the primary helium would exit the building unfiltered, and subsequent discharges would pass through filters before exiting.

Recently a comprehensive assessment of the dust problem took place at the Very High Temperature Reactor Dust Assessment Meeting held in Rockville, Maryland. The objective was to identify and prioritize the phenomena and issues that characterize the effect of carbonaceous dust on high-temperature reactor safety. ${ }^{95}$ The major R\&D needs were identified as (1) generating adsorption isotherms for fission products that display an affinity for dust, (2) investigating the formation and properties of carbonaceous crust on the inside of high-temperature reactor coolant pipes, and (3) confirming that the predominant source of dust is the abrasion between fuel spheres and the fuel handling system (for PBRs).

A major effort addressing the dust problem is also taking place in Europe. The study is being done as part of the RAPHAEL project. ${ }^{96}$ The T/H code SPECTRA is used to model the dust behavior, and $200 \mathrm{~kg}$ was estimated as the primary system inventory in PBMR after 40 years of operation. The graphite dust generated in an HTR/PBMR during normal reactor operation would be deposited inside the primary system and become radioactive from the sorption of fission products. Doses were predicted to be strong functions of particle size distributions, with most deposition occurring in the recuperator (hot side) and with higher doses for smaller particle sizes. 



\section{TRISO FUEL MANUFACTURING I\&C NEEDS}

This section was extracted from an NRC PIRT study on TRISO fuel. ${ }^{97}$ The purpose of this section is to establish a case that instrumentation and control of the TRISO fuel manufacturing process deserves licensing scrutiny at a level comparable to that given I\&C systems involved in reactor operation.

Table 1 summarizes the major TRISO fuel manufacturing process issues, as identified by the PIRT panel members, and Fig. 19 shows the steps involved in a continuous coating process.

Table 1. Manufacturing process phenomena identified by the PIRT panel

\begin{tabular}{|c|c|}
\hline Manufacturing factor & Rationale \\
\hline \multicolumn{2}{|l|}{$\begin{array}{l}\text { Layer coating process } \\
\text { specifications: }\end{array}$} \\
\hline $\begin{array}{l}\text { Gases (levitation gas and } \\
\text { coating gas) }\end{array}$ & $\begin{array}{l}\text { The gases used in the coater directly influence the quality of the layer and the } \\
\text { operation of the coater }\end{array}$ \\
\hline Ratio of gases & The gas mixtures affect the layer properties and production rate \\
\hline Temperature & The properties of the coating layer are dependent on the coater temperature \\
\hline Coating rate & The microstructure of the coating layer is influenced by the coating rate \\
\hline Pressure & $\begin{array}{l}\text { Pressure affects reaction rates. The coaters are generally operated at atmospheric } \\
\text { pressure }\end{array}$ \\
\hline Coater size & Coater size affects the distribution of layer properties \\
\hline Layer coating process & Continuous vs interrupted coating may affect coating layer interface properties \\
\hline Process control & $\begin{array}{l}\text { Controlling the process is important. Coating product measurements may not be } \\
\text { sufficient to guarantee good irradiation performance }\end{array}$ \\
\hline Product control & Coatings must meet designer specifications \\
\hline
\end{tabular}

The coating layers are deposited on the kernel in a fluidized bed by the thermal cracking of the appropriate gas in a fluidizing gas such as argon. Hydrocarbon gases such as acetylene and propylene are used for the carbon layers. Methyl Trichloro Silane is used for the SiC layer, and it is reduced by hydrogen. Temperatures are in the range $1200-1500^{\circ} \mathrm{C}$, and the flow rates of the gases are adjusted to achieve the desired deposition rate.

Layer properties are controlled by temperature, coating rate, coating gas composition, bed loading, and particle size. In general, each layer has its own optimal combination of parameters that are determined experimentally for a particular coater. The process may be continuous or interrupted. In the continuous process, the particles remain in the coater and the composition of the gases and furnace temperature is changed so the coatings can be applied one after another. In the interrupted process, the coater is unloaded after each coating, and the particles can be checked and sorted for gross defects such as out-of-roundness. Sampling can be used for destructive investigation. The bad particles (or a bad batch) are discarded before the next layer is applied. 


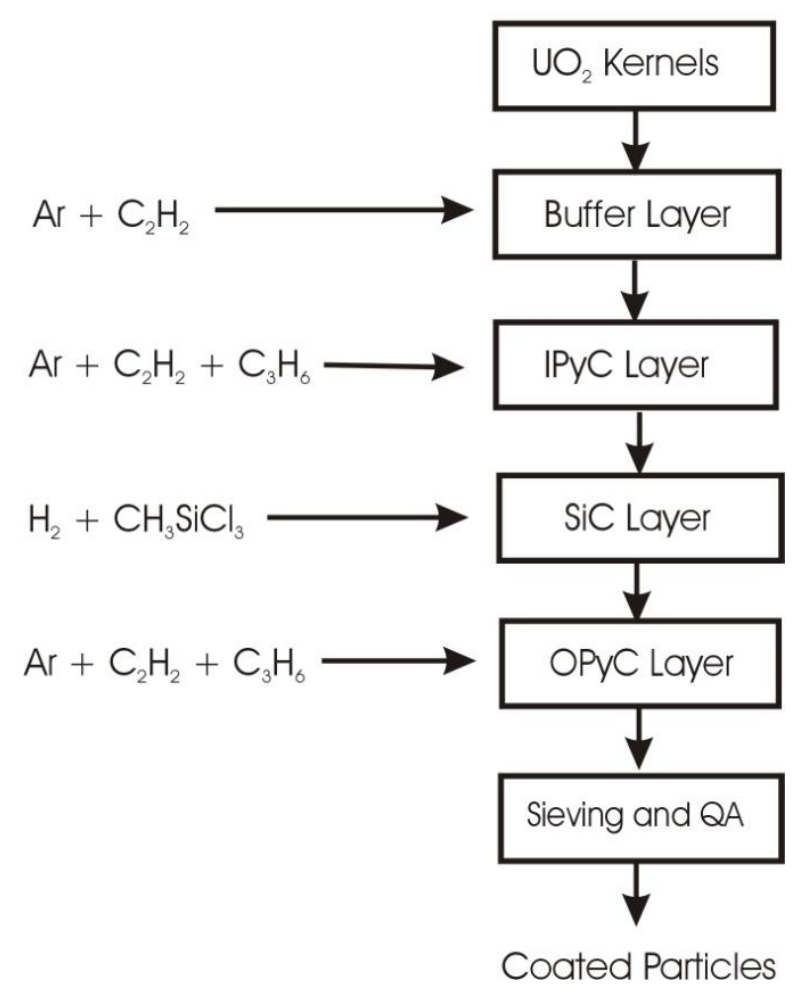

Fig. 19. Flow diagram of the continuous coating process.

At the present time, the continuous coating method has been demonstrated to give acceptable results, but this conclusion is still tentative. The current trend is toward continuous coating, and the highest quality fuel (reference material) has been produced by this method.

An item of interest from the PIRT review is that the specification of layer product properties is not sufficient to ensure satisfactory irradiation performance. At the present state of the art, modest changes in the operation of the coater (such as design issues, coater size, and exactly where the bed temperature is measured) can lead to coating property changes that could result in substandard irradiation performance. These changes either cannot be observed by the present quality control (QC) methods or the changes in material properties are not currently measured.

The integrated manufacturing QC issue is addressed by having both a layer fabrication process and a layer product specification. Thus, both process knowledge and product measurements are required to determine if the fuel has been properly fabricated. This issue appears to be particularly important for pyrocarbon. The Bacon anisotropy factor (BAF) measurement technique is also important. The SiC layer is very important for the control of fission product transport, and it is sensitive to the details of the fluidized bed coater operation.

Figure 20 shows how the nature of deposited $\mathrm{SiC}$ can change with temperature. The fabricator would like to control free silicon, grain size, and grain orientation. SiC has shown good irradiation properties, but like pryocarbon, a clear one-to-one correlation between measured properties and irradiation behavior is not available at present. 


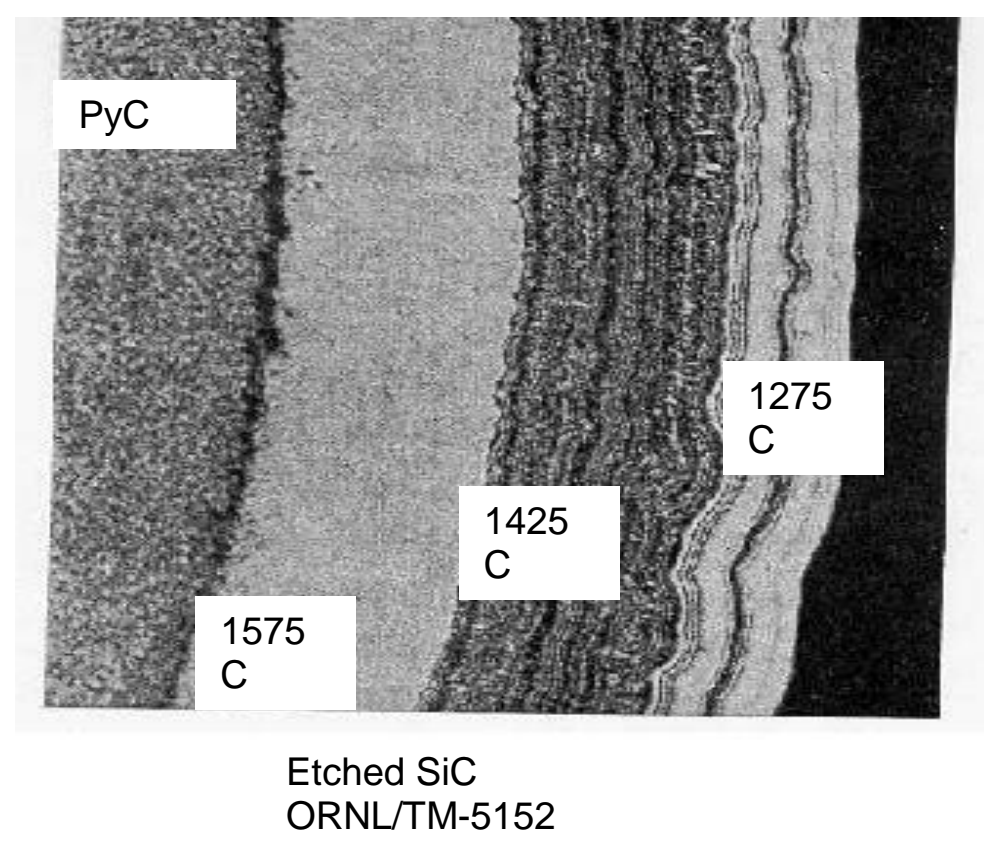

Fig. 20. SiC structure as a function of coater temperature.

Table 2 shows the coating layer product properties measured during fabrication and the measurement methods that are typically employed. The reader is cautioned that measurements alone do not provide a complete picture of the fabrication parameters and must be used in conjunction with process knowledge.

In summary, precise and reliable measurements and control processes during the coating processes in the fluidized bed coaters are crucial to the "success" of the fuel in terms of its performance (retention of fission products) during normal reactor operation and postulated accident conditions. 
Table 2. Coating layer product factors and typical QC methods

\begin{tabular}{ll}
\hline \multicolumn{1}{c}{ Layer attribute } & \multicolumn{1}{c}{ QC method } \\
\hline Thickness & Buffer layer \\
Density & Radiography, metallography \\
$\begin{array}{l}\text { Missing or thin layer (a failure } \\
\text { mechanism) }\end{array}$ & Mercury pycnometry and carbon content analysis (LECO) \\
\hline & Radiography \\
\hline Thickness & IPyC layer \\
Density & Radiography, metallography \\
Anisotropy & Liquid gradient column \\
Microstructure & BAF (other methods under study) \\
& Coating rate and process conditions (temperature, coating \\
Permeability (the heavy metal & gases, time) [Process Knowledge] \\
dispersion will signal a missing layer) & Heavy metal dispersion into layers (radiography, chemical \\
& analysis) \\
\hline Thickness & SiC Layer \\
Density & Radiography, metallography \\
Microstructure & Liquid gradient column \\
Spatial defects or missing layer & Coating rate and process conditions (temperature, coating \\
Strength & gases, time) [Process Knowledge], metallography \\
& Burn/leach \\
\hline Thickness & Crush tests, brittle ring tests \\
Density & OPyC Layer \\
Anisotropy & Radiography, metallography \\
Microstructure & Coating weight and pycnometry \\
Missing or defective layer & BAF \\
Surface connected porosity & Coating rate and process conditions (temperature, coating \\
\hline & gases, time) [Process Knowledge] \\
\hline & Optical microscopy \\
& Mercury porosimetry \\
\hline & \\
\hline &
\end{tabular}




\section{HEAT TRANSPORT SYSTEM INSTRUMENTATION}

\subsection{INTRODUCTION}

A major NGNP design goal is to produce high-temperature process heat, as well as electricity, for nearby chemical plants. Because high-temperature heat can be transported only limited distances, the two plants will, of necessity, be relatively close to each other but with enough separation distance to minimize potential damage emanating from either one to affect the other. Typical separation distances are in the order of $500 \mathrm{~m}$. In these deployment scenarios, the reactor could be located at the site of large chemical or petrochemical processing plants. The industrial process heat plants present potential physical hazards to the reactor heat transfer components because of the required process coupling. Additionally, the physical security requirements for nuclear power reactors are significantly greater than for other industrial plants. Both the potential physical hazard to the reactor and the desired security boundary around the reactor provide incentives for maximizing the physical separation between the reactor and the heat-consuming plant.

For an NGNP design, it is possible that a relatively small fraction of the heat produced will be used for producing hydrogen or other chemicals, with most of the heat used to produce electricity. In contrast, for a commercial HTGR, almost all of the heat might be used for chemical production. Since the local chemical inventory determines the potential hazard to the nuclear plant from a chemical plant, the NGNP chemical plant may present much less of a hazard than a commercial system. The NGNP as a demonstration reactor may be connected to multiple generations of hydrogen production or other chemical production systems. Consequently, the safety analysis at this point needs to envelope the safety implications of a variety of the different technologies.

The primary safety tenets for accidental releases at nuclear and chemical plants are almost entirely opposite. A basic design criterion at a nuclear plant is to contain radioactive material under all conditions. At chemical and petrochemical plants, in contrast, unplanned releases are often vented to the atmosphere (or flared if combustible) to disperse the chemicals to below harmful concentrations. The site layout and major structural elements of chemical and nuclear plants reflect these divergent philosophies. Nuclear plants are contained within strong structures, while chemical plants are frequently built outdoors to prevent trapping and hold-up of toxic or combustible materials.

The regulatory structures governing nuclear and chemical plants are very different. Nuclear plants are bound by NRC rules, whereas chemical plants are governed by a combination of Environmental Protection Agency (EPA), Occupational Safety and Health Administration (OSHA), and state rules. Additionally, becoming an owner of a nuclear power plant would represent a significant increase in responsibility for a chemical company. Consequently, an HTGR, even though proximately located with and interconnected to a chemical plant, may have a different ownership.

Given the differences between the nuclear and chemical plants, the NGNP and its hydrogen plant are most logically viewed as separate entities (i.e., the chemical process plant would be most effectively treated not as an extension of the nuclear plant but as an external facility that can impact reactor operation). In this scenario, accidents such as chemical releases would be treated as external events to the reactor.

\subsection{PROCESS HEAT PLANT INTERFACE AND HEAT TRANSFER LOOP DESCRIPTION}

The intermediate heat transfer loop transfers energy from hot primary helium to the nearby chemical plant. The required separation distance such that an accident or incident at one plant does not adversely 
impact the other plant has not yet been established. The type of chemical plant and the heat transfer medium interconnecting the two plants are also not specified. Both high-pressure vapor-phase loops (steam and helium) as well as low-pressure liquid-phase loops (fluoride salts, chloride salts, sodium, lead, and lead-bismuth) are candidate systems for heat transfer.

The efficiency, technological difficulty, and expense of transporting heat vary greatly with the heat transfer medium selected. Helium and steam heat transfer loops have substantial industrial pedigrees and may be the initial technology selected for the NGNP because of the lower development requirements. Vapor-phase systems, however, contain much less energy per unit volume. Consequently, vapor-phase systems require much higher flow velocities, larger pipes, and higher system pressures to transfer the same amount of heat as a liquid system. The combination of high flow velocity and high pressure increases the pressure drop per unit length of pipe, providing strong incentive to minimize the loop length. The expense of the much thicker pipe walls of high-temperature alloys required for high-pressure vaporphase loops also argues strongly in favor of minimizing the length of the loop.

Low-pressure liquid loops do not have large pressure drops over reasonable heat transfer loop distances $(<1 \mathrm{~km})$ at the flow velocities that would be required. The thinner pipe walls and smaller pipe diameters of low-pressure liquids also decrease the expense of longer loops. However, high-temperature liquidphase heat transport systems are not yet commercial items, and some development risk accrues with any of the liquid-phase coolants noted. Also, all of the liquid-phase heat transfer materials are solids at ambient temperature. Thus, a loop preheating system would be required. Further, especially at higher temperatures, all of the liquids can be corrosive, necessitating unconventional alloys and strict attention to fluid chemistry control. Overall, a fluoride salt heat transfer loop appears to be the most technologically appealing loop over the longer term with the proviso that the supporting technologies for liquid-fluoridesalt-based heat transfer are less well proven than those for either helium or steam.

A number of trade studies on options for connecting a heat transport system to an NGNP for the purpose of producing hydrogen (or potentially for another high-temperature process heat application) have been performed..$^{98}$ In the reference, seven configuration options are identified, and a series of performance analyses was conducted. The selected configurations included both direct and indirect cycles for the production of electricity. All the options included an IHX to separate the operations and the safety functions of the nuclear and hydrogen plants. For the heat transport system that transfers heat from the reactor to a hydrogen production facility, both helium and liquid salts were considered as the working fluid.

In an option using an indirect electrical cycle, a process heat exchanger (PHX) is connected to a secondary heat exchanger (SHX), which is then connected to the IHX, as shown in Fig. 21. This configuration provides good separation between the nuclear island and the process facility. Because of additional components, this option requires the largest mass and the lowest thermodynamic efficiency, as expected. However, considerations such as operational flexibility and license acquisition may favor this option notwithstanding the increased cost and engineering complexity.

Another advantage of this configuration is the possibility of using a different working fluid for the power cycle. Design studies using supercritical $\mathrm{CO}_{2}\left(\mathrm{~S}_{-} \mathrm{CO}_{2}\right)$ indicate that these systems can deliver electricity with a high thermal efficiency. If the liquid salt heat transport loop is connected to a heat source in this configuration, the heat is transferred from the secondary fluid to the liquid salt via an SHX. 


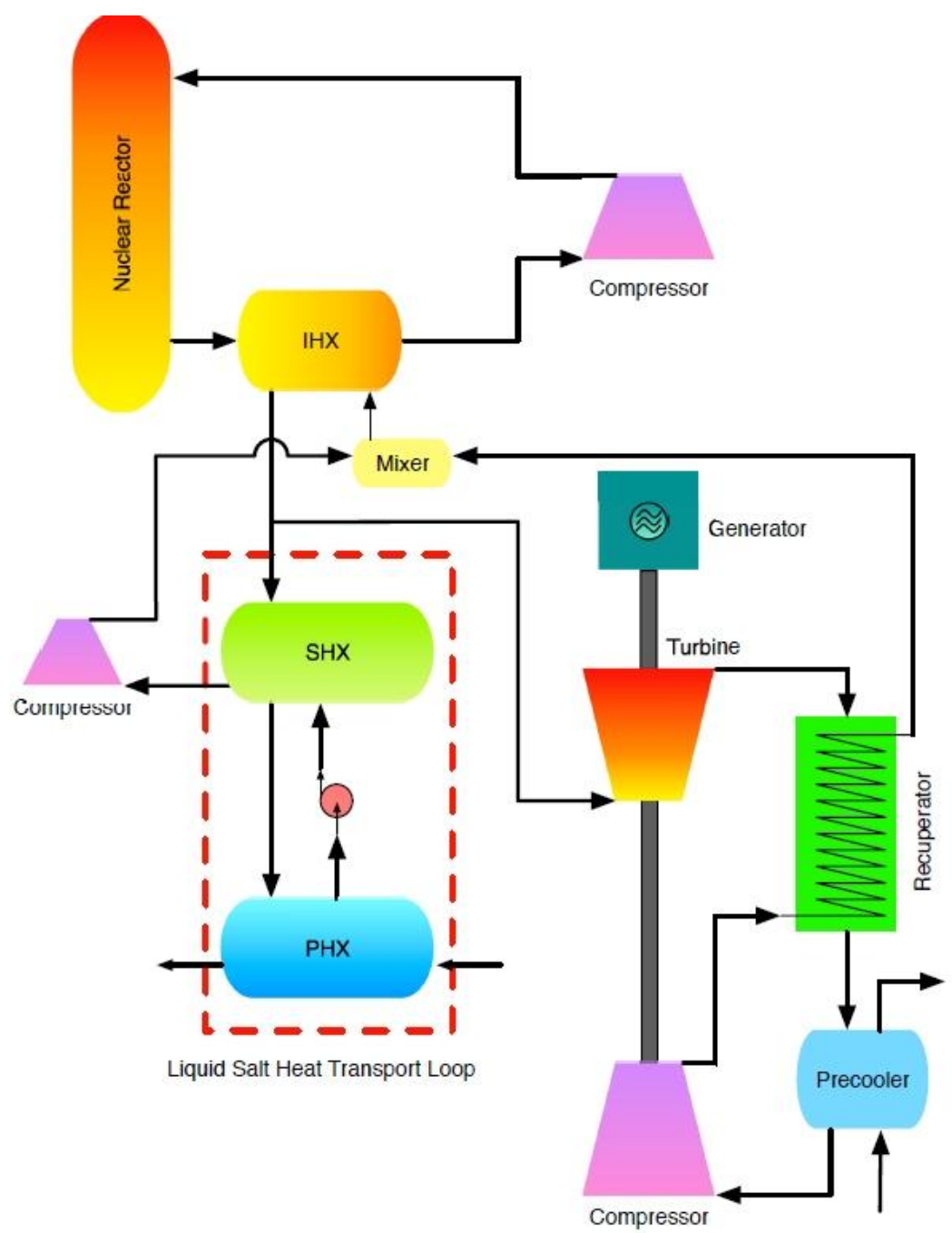

Fig. 21. Possible configuration option for a liquid-salt heat transfer loop-indirect electrical cycle and a parallel SHX.

\subsection{SAFETY ISSUES}

A recent phenomena identification and ranking tables (PIRT) report ${ }^{99}$ provides descriptions of safety issues relevant to interconnecting HTGRs with chemical plants. The discussion of accident scenarios included here is based upon those introduced in Ref. 99 with added emphasis on measurement and communication requirements.

Several technologies are candidates for hydrogen generation, and some use hot, high-pressure caustic fluids. Only reforming hydrogen from natural gas requires large volumes of high-chemical-energy fluid. If oxygen is produced along with the hydrogen (i.e., from high-temperature electrolysis) and stored on site, the oxygen also represents a potential explosion hazard. However, if both natural gas and oxygen were to disperse in the atmosphere, the explosion hazard would be local to the chemical plant. Hydrogen itself is also combustible but disperses readily, rising into the atmosphere. Hydrogen is difficult to bring into a combustible mixture with oxygen outside a confined space, thus the hydrogen presents negligible hazard outside the chemical plant. 
Some of the potential chemical processes at an HTGR-coupled chemical plant involve heavy gases that can form ground-hugging plumes upon release. Oxygen released from storage can also form a hazardous plume before dispersing. The heavy gases can be both toxic and caustic and present a hazard to personnel at the adjacent nuclear plant.

HTGRs have a high-pressure helium primary loop operating at high temperature. The lowest cost, most energy efficient heat transport loops from the HTGR primary to a nearby chemical plant employ lowpressure liquids as the heat transfer medium. Minimizing heat exchange surface thickness (tube wall thickness in a shell and tube heat exchanger) is a key heat transfer efficiency goal. In addition to temperature and pressure stressors, the high-temperature heat transfer surface will have different chemical environments and, consequently, corrosion potentials on opposing sides. Thus, heat transfer surface rupture represents a potential primary system failure mode.

If the NGNP elects to employ a high-pressure helium or steam intermediate heat transfer medium, the pressure drop across the heat exchanger will be less as compared to a low-pressure liquid under normal mode operation, enabling thinner walls. If, however, either the primary or secondary systems decrease in pressure, the heat exchanger walls could then be subjected to a large pressure differential, potentially rupturing the thinner walls.

Rupturing the primary boundary is a loss-of-cooling accident, a means for radioactivity to leave controlled space, and a potential means for nonintended fluids to enter the reactor core. Steam is a particular hazard as it can cause a positive reactivity input and will react with the core graphite at high temperatures. None of the potential low-pressure heat transfer fluids-fluoride or chloride salts, sodium, lead, or lead-bismuth - would provide significant reactivity additions to the core or are normally at high pressures that would enable transport into the core.

If the secondary heat exchanger at the chemical plant were to fail, the intermediate heat transfer loop could undergo rapid unplanned emptying (blowdown). Blowing down the heat transfer loop would remove the heat sink from the reactor, providing a stressor to primary components normally at lower temperatures.

The heat transfer fluids themselves can represent physical and chemical hazards. Rupture of the intermediate loop, if the fluid is at high pressure, represents the largest physical hazard. Hot sodium reacts violently with water. Rupturing a large, pumped, high-temperature sodium loop thus represents a significant thermal and chemical hazard to the immediate surroundings. Hot fluids have significant stored thermal energies. A pumped or pressure-driven spray of heat transfer fluid thus represents a local personnel hazard.

Liquid heat transfer lines require connection to an expansion volume to avoid pressure spikes. If the interconnection between the expansion volume and the loop were to become clogged, large pressure transients could occur in the normally low-pressure loop. Pressure relief mechanisms (e.g., rupture disks) are employed to mitigate the pressure transient hazard.

High-pressure heat transfer loops have significant stored potential energy. Rupture of any high-pressure variant of the intermediate heat transfer loop can potentially result in a missile impacting reactor structures. The pipe chase between the chemical plant and nuclear plant represents a potential intrusion route through the nuclear plant security boundary. Thus, a dual-purpose missile shield and intrusion prevention boundary is a necessary part of the loop design.

\subsection{MEASUREMENT AND INFORMATION ISSUES}

Under normal operating conditions the primary information transferred from the chemical plant to the nuclear plant operators is the heat demand. While HTGRs are naturally load following, receiving a load request signal enables a more rapid nuclear plant response that minimizes temperature-temporal variances 
and thereby decreases stress on the plant equipment. An erroneous load demand signal will result in increased stress on the plant equipment as the reactor thermal feedback adjusts to the actual load.

Loss of heat sink (e.g., from blowdown of the intermediate heat transfer loop) is functionally similar to an erroneous load request. The combination of temperature and flow in the intermediate heat transfer loop provides confirmation of proper heat transfer. The temperature and flow signals would not be required to be safety grade as a loss of heat sink is not an initiator of radiation release in a passively safe plant.

Under chemical plant severe accident conditions, a ground-hugging chemical plume can approach the nuclear plant. Air intake and upstream chemical environmental monitoring signals are thus necessary to ensure that the nuclear control room is isolated from any airborne chemical contamination and to provide warning to plant personnel of the hazardous conditions. As control room environmental isolation is an active response, confirmation of the isolation (typically by differential pressure monitoring across the one-way air valve) is also required.

Pressure mismatch across the heat exchanger would be a safety-grade measurement for designs in which the heat exchanger heat transfer surface thickness has been decreased. For example, in a high-pressure helium to high-pressure steam heat exchanger, loss of steam will increase the differential pressure across the heat exchange surface. If the heat exchange surface has not been designed to take full primary system pressure, the differential pressure transient may lead to primary pressure boundary rupture.

An expansion tank needs to be provided in an incompressible fluid-based heat transfer loop. If the interconnection between the tank and the loop becomes blocked, the loop becomes vulnerable to pressure spikes and consequent mechanical failures. Liquid level measurement within the expansion tank of sufficient precision to observe normal liquid level shifts and, thereby, avoid stuck indicator errors is required to confirm flow.

As all of the candidate liquid heat transfer media have freezing points well above ambient, an expansion tank vulnerability would be the freezing up of the tank and/or the interconnecting piping. Tank and interconnection line temperature measurements are thus also necessary. A tank and loop heating system will also be necessary prior to loop filling or for longer-term reactor shutdown conditions if undrained. The expansion tank is also likely to include the gas vent employed during loop filling and the backpressure gas source to empty the loop for maintenance. As the gas connection port is a potential vent under accident conditions, both flow and radiation measurements will be necessary on the gas line interconnection.

Corrosion occurs more rapidly at higher temperatures. Structural measurements of the heat transfer surface between the primary and secondary fluids need to be performed sufficiently regularly so as to ensure that the material strength has not been compromised. In particular, if the pressure boundary includes an anticorrosion cladding, the integrity and bonding of the cladding needs to be ensured. The heat transfer media become much more corrosive under improperly maintained chemical conditions. For example, the fluorine potential (and corrosivity) of fluoride salt loops increases several fold if an electronegative impurity such as oxygen from environmental water is permitted to contaminate the system. Thus, high-quality monitoring of the intermediate loop chemical condition is required.

A leak of hydrogenous material into the core is the most hazardous accident identified for an HTGR. Large-scale water leakage into the core is only a significant concern for those designs that include a primary loop SG or a steam/water-based heat transfer loop. In addition to periodic corrosion surveillance measurements, safety-grade water ingress measurements need to be provided for in the primary loop. Additionally, acoustic monitoring of the IHX would be a useful diverse measurement to confirm the leak existence and to diagnose its size.

The piping chase between the nuclear and chemical plant represents an intrusion path into the nuclear plant. The pipe chase needs to be in the plant security plan and include intrusion monitoring. A physical barrier within the pipe chase would be a useful adjunct to the intrusion monitoring. 


\subsection{STEAM INSTRUMENTATION}

A water-steam heat transport loop would have many of the same features as a PWR secondary side or a fossil-fuel boiler - hence, most of the required steam instrumentation would not be distinctive, and much of the relevant information could be obtained from standard overviews of steam cycle instrumentation and control such as that available in a comprehensive book by Lindsey. ${ }^{100}$

Some of the recent NGNP candidate designs, however, are focusing on SG designs such as those developed by General Atomics (GA) in the 1980s and shortly thereafter. Of those, the direct cycle (SG in the primary loop) versions are also being favored for a number of reasons, but mainly because they would avoid the problems associated with development, cost, and operation of an IHX. ${ }^{101}$ For electrical production, these Rankine direct cycle designs have the potential for significant improvements in efficiency ( 20\%) over LWRs on account of the higher steam temperatures (Fig. 22), so their development is well-warranted for both process heat and electrical production applications.

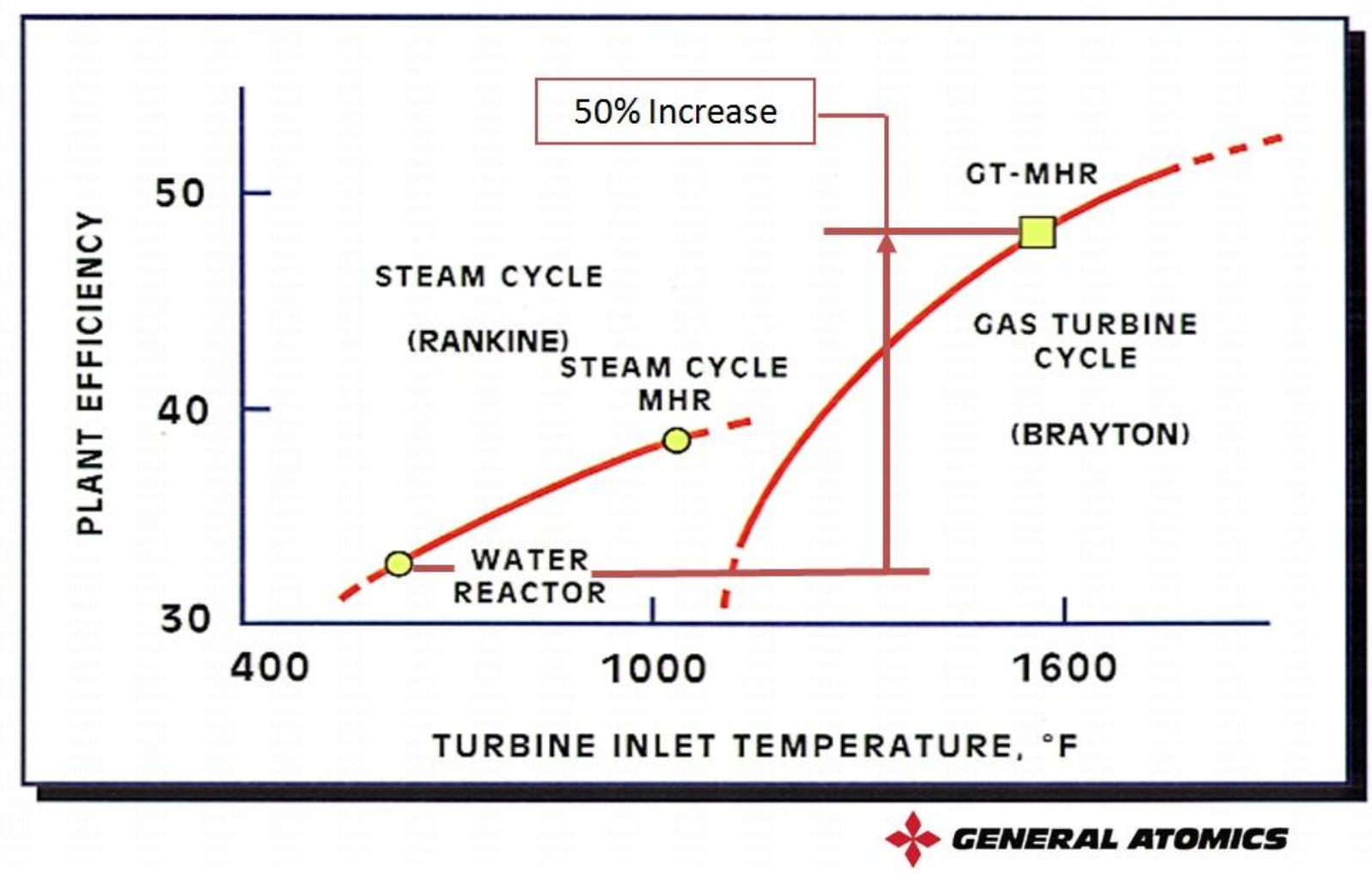

Fig. 22. Electrical production efficiency as a function of turbine inlet temperature.

There are several variations of the higher-temperature SG designs, but a typical feature is the hightemperature section needed to produce the final steam outlet temperature, which requires special hightemperature materials. An example design is shown in Fig. 23. 


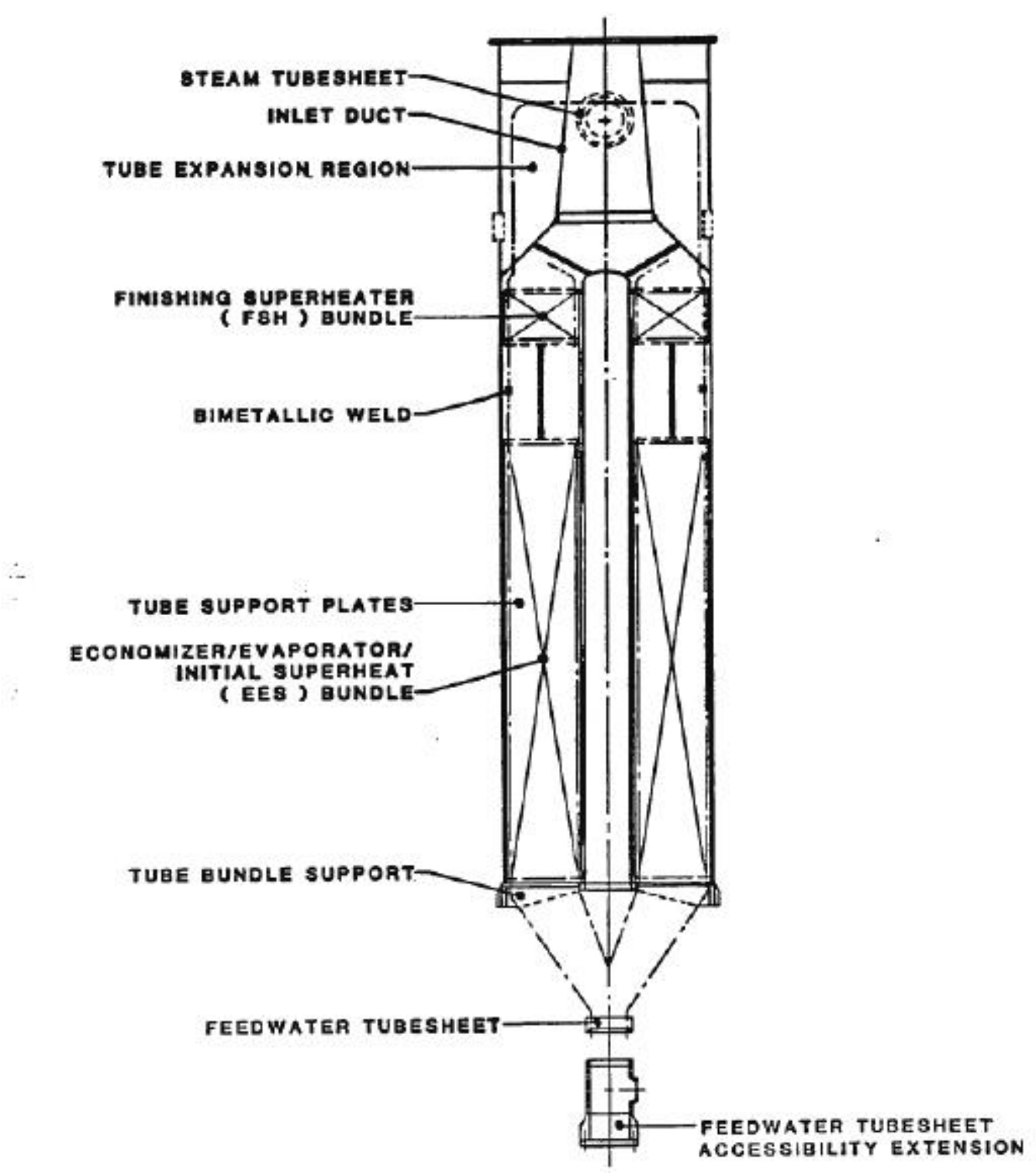

Fig. 23. Typical once-through steam generator employing a finishing superheater section. ${ }^{101}$

The SG is a vertically oriented, up-flow-boiling, cross-counter-flowing, once-through shell-and-tube heat exchanger that utilizes multiple-tube, helically wound tube bundles. The design shown employs two sets of bundles, where the lower bundle contains economizer, evaporator, and initial superheater sections using $2 \frac{1}{4} \mathrm{Cr}-1$ Mo material for the tubing. The upper bundle that contains a finishing superheater section uses the higher temperature Inconel 617 material. A bimetallic weld located between the two bundles is required to join the two dissimilar tube materials.

Locating the SG in the primary circuit raises a number of safety concerns that impact the I\&C requirements. The major concern is for water/steam ingress into the primary coolant system because the secondary (water) side operating pressure is much greater than the helium coolant pressure. Steam contacting the hot core has a number of adverse effects, including positive reactivity insertion and corrosion of the graphite as a result of $\mathrm{CO}, \mathrm{CO}_{2}$, and $\mathrm{CH}_{4}$ production. A detailed analysis of these issues ${ }^{102}$ was generated for the reference steam-cycle modular helium reactor (SC-MHR) plant. Regarding 
moisture ingress into the primary coolant system from SG leakage, the GA analysis predicted that, while a concern, as long as the prescribed corrective actions are taken, it is not expected to result in unacceptable average or localized oxidation of either the bulk core moderator graphite or the graphite core support components, and leakage is not expected to result in radionuclide releases in excess of regulatory limits.

The alternative (i.e., placement of the SG in a secondary loop connected to the nuclear heat source through an IHX) would eliminate most issues associated with moisture ingress into the core; however, there are also safety-related and other issues associated with including an IHX in the primary circuit:

1. The probability of a major pressure difference developing between the primary and secondary sections of an IHX. Either the IHX would have to be designed as a Class I primary pressure boundary component, or the secondary system must contain Class I isolation valves near the IHX, or the secondary system must be designed as the primary pressure boundary.

2. Loss of secondary helium flow without tripping the primary helium flow would result in rapid IHX heat-up with possible damage to the IHX internals.

3. There is uncertainty that an IHX can be designed as a Class 1 component having a reasonable lifetime, taking into account the creep fatigue damage caused by occasional high-pressure differentials at the high operating temperatures.

4. It is not certain that suitable isolation valves could be developed. No suitable designs of largesize, high-temperature helium leak-tight valves are currently available.

A reactor protection system (including a related investment protection system) would have a number of features related to steam production:

1. Detect and provide corrective action if the moisture level in the primary circuit indicated steam inleakage. In the case of multiple SGs in the loop, the moisture sensing system must be able to determine which SG is leaking and initiate SG isolation and dump on the appropriate module.

2. Detect and provide corrective action if changes in the reactor building (including changes in temperature, pressure, and radiation levels) indicate the presence of primary coolant or steam at levels that could potentially expose the general public to low-level radiation effects.

3. Detect and provide corrective action if conditions of pressure, temperature, or flow indicate an interruption of normal cooling functions or steam leakages.

4. Detect and provide corrective action if conditions of pressure and temperature, within and around the vessel system (VS) primary coolant boundary, indicate a level of operation that exceeds the normal VS design levels.

5. Detect and provide corrective action if conditions of environment or service to the reactor system indicate potential interruption of processes necessary to protect the reactor (e.g., non-1E electric systems) and are not suited for a particular environmental event.

Figure 24 (from Ref. 101) shows typical system protection logic for the case where the SG is in the primary system. Of particular note are the SG isolation and dump and reactor building isolation functions. 


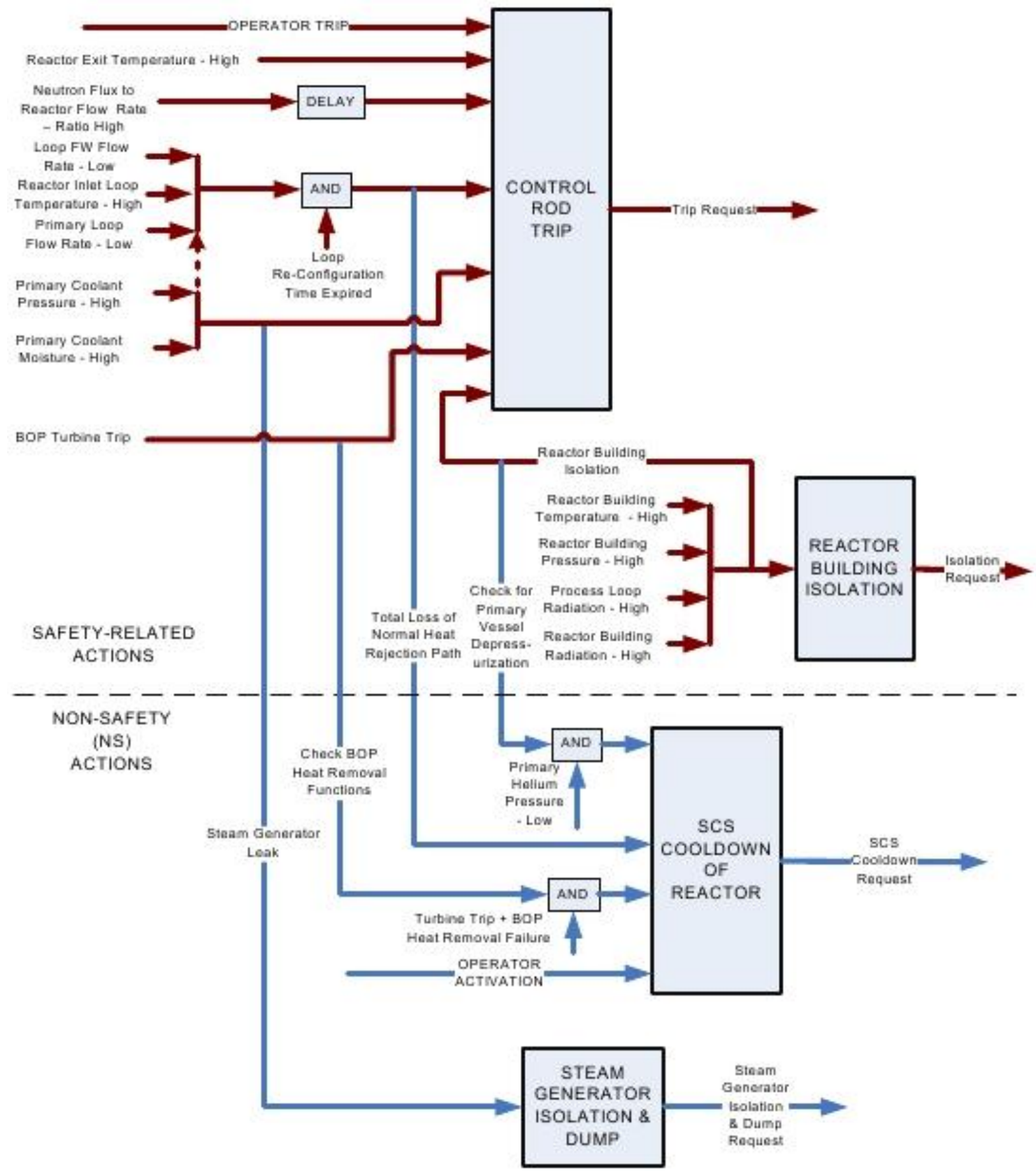

Fig. 24. Integration of steam related protection systems—steam generator in primary loop. 


\subsection{LIQUID SALT LOOP}

\subsubsection{Liquid salt system description}

Functionally, all heat transfer loops consist of a heat source, a heat sink, and a heat-transfer mechanism. A typical liquid salt heat transfer (LSHT) loop, consisting of a single-phase, incompressible liquid coolant, is required to have an expansion volume to prevent pressure spikes. A drain tank is also necessary to enable initial filling and to allow for servicing. Since the fluoride salts have melt points well above ambient loop, preheating is also required. Further, chemistry control is required since fluoride salts only maintain their relatively inert nature when the free fluorine potential is minimized. Further, since a primary purpose for an LSHT loop is to physically separate two energetic processes (possibly at high pressure), sufficient physical loop length is required to prevent severe accidents (blast wave, fire, caustic chemicals) from propagating between the heat source and heat sink processes, and pressure relief mechanisms are required to prevent the liquid salt itself from propagating the accident. Additionally, nuclear security requirements will necessitate either applying nuclear power level security to the heat sink process plant or providing sufficient distance between the reactor and the process plant to incorporate a security boundary. A summary of LSHT technology is available in an ORNL overview report. ${ }^{103}$

\subsubsection{Liquid salt loop instrumentation}

LSHT loop operations require measurement of a broad set of process variables including temperature, flow, and level. Coolant chemistry measurements (as a corrosion indicator) and component health monitoring are also important for longer-term operation.

\subsubsection{Temperature}

Temperature measurement is both indicative of process conditions and a primary component of the energy transfer measurements necessary for efficient power plant operation. Thermocouples are the most common transducer for process temperature measurement. However, base metal thermocouples lack the long-term accuracy necessary for the heat balance measurements required for efficient process operation. Precious metal thermocouples are a possible higher accuracy temperature measurement alternative. Alternatively, two optical instruments potentially have the stability and accuracy required to characterize the heat transfer with low enough uncertainty to maximize efficiency. Both fiber optic coupled pyrometry and Fizeau cavity-type thermometers are candidate technologies for high-accuracy temperature measurement. Ultrasonic wireline thermometry is also a strong candidate technology for low-uncertainty temperature measurement at elevated temperatures.

Although the field of ultrasonic temperature measurement has many embodiments, a wireline pulse-echo ultrasonic sensor is especially applicable to aggressive environment temperature measurement owing to its rugged nature. Ultrasonic wireline thermometry has been demonstrated as early as the 1960s in nuclear applications within as severe an environment as molten corium. ${ }^{104} \mathrm{~A}$ review of the technology stressing nuclear power applications was published in 1972. ${ }^{105}$ More recently, Lynnworth provided a detailed overview of ultrasonic probe temperature sensors. ${ }^{106}$ Ultrasonic wireline thermometry is based upon the change in the velocity of sound within a wire with temperature (Fig. 25). The speed of sound in a wire varies with its elastic modulus and density as described in Eq. (1). 


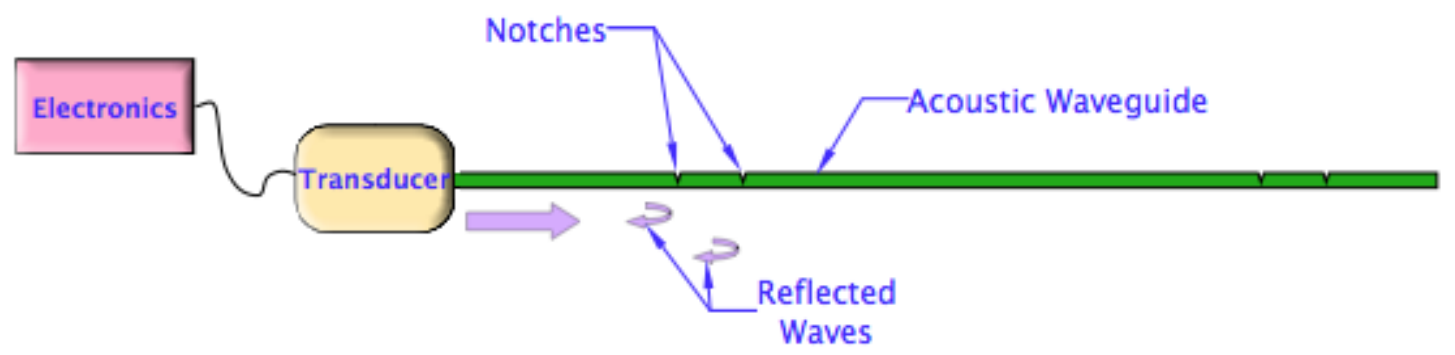

Fig. 25. An ultrasonic thermometry system including a notched waveguide.

$$
v(T)=\sqrt{\frac{Y(T)}{\rho(T)}}
$$

In Eq. (1), $Y(T)$ represents Young's modulus and $\rho(T)$ is the density of the waveguide, both being a function of local temperature. Although both parameters are temperature dependent, the temperature effect on elastic modulus dominates by about an order of magnitude over that of density, which causes sound velocity to decrease with increasing temperature.

Type N (Nicrosil-Nisil) thermocouples were developed in the 1970s and 1980s as a lower drift alternative to other base metal (particularly Type K) thermocouples. ${ }^{107,108}$ Having achieved designation as a standard thermocouple type by the Instrument Society of America in 1983, Type-N thermocouples have been in widespread use for more than 25 years. The Nicrosil and Nisil alloys composing Type $\mathrm{N}$ thermocouples were developed after the instability mechanisms of other base-metal thermocouples were understood, specifically to overcome these instabilities. Nicrosil and Nisil alloy compositions feature increased component solute concentrations (chromium and silicon) in the nickel base to transition from internal to surface modes of oxidation and include solutes (silicon and magnesium) that preferentially oxidize to form oxygen diffusion barriers. ${ }^{109}$

\subsubsection{Flow}

Liquid salt flow measurement will likely be performed with either external, ultrasonic flowmeters or Venturi-type flowmeters that use differential pressure gauges as their active element. Ultrasonic flowmeters are currently gaining wide acceptance in LWRs as a primary coolant flowmeter because of their low uncertainty and high stability. The high temperature of HTGRs requires the use of mechanical stand-offs to limit the ultrasonic transducer temperature exposure. The electronics for water and salt ultrasonic flowmeters would be essentially identical. The differential pressure gauges required for Venturi-base flow measurement require either diaphragm deflection measurement tolerant of NGNP temperatures or impulse line interconnection between a high-temperature and a low-temperature diaphragm, which would be instrumented with conventional low-temperature diaphragm deflection technology. The impulse line fluid would be either a lower-melting-point fluid such as a lead-bismuth eutectic $(44.5 \% \mathrm{~Pb}-55.5 \% \mathrm{Bi})$ with a $123^{\circ} \mathrm{C}$ melting point or a lower-melting-point salt. Both optically and capacitively based diaphragm deflection measurements are strong candidates for direct, high-temperature implementation. These types of devices are commercially available with a specialized molten salt melt compatible diaphragm deflection-type pressure gauge that employs $\mathrm{NaK}$ (78\% potassium, 22\% sodium) impulse line isolation of the high-temperature diaphragm and offers diamond-like carbon diaphragm coating for good chemical compatibility with the salt. 


\subsubsection{Level}

Several technologies are available for salt level measurement in the surge tank. Bubbler-type level measurements based upon the pressure required for minimal flow in a vertical tube are commercially available technology. Also, radar-type level measurements based upon reflection off the top surface of the salt are commercially available. The radar gun and electronics would be located in a standpipe above the fluid well outside the high-temperature and high-radiation zones. Mechanical float-type level measurements can also be readily adapted to the salt loop by attaching a mechanical extension to a float on the surface of the salt. The mechanical extension would be configured such that it would extend into a nonmetallic standpipe above the vessel, enabling the position of the end of the mechanical extension to be determined magnetically. Heated lance-type level measurements within a salt-compatible sheath would also provide discrete position level measurement. ${ }^{110}$

\subsubsection{Salt chemistry}

Maintaining the relatively low corrosivity of fluoride salt is critically dependent on controlling its reduction-oxidation state. The instrumentation required to characterize the detailed chemical state of fluoride salt exists as laboratory-type instrumentation and is not readily available in an industrial format. Electrochemical measurements are the standard technique for monitoring the redox condition of salt components. Optical absorption spectroscopy is also a potentially useful methodology for identifying trace chemical constituents and their valence state. However, the hot salt is itself a broad-spectrum infrared emitter that makes isolating particular absorption lines challenging. Optical access to the salt is most readily provided through a standpipe above the salt containing an inert gas bubble; a noble metal mirror within the salt would provide the optical return path.

\subsubsection{Maturity evaluation}

Very little molten salt instrumentation is commercially available, and the longer-term reliability and drift performance of such sensors have not been established. In general, specialized high-temperature-tolerant, high-reliability transducers and the supporting electronics are only available as designs from the literature. A sufficient market has not existed for commercial vendors to establish and maintain sources of supply for the specialized instrumentation.

Fiber optic coupled pyrometry and Fizeau cavity-type thermometers are available commercially. The remaining issues with the technology are in the longer-term performance of the transducers under plant conditions and the stability and reliability of both the opto-electronics and their control logic. Ultrasonic wireline thermometry has been demonstrated repeatedly in harsh, nuclear environments. However, a highreliability commercial implementation does not currently exist.

Clamp-on, ultrasonic flow meters are a commercial technology in widespread use. High-temperature standoffs to implement the flow meter on very hot piping have been demonstrated in the past and can be ordered as a custom engineered component. However, as a custom component, the long-term reliability under engineering service conditions has not yet been established.

Type-N thermocouples are now widely commercially available at similar cost to other base metal thermocouples and with similar values of thermoelectric voltage output. As commercial nuclear power plants attempt to reduce the required instrumentation margins in their technical specifications, adoption of Type-N thermocouples as a general replacement for other (specifically Type-K) thermocouples should be anticipated.

Venturi flow meters require accurate differential pressure measurement. Pressure measurement is often implemented as a diaphragm deflection measurement. High-temperature-tolerant carbon-based ceramic pressure gauges are just entering the commercial market. ${ }^{111}$ Precious and refractory metal (or precious metal coated) diaphragms are also compatible with fluoride salts. The pressure-sensitive diaphragm can be implemented at the distal end of a small-diameter hollow tube. Optical fibers are commercially 
available with temperature ratings higher than the primary coolant temperatures of fluoride-salt-cooled high-temperature reactors. Interferometric methods are commercially available to measure diaphragm deflection at the distal end of an optical fiber. The central issue for the optical fiber coupled technique is to establish the long-term system reliability under actual service conditions. As an alternative to directly measuring the high-temperature diaphragm deflection, an incompressible fluid (such as NaK) can be employed to transfer the pressure from the high-temperature bellows, along an impulse line, to a lower temperature diaphragm whose deflection can be measured with well-proven technology.

Mechanical float, heated lance, bubbler, and radar-based level measurement technologies are all established commercial technologies. While custom implementations for a specific LSHT variant would be useful, liquid salt level measurement technology is mature. 



\section{SUMMARY AND CONCLUSIONS}

This report takes a broad view of the instrumentation systems for the modular HTGRs, characterizing them as nerve centers for implementing safe and efficient plant operation. To this end, the I\&C requirements, especially noting differences vs LWRs, are elaborated upon with background discussions of plant behavior for both normal and postulated accident conditions.

\subsection{INSTRUMENTATION R\&D AND SPECIAL DEVELOPMENT NEEDS}

For normal operation, the primary (essential) measurement is reactor thermal power and, unfortunately, there are usually no simple direct means of making that measurement in HTGRs. There are different requirements or components for steady state and transient power measurement. For the steady state, the usual means is to derive the power level from heat balance information, while for transients (which require rapid response measurements for protection systems), neutron detectors are used. While neutron detectors have sufficiently fast response, their output signals drift with time and are also affected by control rod motion. The typical means for correcting the neutron flux signal is to continually reset the gain coefficient(s) with a long-term (very slow response) heat balance signal.

The primary heat balance computed power signal, $P$, uses mass flow rate $w$, helium specific heat, $C_{p}$, and reactor inlet and outlet temperature difference, $\Delta T$, that is,

$$
P=w C_{p} \Delta T
$$

The specific heat of helium is essentially constant over the full operating (and accident) ranges of interest. Flow in most HTGR configurations is not easy to measure unless there is a (unlikely) long run of straight pipe incorporating a venturi meter. In the Fort St. Vrain reactor, helium flow was approximated by a calculation using the measured circulator speed, along with helium temperature and pressure at the circulator, and factoring in known circulator characteristics. Similar means are likely to be used in NGNP. Depending on the balance of plant configuration, secondary side heat balances can also be used to estimate power.

Helium temperatures are measured by thermocouples capable of withstanding high temperatures and radiation with minimal drift. Type-N thermocouples (nickel-chromium-silicon/nickel-silicon) are rated for temperatures up to $\sim 1200^{\circ} \mathrm{C}$ and are likely to be the best candidates. In general, they would be located in tough, durable, and nonvibrating thermal wells, which would purposely slow their response to filter out temperature fluctuation noise. Steps need to be taken to ensure that temperature measurements give an accurate "mixed mean" signal. Depending on the mixing and measurement distances from heating or cooling components, there can be significant biases and gradients within a pipe or vessel, and those gradients can also vary with changing conditions.

Reactor vessel coolant inlet and outlet temperatures being used for nuclear power $\Delta \mathrm{T}$ measurements would also include the power lost to the RCCS (and other losses within the reactor cavity), while a secondary side power measurement would not, of course. If the reactor "inlet" signal were derived from core inlet (upper plenum) measurements, the RCCS power would need to be factored in as well to obtain total nuclear power. Circulator power would also need to be considered in any heat balance calculation.

Regarding temperature measurement limits, the coolant temperature distributions at the core exit are expected to vary widely because of spatial variations in power and flow rate and also bypass flows that may be almost entirely unheated. Unless special means are used in pebble bed cores (without a central 
reflector) to flatten the radial power peaking, the spatial variations in core outlet temperatures for both the coolant and support structures would be expected to be especially large.

Another parameter of great interest is core fuel temperature, since fuel operating temperatures are important inputs to fuel performance models. There are no known direct means of measuring pebble fuel temperatures in situ, especially since with online refueling, the bed of pebbles is continually in motion (albeit very slow). Melt-wire measurements can be made in dummy graphite-only pebbles to determine after-the-fact maximum pebble temperatures, although the path and power/flow history of the pebbles would be unknown. Some in-core measurements were made on the prismatic fuel blocks in Fort St. Vrain, where an "instrument package" was temporarily substituted for a control rod for special testing.

Continuous measurements of RCCS power performance are also important, since assumption of the safety-grade RCCS capability to perform well in loss-of-cooling accidents is crucial to the safety case. Such a measurement can be difficult, depending somewhat on the design, since the RCCS cooling panels are spread out widely around the reactor cavity, and the spatial flow and temperature distributions in the panels would be expected to vary widely as well. RCCS performance can also be verified online to some extent by monitoring external reactor vessel temperature distributions. If the operating mode of the RCCS is forced flow instead of entirely passive, a means of validating RCCS performance in an accident mode (with natural circulation cooling) would need to be available for periodic testing during normal operation. These tests would require special procedures for testing, measurement, and analysis.

Other measurements that need further development and validation for conditions peculiar to NGNP would be continuous monitoring of primary system moisture and circulating activity (radioactivity and dust), and chemical conditions (helium, $\mathrm{CO}_{2}$ and $\mathrm{CO}$, moisture) in the reactor cavity and elsewhere in the reactor building. In the case of primary moisture measurements, if there is more than one SG in the loop, the detection would need to determine which SG module had the leak in order to initiate the proper isolation and dump process.

\subsection{SUMMARY OF IMPACTS OF INSTRUMENTATION FAILURES}

Results from the qualitative assessments of the safety implications of failures in key measurements during normal operation are summarized in Table 3. The impact ratings are the relative and "approximate" opinions of the authors. Additional background material for these concerns and judgments is contained in an NGNP gap analysis report, ${ }^{112}$ where the "gap" refers to the difference between what is needed and what is available.

Results for accident measurement needs are summarized in Table 4. As before, impact ratings are relative and the "approximate" opinions of the authors, with background material for the concerns available in Ref. 98.

Emphasis is put on new capabilities for measurements likely to be employed in an NGNP design, noting how these could be used along with online simulation analyses to learn more details of event consequences that would not otherwise be available. Such information would be very useful in guiding any potentially beneficial remedial action.

It can be concluded that the application of new and emerging instrumentation and networking systems can be beneficial to the safe operation of modular HTGRs with NGNP design features. 
Table 3. Summary of normal operation measurement aberration impacts

\begin{tabular}{|c|c|c|c|}
\hline $\begin{array}{c}\text { Parameter } \\
\text { measurement* }\end{array}$ & Comment & $\begin{array}{c}\text { Backup } \\
\text { measurement? }\end{array}$ & $\begin{array}{l}\text { Safety consideration } \\
\text { impact }(\mathrm{H}, \mathrm{M}, \mathrm{L}) \dagger\end{array}$ \\
\hline Fuel temperature & Calculated & None & $\begin{array}{l}\text { Fuel failure mechanisms } \\
\text { (H) }\end{array}$ \\
\hline $\begin{array}{l}\text { Coolant outlet } \\
\text { temperature }^{\mathrm{d}}\end{array}$ & $\begin{array}{l}\text { High-temperature drift, } \\
\text { fluctuations, bias }\end{array}$ & $\begin{array}{l}\text { Other heat balance } \\
\text { calculations }\end{array}$ & $\begin{array}{l}\text { In heat balance power } \\
\text { calculation. Operating } \\
\text { margin affected }(\mathrm{M})\end{array}$ \\
\hline Primary flow rate & Primary cooling & $\begin{array}{l}\text { Other heat balance } \\
\text { calculations }\end{array}$ & $\begin{array}{l}\text { In heat balance power } \\
\text { calculation. Operating } \\
\text { margin affected }(\mathrm{M})\end{array}$ \\
\hline Neutron, ${ }^{\mathrm{s}, \mathrm{d}}$ power level & $\begin{array}{l}\text { Fast response; ex-vessel } \\
\text { signal strength }\end{array}$ & Heat balance & Reactivity transients (M) \\
\hline Primary pressure & $\begin{array}{l}\text { Detect leakage, steam } \\
\text { ingress; big variations } \\
\text { normal for direct } \\
\text { Brayton cycle }\end{array}$ & $\begin{array}{l}\text { Moisture (for steam } \\
\text { ingress) }\end{array}$ & $\begin{array}{l}\text { Steam ingress }(\mathrm{H}) ; \\
\quad \text { depressurization }(\mathrm{M})\end{array}$ \\
\hline Primary moisture ${ }^{\mathrm{a}, \mathrm{f}}$ & $\begin{array}{l}\text { Detect steam ingress; } \\
\quad \text { maintain } \mathrm{O}_{2} \text { potential }\end{array}$ & $\begin{array}{l}\text { Pressure (for steam } \\
\text { ingress) }\end{array}$ & $\begin{array}{l}\text { Reactivity, graphite } \\
\text { corrosion, fuel failure } \\
\text { (if exposed) }(\mathrm{H})\end{array}$ \\
\hline Primary activity & Liftoff potential & Filters & Primary source term (M) \\
\hline $\begin{array}{l}\text { Circulating dust- } \\
\text { primary }^{\mathrm{a}}\end{array}$ & Escape potential & Filters & $\begin{array}{l}\text { A primary source term for } \\
\text { pebble bed }(\mathrm{H})\end{array}$ \\
\hline $\begin{array}{l}\text { Pebble burnup online } \\
\text { monitoring }\end{array}$ & $\begin{array}{l}\text { Decide to recycle or store } \\
\text { each discharged pebble }\end{array}$ & Reactivity balance & Minor effects (L) \\
\hline Vibration (quake) & Pebble bed compacting & Power level & Minor effects (L) \\
\hline $\begin{array}{l}\text { RCCS performance } \\
\text { monitoring }\end{array}$ & $\begin{array}{l}\text { Safety grade, ultimate } \\
\text { heat sink }\end{array}$ & Vessel temperatures & Slow response (L) \\
\hline Reactor cavity atmosphere & Helium leak & Pressure loss & Minor effects (L) \\
\hline
\end{tabular}

*Superscripts on parameters measured indicate sensor concerns: a, availability (or development) concerns; $d$, decalibrate/drift potential; f, failure concerns; s, signal strength concerns.

†Impact: H, high; M, medium; L, low. 
Table 4. Summary of accident scenario measurement aberration impacts

\begin{tabular}{|c|c|c|c|}
\hline $\begin{array}{c}\text { Parameter } \\
\text { measurement }\end{array}$ & Comment & $\begin{array}{c}\text { Backup } \\
\text { measurement }\end{array}$ & $\begin{array}{l}\text { Safety consideration } \\
\text { impact }(\mathrm{H}, \mathrm{M}, \mathrm{L})^{*}\end{array}$ \\
\hline Fuel temperature & Calculated & None & $\begin{array}{l}\text { Fuel failure mechanism } \\
\text { (H) }\end{array}$ \\
\hline $\begin{array}{l}\text { Coolant outlet } \\
\text { temperature }^{\mathrm{d}}\end{array}$ & $\begin{array}{l}\text { High-temperature drift, } \\
\text { fluctuations, bias }\end{array}$ & $\begin{array}{l}\text { Heat balance, overpower } \\
\text { detection }\end{array}$ & $\begin{array}{l}\text { In heat balance power } \\
\text { calculation (L) }\end{array}$ \\
\hline Primary flow rate & $\begin{array}{l}\text { Scram on low flow } \\
\text { (adaptations for direct } \\
\text { Brayton cycle) }\end{array}$ & Pressure & Trip signal (L) \\
\hline Neutron $^{\mathrm{s}, \mathrm{d}}$, power level & $\begin{array}{l}\text { Fast response; ex-vessel } \\
\text { signal strength }\end{array}$ & Heat balance & Reactivity transients (L) \\
\hline Primary pressure & $\begin{array}{l}\text { Detect D-LOFC, steam } \\
\text { ingress }\end{array}$ & $\begin{array}{l}\text { Moisture (for steam } \\
\text { ingress) }\end{array}$ & $\begin{array}{l}\text { Steam ingress }(M) ; \\
\quad \text { depressurization }(\mathrm{L})\end{array}$ \\
\hline Primary moisture ${ }^{\mathrm{a}, \mathrm{f}}$ & $\begin{array}{l}\text { Detect steam ingress for } \\
\text { major leaks }\end{array}$ & $\begin{array}{l}\text { Pressure (for steam } \\
\text { ingress) }\end{array}$ & $\begin{array}{l}\text { Reactivity, graphite } \\
\text { corrosion, fuel failure } \\
\text { (M) }\end{array}$ \\
\hline Primary activity & Liftoff potential D-LOFC & Filters & Primary source term $(\mathrm{H})$ \\
\hline $\begin{array}{l}\text { Circulating dust- } \\
\text { primary }^{\mathrm{a}}\end{array}$ & $\begin{array}{l}\text { Escape potential for } \\
\text { D-LOFC events }\end{array}$ & Filters & $\begin{array}{l}\text { A primary source term for } \\
\text { pebble bed }(\mathrm{H})\end{array}$ \\
\hline Vibration (quake) & Pebble bed compacting & Power level & Minor effects (L) \\
\hline $\begin{array}{l}\text { RCCS performance } \\
\text { monitoring } \mathrm{g}^{\mathrm{a}}\end{array}$ & $\begin{array}{l}\text { Safety grade, needed for } \\
\text { all LOFC events }\end{array}$ & Vessel temperatures & $\begin{array}{l}\text { Heat balance, slow } \\
\text { response }(\mathrm{M})\end{array}$ \\
\hline $\begin{array}{l}\text { Reactor cavity } \\
\text { atmosphere chemistry } \\
\text { and activity }\end{array}$ & $\begin{array}{l}\text { Air and steam ingress } \\
\text { effects; accident } \\
\text { mitigation planning }\end{array}$ & None & $\begin{array}{l}\text { Major needs for very } \\
\text { unlikely scenarios }(\mathrm{H})\end{array}$ \\
\hline
\end{tabular}

*Superscripts on parameters measured indicate sensor concerns: a, availability (or development) concerns; $\mathrm{d}$, decalibrate/drift potential; f, failure concerns; s, signal strength concerns.

†Impact: H, high; M, medium; L, low. 


\section{REFERENCES}

1. T. J. Wilson, Jr., et al., Advanced Control and Protection System Design Methods for Modular HTGRs, ORNL/TM-2012/170, Oak Ridge National Laboratory, Oak Ridge, TN, May 2012.

2. H. Kalinowski, Core Physics and Pebble Flow Examples from THTR Operation, July 2001 (unpublished, English version - document available in the NRC Tomoye database).

3. F. Chen, Y. Dong, Y. Zheng, L. Shi, and Z. Zhang, "Benchmark Calculation for the Steady-State Temperature Distribution of the HTR-10 under Full-Power Operation," Journal of Nuclear Science and Technology, 46(6), pp. 572-580 (2009).

4. S. J. Ball, "Dynamic Model Verification Studies for the Thermal Response of the FSV HTGR Core," in Proceedings of the 4th Power Plant Dynamics, Control, and Testing Symposium, University of Tennessee, Knoxville, TN, 1980.

5. T. Takeda, S. Nakagawa, F. Honma, E. Takada, and N. Fujimoto, "Safety Shutdown of the High Temperature Engineering Test Reactor During Loss of Off-Site Electric Power Simulation Test," Journal of Nuclear Science and Technology, 39(9), pp. 986-995 (2002).

6. International Atomic Energy Agency, Heat Transport and Afterheat Removal for Gas Cooled Reactors under Accident Conditions, IAEA-TECDOC-1163 (CRP-3), Vienna, Austria, 2000.

7. $\quad$ S. J. Ball et al, Independent Analysis: HTTR Rise-to-Power and Test Analysis, JAERI-MEMO-09258 (1997).

8. D. McEligot, Scaling Studies and Conceptual Experiment Designs for NGNP CFD Assessment, INEEL/EXT-04-02502, Idaho National Laboratory, Idaho Falls, ID, November 2004.

9. American Society of Mechanical Engineers, Thermowells Performance Test Codes, ASME PTC 19.3, TW-2010 (http://www.te-direct.com/pdf/press-releases/ThermowellCalculation.pdf).

10. U. S. Nuclear Regulatory Commission, Clarification of TMI Action Plan Requirements, NUREG0737 (Section II.B), November 1980.

11. Public Service Company of Colorado, Post-Accident Sampling System, PSC P-82423 (document available in the NRC Tomoye database), September 1982.

12. International Atomic Energy Agency, Accident Analysis for Nuclear Power Plants with Modular $H T G R s$, IAEA SRS No. 54 (IAEA Safety Report Series), Vienna, Austria, 2008.

13. Idaho National Laboratory Next Generation Nuclear Plant Project, Assessment of NGNP Moisture Ingress Events, INL/EXT-11-21397, Idaho National Laboratory, Idaho Fall, ID, April 2011.

14. M. Hishida and K. Takada, "Study on Air Ingress During an Early Stage of a Primary-Pipe Rupture Accident of an HTGR," Nuclear Engineering and Design, 126, pp. 175-187 (1991).

15. C. Oh et al., "Air-Ingress Analysis: Part 2-Computational Fluid Dynamic Models, Nuclear Engineering and Design, 241, pp. 213-225 (2011).

16. S. J. Ball et al., "Sensitivity Studies of Air Ingress Accidents in Modular HTGRs," Nuclear Engineering and Design, 238, pp. 2935-2942 (2008).

17. P. M. Williams et al., Draft Preapplication Safety Evaluation Report for the Modular HighTemperature Gas-Cooled Reactor, NUREG-1338, U.S. Nuclear Regulatory Commission, Washington, DC, March 1989.

18. Bechtel National et al., Preliminary Safety Information Document (PSID) for the Standard MHTGR, HTGR-86-024, 1986.

19. S. J. Ball et al., Assessment of NGNP Moisture Ingress Events, Idaho National Laboratory, Idaho Falls, ID, INL/EXT-11-21397, April 2011. 
20. V. S. Gorbunov et al., "Uncertainties in the Analysis of Water Ingress Accident for the HTGR Cores," pp. 112-116 in Uncertainties in Physics Calculations for Gas Cooled Reactor Cores; Proceedings of A Specialist's Meeting, Villigen, Switzerland, May 9-11, 1990, IWGGCR-24, International Atomic Energy Agency, Vienna (Austria). International Working Group on GasCooled Reactors (May 1990).

21. Z. Zhang, Z. Wu, D. Wang, Y. Xu, Y. Sun, F. Li, and Y. Dong, "Current Status and Technical Description of Chinese $2 \times 250 \mathrm{MW}_{\text {th }}$ HTR-PM Demonstration Plant," Nuclear Engineering and Design, 239, pp. 1212-1219 (2009).

22. M. LaBar et al., Engineering Services for the NGNP with Hydrogen Production, General Atomics Report 911120 (April 2008).

23. R. Kisner et al., Design Practices of Communications and Workstations in Highly Integrated Control Rooms, NUREG/CR-6991, U.S. Nuclear Regulatory Commission, Washington, DC, 2009.

24. "IEEE Standard for Broadband Over Power Line Networks: Medium Access Control and Physical Layer Specifications," IEEE Standard 1901-2010 (Dec. 30, 2010).

25. R. A. Pease, "The Design of Band-Gap Reference Circuits: Trials and Tribulations," IEEE 1990 Bipolar Circuits and Technology Meeting, pp. 214-218 (September 17-18, 1990).

26. H. Zhou, C. Nicholls, T. Kunz, and H. Schwartz, Frequency Accuracy and Stability Dependencies of Crystal Oscillators, Technical Report SCE-08-12, Carleton University, Systems and Computer Engineering, November 2008.

27. S. J. Ball, A Graphite Reactor Severe Accident Code (GRSAC) for Modular High-Temperature GasCooled Reactors (HTGRs) User Manual, ORNL/TM-2010/096, Oak Ridge National Laboratory, Oak Ridge, TN, June 2010.

28. Techniques for Approximating the International Temperature Scale of 1990, Organisation Intergouvernementale de la Convention du Mètre, Bureau International Des Poids et Mesures, 1997 (reprinting of the 1990 first edition, Chapter 9 "Platinum Thermocouples").

29. Y.-G. Kim, K. S. Gam, and K. H. Kang, "Thermoelectric Properties of the Au/Pt Thermocouple," Review of Scientific Instruments, 69(10), pp. 3577-3582 (October 1998).

30. D. E. Holcomb, R. A. Kisner, and C. L. Britton, Jr., "Fundamental Thermometry for Long-Term and High-Temperature Deployment In Generation IV Reactors," in Proceedings of the International Symposium on Future Instrumentation and Controls 2005, Tonyeong, Republic of Korea, November 1-3, 2005.

31. M. J. de Groot and J. F. Dubbeldam, "Development of a Resistance Thermometer for Use Up to $1600^{\circ}$ C," Cal Lab, pp. 38-41 (July-August 1996).

32. M.-Y. Kao, "Properties of Silicon Nitride-Molybdenum Disilicide Particulate Ceramic Composites," Journal of the American Ceramic Society, 76(11), pp. 2879-2883 (1993).

33. K. J. Moriarty, F. H. Just, and L. J. Christensen, "Neutron-Flux Signal Conditioning," Chapter 5 of Nuclear Power Reactor Instrumentation Systems Handbook, Volume 1, edited by Joseph M. Harrer and James G. Beckerley.

34. AVR-Experimental High-Temperature Reactor, 21 Years of Successful Operation for a Future Energy Technology, Association of German Engineers (VDI), VDI-Verlag GmbH, Düsseldorf 1990.

35. A. A. G. Driskill-Smith, D. G. Hasko, and H. Ahmed, "The "Nanotriode:" A Nanoscale FieldEmission Tube," Applied Physics Letters, 75(18), pp. 2845-2847 (November 1, 1999).

36. L. C. Lynnworth and E. H. Carnevale, Ultrasonic Temperature Measuring Device, NASA-CR72339, 1967. 
37. H. A. Tasman, M. Campana, D. Pel, and J. Richter, "Ultrasonic Thin-Wire Thermometry for Nuclear Applications," from Temperature -Its Measurement and Control in Science and Industry, Vol. 5, 1982.

38. K. E. Kneidel, "Advances in Multizone Ultrasonic Thermometry Used to Detect Critical Heat Flux," IEEE Trans. On Sonics and Ultrasonics, SU-29(3) (May 1982).

39. L. C. Lynnworth, E. H. Carnevale, M. S. McDonough, and S. S. Fam, "Ultrasonic Thermometry for Nuclear Reactors," IEEE Trans. Nucl. Sci., S-16(1), pp. 184-187 (February 1969).

40. R. L. Shepard, C. J. Borkowski, et al., "Ultrasonic and Johnson Noise Fuel Centerline Thermometry," International Colloquium on High Temperature In-Pile Thermometry, Petten, Netherlands, pp. 737-774 (Dec. 12, 1974).

41. R. S. Fielder, D. Klemer, and K. L. Stinson-Bagby, "High-Temperature Fiber Optic Sensors, An Enabling Technology for Nuclear Reactor Applications," pp. 2295-2305 in Proceedings of ICAPP '04, Pittsburgh, PA, June 13-17, 2004.

42. R. S. Fielder, R. G. Duncan, and M. L. Palmer, "Recent Advancements in Harsh Environment Fiber Optic Sensors: An Enabling Technology for Space Nuclear Power," pp. 476-484 in Proceedings of the Space Nuclear Conference 2005, San Diego, California, June 5-9, 2005.

43. A. F. Fernandez, A. I. Gusarov, B. Brichard, S. Bodart, K. Lammens, F. Berghmans, M. Decréton, P. Mégret, M. Blondel, and A. Delchambre, "Temperature Monitoring of Nuclear Reactor Cores with Multiplexed Fiber Bragg Grating Sensors," Opt. Eng., 41(6), pp. 1246-54 (June 2002).

44. A. I. Gusarov, F. Berghmans, O. Deparis, A. Fernandez, Y. Defosse, P. Mégret, M. Décreton, and M. Blondel, "High Total Dose Radiation Effects on Temperature Sensing Fiber Bragg Gratings," IEEE Photonics Technology Letters, 11(9), pp. 1159-1161 (September 1999).

45. J. O. Johnson and T. J. Burns, Thermal-Hydraulic Analysis of the Dual-Function Gamma Thermometer, ORNL/TM-8089, Oak Ridge National Laboratory, Oak Ridge, TN, December 1981.

46. C. I. Moir, "Miniature Laser Doppler Velocimetry Systems," Optical Sensors 2009_Proceedings of the SPIE, 7356, 73560I-1 (2009).

47. Y. Wang, L. Zhang, W. Xu, T. Jiang, Y. Fan, D. Jiang, and L. An, "Effect of Thermal Initiator Concentration on the Electrical Behavior of Polymer-Derived Amorphous Silicon Carbonitrides," J. Am. Ceram. Soc., 91(12), pp. 3971-3975 (2008).

48. P. Colombo, G. Mera, R. Riedel, and G. D. Sorarù, "Polymer-Derived Ceramics: 40 Years of Research and Innovation in Advanced Ceramics," J. Am. Ceram. Soc., 93(7), pp. 1805-1837 (2010).

49. http://www.sporian.com/harsh.html.

50. http://www.gp50.com/melt.html.

51. L. N. Wesson, N. L. Cabato, and N. L. Pine, "Fiber-Optic Pressure System for Gas Turbine Engine Control, Proceedings of the SPIE, 1367 Fiber Optic and Laser Sensors VIII, pp. 204-213 (1990).

52. Y. J. Rao, D. A. Jackson, R. Jones, and C. Shannon, "Development of Prototype Fiber-Optic-Based Fizeau Pressure Sensors with Temperature Compensation and Signal Recovery by Coherence Reading," Journal of Lightwave Technology, 12(9), pp. 1685-1695 (September 1994).

53. R. S. Fielder, D. Klemer, and K. L. Stinson-Bagby, "High-Temperature Fiber Optic Sensors, an Enabling Technology for Nuclear Reactor Applications," pp. 2295-2305 in Proceedings of ICAPP '04, Pittsburgh, PA, June 13-17, 2004.

54. H. Liu, D. W. Miller, and J. W. Talnagi, "Performance Evaluation of Fabry-Perot Temperature Sensors in Nuclear Power Plant Measurements," Nuclear Technology, 143(2), pp. 208-216 (August 2003). 
55. K. Sakasai, N. Wakayama, H. Yamagishi, H. Itoh, M. Tamura, S. Fukakusa, and H. Ieki, "Development of Wide-Range In-Core Fission Counter-Chamber for HTGR," IEEE Transactions on Nuclear Science, 37(3), pp. 1405-1410 (June 1990).

56. R. Hecker, H. Yamagishi, H. Brixy, J. Oehmen, N. Wakayama, H. Itoh, and K. Sakasai, Demonstration Tests of the High Temperature Wide Range Neutron Monitoring System in the AVR, Juel-2468, 1991.

57. Idaho National Laboratory, Next Generation Nuclear Plant Pre-Conceptual Design Report, INL/EXT-0712967, November 2007.

58. R. H. Leyse and R. D. Smith, "Gamma Thermometer Developments for Light Water Reactors," IEEE Transactions on Nuclear Science, NS-26(1), pp. 934-943 (February 1979).

59. D. S. McGregor, M. F. Ohmes, R. E. Ortiz, A. S. M. Sabbir Ahmed, and J. K. Shultis, "MicroPocket Fission Detectors (MPFD) for In-Core Neutron Flux Monitoring," Nuclear Instruments and Methods in Physics Research A, 554, pp. 494-499 (2005).

60. M. F. Ohmes, J. K. Shultis, and D. S. McGregor, "3D Real-Time In-Core Neutron Flux Mapping with Micro-Pocket Fission Detectors (MPFD),” 2007 IEEE Nuclear Science Symposium, pp. 2060-2064 (2007).

61. V. Nagali and R. K. Hanson, "Design of A Diode-Laser Sensor to Monitor Water Vapor in HighPressure Combustion Gases," Applied Optics, 36(36), pp. 9518-9527 (December 20, 1997).

62. C. Lauer, S. Szalay, G. Böhm, C. Lin, F. Köhler, and M.-C. Amann, "Laser Hygrometer Using A Vertical-Cavity Surface-Emitting Laser (VCSEL) with An Emission Wavelength of $1.84 \mu \mathrm{m}$," IEEE Transactions on Instrumentation and Measurement, 54(3), pp. 1214-1218 (June 2005).

63. P. R. Wiederhold, Water Vapor Measurement, Marcel Dekker, Inc., New York, pp. 87-89 (1997).

64. P. R. Wiederhold, Water Vapor Measurement, Marcel Dekker, Inc., New York, pp. $92-97$ (1997).

65. J. Y. Wang, M. E. Suddards, and J. R. Owers-Bradley, "Application Of Quartz Tuning Forks In Multiple-Breath-Helium Washout Measurement," 4th IET International Conference on Advances in Medical, Signal and Information Processing, 2008. MEDSIP 2008, Santa Margherita Ligure, Itale, July 14-16, 2008.

66. H. Teichert, T. Fernholz, and V. Ebert, "Simultaneous In Situ Measurement of CO, $\mathrm{H}_{2} \mathrm{O}$, and Gas Temperatures in A Full-Sized Coal-Fired Power Plant by Near-Infrared Diode Lasers, Applied Optics, 42(12), pp. 2043-2051 (April 20, 2003).

67. V. Ebert, T. Fernholz, C. Giesemann, H. Pitz, H. Teichert, J. Wolfrum, and H. Jaritz, "Simultaneous Diode-Laser-Based In Situ Detection of Multiple Species and Temperature in A Gas-Fired Power Plant, Proceedings of the Combustion Institute, 28, pp. 423-430 (2000).

68. H. E, Schlosser, J. Wolfrum, V. Ebert, B. A. Williams, R. S. Sheinson, and J. W. Fleming, "In Situ Determination of Molecular Oxygen Concentrations in Full-Scale Fire-Suppression Tests Using Tunable Diode Laser Absorption Spectroscopy," Proceedings of the Combustion Institute, 29, pp. 353-360 (2002).

69. General Atomics, Engineering Services for the Next Generation Nuclear Plant (NGNP) with Hydrogen Production, "NGNP Contamination Control Study," GA Project 30281, Document 911117, Issued April, 23, 2008.

70. J. R. Waters, "Precautions in the Measurement of Tritium Concentrations in Air When Using FlowThrough Ion Chambers," Nuclear Instruments and Methods, 117, pp. 39-44 (1974).

71. R. A. Jalbert and R. D. Hiebert, "Gamma Insensitive Air Monitor for Radioactive Gases," Nuclear Instruments and Methods, 96, pp. 61-66 (1971).

72. http://www.perkinelmer.com/CMSResources/Images/4473238BRO_ScintillationCocktailsAndConsumables.pdf. 
73. J. T. Maki, AGR-1 Irradiation Experiment Test Plan, INL/EXT-05-00593 Rev. 3, Idaho National Laboratory, Idaho Falls, ID, October 2009.

74. M. Nakamichi, Y. Nagao, C. Yamamura, M. Nakazawa, and H. Kawamura, "Characterization of Hybrid Self-Powered Neutron Detector Under Neutron Irradiation," Fusion Engineering and Design, 51-52, pp. 837-841 (2000).

75. R. L. Shepard, C. J. Borkowski, J. K. East, R. J. Fox, and J. L. Horton, "Ultrasonic and Johnson Noise Fuel Centerline Thermometry," presented at the International Colloquium on HighTemperature In-Pile Thermometry, Petten, Netherlands, December 12-13, 1974.

76. F. A. Reichardt, "Measurement of High Temperatures Under Irradiation Conditions-The Use of Molybdenum-Platinum Thermocouples," Platinum Metals Review, 7(4), pp. 122-125 (1963).

77. R. Schley and G. Metauer, "Thermocouples for Measurements Under Conditions of High Temperature and Nuclear Irradiation," Temperature: Its Measurement and Control in Science and Industry, 5(2), pp. 1109-1113 (1982).

78. M. S. El-Genk and J.-M. Tournier, “A Review of Refractory Metal Alloys and Mechanically Alloyed-Oxide Dispersion Strengthened Steels for Space Nuclear Power Systems, Journal of Nuclear Material, 340 pp. 93-112 (2005).

79. J. L. Rempe, D. L. Knudson, K. G. Condie, and S. C. Wilkins, "Evaluation of Specialized Thermocouples of High-Temperature In-Pile Testing," Proceedings of ICAPP'06, Reno, NV, June 2006.

80. A. L. Habush and A. M. Harris, "330-MW(e) Fort St. Vrain High-Temperature Gas-Cooled Reactor," Nucl. Engr. and Design, 7(4), pp. 312-321 (April 1968).

81. R. M. Meyer, L. J. Bond, P. Ramuhalli, and S. R. Doctor, Advanced Instrumentation, Information, and Control System Technologies: Nondestructive Examination Technologies-An Assessment, PNNL-19705, Pacific Northwest National Laboratory, Richland, WA, August 2010.

82. L. J. Bond, S. R. Doctor, D. B. Jarrell, and J. W. D. Bond, "Improved Economics of Nuclear Plant Life Management," Proceedings of the Second International Symposium on Nuclear Power Plant Life Management. October 15-18, 2007, Shanghai, China, International Atomic Energy Agency, Vienna, Austria, IAEA Paper IAEA-CN-155-008KS, 2007.

83. L. J. Bond, S. R. Doctor, and T. T. Taylor, Proactive Management of Materials Degradation - A Review of Principles and Programs, PNNL-17779, Pacific Northwest National Laboratory, Richland, WA, August 2008.

84. H. M. Hashemian, Sensor Performance and Reliability, ISA - The Instrumentation, Systems, and Automation Society, Research Triangle Park, NC, 2005.

85. H. M. Hashemian, Maintenance of Process Instrumentation in Nuclear Power Plants, SpringerVerlag, Berlin Heidelberg, 2006.

86. D. A. Copinger and D. L. Moses, Fort Saint Vrain Gas Cooled Reactor Operational Experience, NUREG/CR-6839 (ORNL/TM-2003/223), Oak Ridge National Laboratory, Oak Ridge, TN, January 2004.

87. Y. Guojun, X. Yang, S. Zhengang, and G. Huidong, "Characteristic Analysis of Rotor Dynamics and Experiments of Active Magnetic Bearing for HTR-10GT," Nuclear Engineering and Design, 237, pp. 1363-1371 (2007).

88. M.-H. Li, A. B. Palazzolo, A. Kenny, A. J. Provenza, R. F. Beach, and A. F. Kascak, "FaultTolerant Homopolar Magnetic Bearings," IEEE Transactions on Magnetics, 40(5), pp. 3308-3319 (September 2004).

89. R. Nordmann and M. Aenis, "Fault Diagnosis in a Centrifugal Pump Using Active Magnetic Bearings," International Journal of Rotating Machinery, 10(3), pp. 183-191 (2004). 
90. H. D. Haynes, "Electrical Signature Analysis (ESA) Developments at the Oak Ridge Diagnostics Applied Research Center," Proceedings of the $8^{\text {th }}$ International Congress on Condition Monitoring and Diagnostic Engineering Management, (COMADEM 95), Vol. 2, pp. 511-518 (1995).

91. H. D. Haynes, Aging and Service Wear of Electric Motor-Operated Valves Used in Engineered Safety-Feature Systems of Nuclear Power Plants_-Volume II Aging Assessments and Monitoring Method Evaluations, NUREG/CR-4234 Volume 2, Oak Ridge National Laboratory, Oak Ridge, TN, August 1989.

92. T. W. Kerlin, S. J. Ball, R. C. Steffy, and M. R. Buckner, "Experiences with Dynamic Testing Methods at the Molten-Salt Reactor Experiment," Nuclear Technology, 10, pp. 103-117 (1971).

93. K. E. Asmussen et al., Testing at Fort St. Vrain After Installation of Region Constraint Devices, General Atomics, GA-C16277, February 1981.

94. A. Mizuno, "Electrostatic Precipitation," IEEE Transactions on Dielectrics and Electrical Insulation, 7(5), pp. 615-624 (October 2000).

95. P. W. Humrickhouse, HTGR Dust Safety issues and Needs for Research and Development, INL/EXT-11-21097, Idaho National Laboratory, Idaho Falls, ID, June 2011.

96. J. C. Kuiiper et al., "HTGR Source Term Elements: Irradiated Fuel Composition and Graphite Due Transport," IAEA Technical Meeting on Safety Aspects of Modular HTGRs, Beijing, P.R. China, October 23-26, 2007.

97. R. N. Morris et al., TRISO-Coated Particle Fuel PIRTs for Fission Product Transport Due to Manufacturing, Operations, and Accidents (Main Report)," NUREG/CR-6844, Vol.1, U.S. Nuclear Regulatory Commission, Washington, DC (July 2004).

98. C. B. Davis, R. B. Barner, S. R. Sherman, and D. F. Wilson, Thermal-Hydraulic Analyses of Heat Transfer Fluid Requirements and Characteristics for Coupling a Hydrogen Product Plant to a High-Temperature Nuclear Reactor, INL/EXT-05-00453, Idaho National Laboratory, Idaho Falls, ID (June 2005).

99. C. W. Forsberg et al., Next Generation Nuclear Plant Phenomena Identification and Ranking Tables (PIRTs), Volume 6: Process Heat and Hydrogen Co-Generation PIRTs, NUREG/CR-6944, Vol. 6 (ORNL/TM-2007/147, Vol. 6), Oak Ridge National Laboratory, Oak Ridge, TN, March 2008.

100. D. Lindsey, Power-Plant Control and Instrumentation-The Control of Boilers and HRSG Systems, The Institution of Electrical Engineers, London, United Kingdom, 2000.

101. NGNP Steam Generator Alternatives Study, GA-911120, General Atomics, 2008.

102. Preliminary Safety Information Document for the SC-MHR, General Atomics, p. 31, 1992.

103. An Overview of Liquid Fluoride Salt Heat Transport Systems, ORNL/TM-2010/156, August 2010.

104. G. A. Carlson, W. H. Sullivan, and H. G. Plein, "Application of Ultrasonic Thermometry in LMFBR Safety Research," pp. 24-28 in 1977 IEEE Ultrasonics Symposium Proceedings, Phoenix, AZ, October 26-28, 1977.

105. L. C. Lynnworth and E. H. Carnevale, "Ultrasonic Thermometry Using Pulse Techniques," Temperature: Its Measurement and Control in Science and Industry, Instrument Society of America, 4(1), pp. 715-32 (1972).

106. L. C. Lynnworth, "Ultrasonic Measurements for Process Control," pp. 369-447, Academic Press, Inc., 1989.

107. A. V. Belevstev, A. V. Karzhavin, and A. A. Ulanowsky, "Stability of a Cable Nicrosil-Nisil Thermocouple Under Thermal Cycling," in Temperature: Its Measurement and Control in Science and Industry, Volume 7, Dean C. Ripple, Ed., AIP, pp. 453-457 (2003). 
108. J. Jablin, M. R. Storar, and P. L. Gray, "Improved Operating Efficiency Through the Use of Stabilized Thermocouples," Journal of Engineering for Gas Turbines and Power, 122, pp. 659-663 (October 2000).

109. N. A. Burley, "Advanced Integrally Sheathed Type N Thermocouple of Ultra-High Thermoelectric Stability," Measurement, 8(1), pp. 36-41 (January-March 1990).

110. K. Termaat, J. Kops, K. Ara, M. Katagiri, and K. Kobayashi, "Fabrication Tests of Tricoth-Type Reactor-Water Level Sensor," IEEE Transactions on Nuclear Sciences, 37(2), pp. 1024-1031 (April 1990).

111. http://www.sporian.com/high temperature mems.html.

112. S. J. Ball et al., Next Generation Nuclear Plant Gap Analysis Report, ORNL/TM-2007/228, Oak Ridge National Laboratory, Oak Ridge, TN (July 2008). 